\title{
Slip rate and slip magnitudes of past earthquakes along the Bogd left-lateral strike-slip fault (Mongolia)
}

\author{
M. Rizza, ${ }^{1}$ J.-F. Ritz, ${ }^{1}$ R. Braucher, ${ }^{2}$ R. Vassallo, ${ }^{3}$ C. Prentice, ${ }^{4}$ S. Mahan, ${ }^{5}$ S. McGill, ${ }^{6}$
} A. Chauvet, ${ }^{1}$ S. Marco,${ }^{7}$ M. Todbileg, ${ }^{8}$ S. Demberel ${ }^{9}$ and D. Bourlès ${ }^{2}$

${ }_{1}^{1}$ Géosciences Montpellier-UMR 5243, Université Montpellier 2, Montpellier 34095, France. E-mail: rizza@gm.univ-montp2.fr

${ }^{2}$ CNRS-CEREGE-UMR 6635, Aix-Marseille Universités, Aix en Provence 13545, France

${ }^{3}$ LGCA- UMR 5025, Université de Savoie, Chambéry 73011, France

${ }^{4}$ US Geological Survey, 345 Middlefield Rd MS 977, Menlo Park, CA 94025, USA

${ }^{5}$ US Geological Survey, Denver Federal Center, Box 25046, MS 974, Denver, CO 80225, USA

${ }^{6}$ Department of Geological Sciences, California State University, San Bernardino, CA 92407, USA

${ }^{7}$ Department of Geophysics and Planetary Sciences, Tel Aviv University, Tel Aviv 69978, Israel

${ }^{8}$ Mongolian University of Science and Technology, P.O. Box 46/433, Ulaanbaatar, 210646, Mongolia

${ }^{9} R C A G$, P.O. Box 152, Ulaanbaatar 51, Mongolia

Accepted 2011 May 9. Received 2011 May 9; in original form 2010 November 23

\section{SUMMAR Y}

We carried out morphotectonic studies along the left-lateral strike-slip Bogd Fault, the principal structure involved in the Gobi-Altay earthquake of 1957 December 4 (published magnitudes range from 7.8 to 8.3 ). The Bogd Fault is $260 \mathrm{~km}$ long and can be subdivided into five main geometric segments, based on variation in strike direction. West to East these segments are, respectively: the West Ih Bogd (WIB), The North Ih Bogd (NIB), the West Ih Bogd (WIB), the West Baga Bogd (WBB) and the East Baga Bogd (EBB) segments. Morphological analysis of offset streams, ridges and alluvial fans - particularly well preserved in the arid environment of the Gobi region-allows evaluation of late Quaternary slip rates along the different faults segments. In this paper, we measure slip rates over the past $200 \mathrm{ka}$ at four sites distributed across the three western segments of the Bogd Fault. Our results show that the left-lateral slip rate is $\sim 1 \mathrm{~mm} \mathrm{yr}^{-1}$ along the WIB and EIB segments and $\sim 0.5 \mathrm{~mm} \mathrm{yr}^{-1}$ along the NIB segment. These variations are consistent with the restraining bend geometry of the Bogd Fault.

Our study also provides additional estimates of the horizontal offset associated with the 1957 earthquake along the western part of the Bogd rupture, complementing previously published studies. We show that the mean horizontal offset associated with the 1957 earthquake decreases progressively from $5.2 \mathrm{~m}$ in the west to $2.0 \mathrm{~m}$ in the east, reflecting the progressive change of kinematic style from pure left-lateral strike-slip faulting to left-lateral-reverse faulting. Along the three western segments, we measure cumulative displacements that are multiples of the 1957 coseismic offset, which may be consistent with a characteristic slip. Moreover, using these data, we re-estimate the moment magnitude of the Gobi-Altay earthquake at $M_{\mathrm{w}}$ 7.78-7.95.

Combining our slip rate estimates and the slip distribution per event we also determined a mean recurrence interval of $\sim 2500-5200 \mathrm{yr}$ for past earthquakes along the different segments of the western Bogd Fault. This suggests that the three western segments of the Bogd Fault and the Gurvan Bulag thrust fault (a reverse fault bounding the southern side of the Ih Bogd range that ruptured during the 1957 earthquake) have similar average recurrence times, and therefore may have ruptured together in previous earthquakes as they did in 1957. These results suggest that the western part of the Bogd Fault system, including the Gurvan Bulag thrust fault, usually behaves in a 'characteristic earthquake' mode.

Keywords: Seismic cycle; Geomorphology; Earthquake dynamics; Continental neotectonics; Continental tectonics: strike-slip and transform; Asia. 


\section{INTRODUCTION AND TECTONIC SET T IN G}

Western Mongolia is undergoing NNE-SSW compression related to the India-Asia collision (Molnar et al. 1977). The Altay mountain range and its southeastern extension, the Gobi-Altay, represent the northernmost active compressional belt in central Asia (Tapponnier \& Molnar 1979; Cunningham 1998, 2005; Vassallo et al. 2007a). Fission track analyses carried out within the Gurvan Bogd mountain range, the easternmost part of the Gobi-Altay, show that Cenozoic transpressional tectonics started $5 \pm 3 \mathrm{Ma}$ (Vassallo et al. 2007a), uplifting an ancient peneplain that had formed during Jurassic time (Jolivet et al. 2007).

During the last century, between 1905 and 1957, four M8 earthquakes occurred in western Mongolia and the immediately adjacent area of China (Molnar \& Deng 1984; Baljinnyam et al. 1993; Schlupp 1996) making this region one of the most tectonically active intracontinental domains in the world (Fig. 1A). These earthquakes were produced by large strike-slip faults reactivating pre-Cenozoic structures (see Florensov \& Sololenko 1965; Baljinnyam et al. 1993; Jolivet et al. 2007).

Several morphotectonic studies show that the Bogd and Bulnay left-lateral strike-slip faults have late-Quaternary slip rates of $\sim 1 \mathrm{~mm} \mathrm{yr}^{-1}$ (Ritz et al. 1995, 2006; Rizza 2010) as do strikeslip faults in Altay (Walker et al. 2006; Vassallo 2006; Nissen et al. 2009a), consistent with geodetic measurements (Calais et al. 2003; Vergnolle et al. 2003). These low slip rates imply long recurrence intervals for large earthquakes, consistent with palaeoseismological investigations (Schwartz et al. 1996; Prentice et al. 2002; Schwartz et al. 2007; Ritz et al. 2009; Rizza 2010). Considering these long recurrence intervals, the 20th century Mongolian seismicity has been described as a seismic cluster involving mechanical coupling between large strike-slip faults via viscoelastic post-seismic stress transfer in the lower crust (Chery et al. 2001; Pollitz et al. 2003; Vergnolle 2003).

Among the four historical earthquakes, the 1957 Gobi-Altay event is the best known because it is the most recent event, was exceptionally mapped shortly after the event (Florensov \& Solonenko 1965) and is associated with a complex pattern of surface rupture. The earthquake occurred along the fault zone that bounds the northern Gobi-Altay range and the seismotectonics features were first described in Florensov \& Solonenko (1965). The main 1957 rupture is along a 260-km-long left-lateral strike-slip Bogd Fault with an average trend of $\mathrm{N} 100^{\circ} \mathrm{E}$. About $100 \mathrm{~km}$ of reverse faulting along the Ih Bogd and Baga Bogd massifs also occurred simultaneously with the Bogd Fault in 1957 (Fig. 1B).

Kurushin et al. (1997) resurveyed and updated the offsets along the entire 1957 surface rupture providing a detailed map of the slip distribution throughout the entire region of surface breaks, including $260 \mathrm{~km}$ of rupture along the Bogd Fault and $100 \mathrm{~km}$ of ruptures along other faults. Kurushin et al. (1997) estimated an average horizontal displacement of 3-4 m, with a maximum offset of $7 \mathrm{~m}$. The overall 1957 fault surface ruptures are consistent in terms of geometry, kinematics and slip distribution with the accumulated topography (Bayasgalan et al. 1999a; Ritz et al. 2006).

Morphological analysis of offset streams, ridges and alluvial fans-particularly well preserved in the arid environment of the Gobi region-allows evaluation of late-Quaternary slip rates along the different faults segments (e.g. Ritz et al. 2006). Vertical slip rates have been estimated and are similar $\left(0.1-0.2 \mathrm{~mm} \mathrm{yr}^{-1}\right)$ on several of the reverse fault segments, at Bitut (Vassallo et al. 2007b), Dalan Turuu (Hanks et al. 1997) and Gurvan Bulag (Carretier et al. 2002;

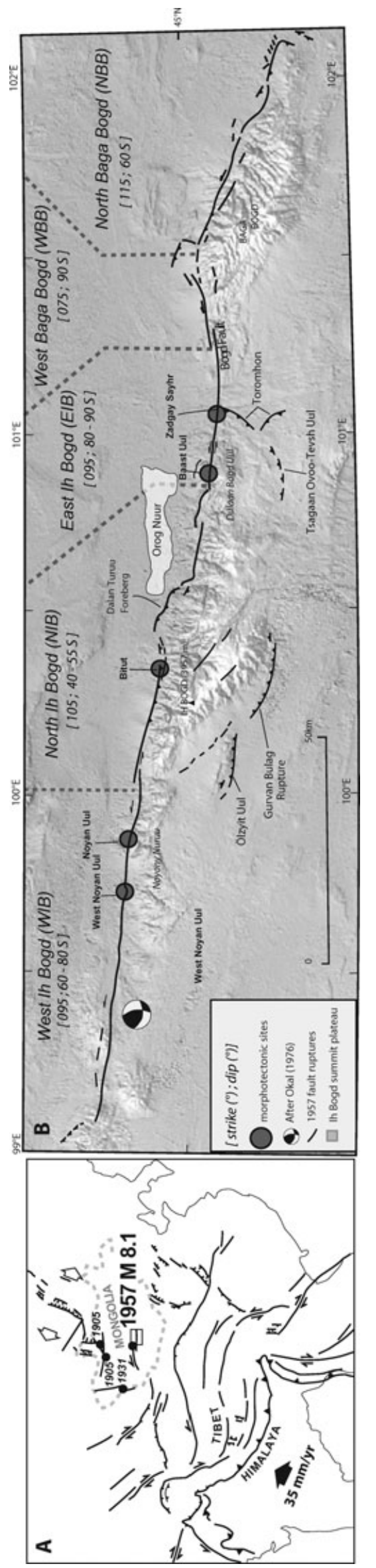

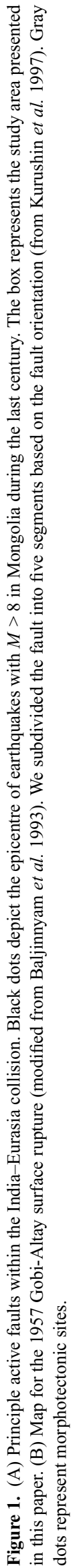

(C) 2011 The Authors, GJI, 186, 897-927 Geophysical Journal International (c) 2011 RAS 
Ritz et al. 2003; Vassallo et al. 2005). In addition, the horizontal slip rate has been estimated on the Bogd Fault at Noyan Uul, where an alluvial fan displaced by $\sim 110 \mathrm{~m}$ was dated at $\sim 80 \mathrm{ka}$ yielding a maximum left-lateral slip rate of $\sim 1.2 \mathrm{~mm} \mathrm{yr}^{-1}$ (Ritz et al. 1995).

In this paper, we provide new estimates on the horizontal slip rate along the Bogd Fault at four sites: Noyan Uul, West Noyan Uul, Bitut and Baast Uul (Fig. 1B). We refine previous morphotectonics interpretations at Noyan Uul (i.e. Ritz et al. 1995, 2006) and present new field-based measurements of lateral offset features within the three other sites. This work also refines published in situ ${ }^{10} \mathrm{Be}$ data in Noyan Uul and Bitut (i.e. Ritz et al. 1995, 2006; Vassallo et al. 2007a) together with new in situ ${ }^{10} \mathrm{Be}$ and luminescence age constraints. We also study the slip distribution along the fault at Noyan Uul, Bitut and Baast Uul and Zadgay Sayhr, a site located $11 \mathrm{~km}$ east of Baast Uul. Comparing 1957 offsets with cumulative displacements allows us to estimate the distribution of slip associated with past earthquakes. Combining slip rate estimates and the slip distribution per event allows us to estimate the mean recurrence intervals of past earthquakes.

\section{SLiP RATE ANALYSis ALONG THE BOGD FAULT}

The 260-km-long Bogd Fault can be subdivided into five geometric segments based on the variation in strike direction (Fig. 1B and Table 1). West to east these segments are, respectively: the West Ih Bogd segment (WIB), the North Ih Bogd segment (NIB) which is characterized by a significant reverse component of slip, the East Ih Bogd segment (EIB), the West Baga Bogd segment (WBB) and the North Baga Bogd segment (NBB). The epicentre of the 1957 earthquake is located along the West Ih Bogd segment (Florensov \& Solonenko 1965; Okal 1976).

In this study, we focus our morphotectonic analyses within the WIB, NIB and EIB segments. To determine horizontal slip rates along these three segments, we analyse cumulative displacements of alluvial surfaces $(\sim 20$ to $\sim 300 \mathrm{~m}$ ) that we dated using in situ produced ${ }^{10} \mathrm{Be}$ (e.g. Bierman 1994; Ritz et al. 1995; Braucher et al. 1998; Siame et al. 2000) and Optically Stimulated Luminescence (OSL, e.g. Le Dortz et al. 2009; Nissen et al. 2009b; Rizza et al. 2011). We also use published ${ }^{10} \mathrm{Be}$ data from two sites along the WIB and NIB segments to refine our previous slip rate estimates at Noyan Uul (Ritz et al. 1995; Vassallo et al. 2005; Ritz et al. 2006) and to estimate the horizontal slip rate at Bitut (Vassallo et al. 2007b).

Because previously published data were obtained at the Tandetron [the French Accelerator Mass Spectrometer (AMS, Raisbeck \& Yiou 1987)], they have been recalculated to be compared with the newly acquired data acquired from ASTER, the new French AMS (Arnold et al. 2010). This means the use of the same standard value, the NIST Standard Reference materials with an assigned ${ }^{10} \mathrm{Be} /{ }^{9} \mathrm{Be}$ ratio of 2.79.10 $0^{-11}$, and $\mathrm{a}^{10} \mathrm{Be}$ half-life of $1.387 .10^{6} \mathrm{yr}^{-1}$ (Chmeleff

Table 1. Characteristics of the five main segments of the Bogd Fault. The dips reported along the fault are from the Kurushin et al. (1997) estimates.

\begin{tabular}{lcccc}
\hline Segment & $\begin{array}{c}\text { Longitude } \\
\text { position }\end{array}$ & $\begin{array}{c}\text { Length } \\
(\mathrm{km})\end{array}$ & $\begin{array}{c}\text { Strike } \\
\text { direction }\end{array}$ & Dip $\left(^{\circ}\right)$ \\
\hline WIB & $99.09^{\circ} \mathrm{E}-100.03^{\circ} \mathrm{E}$ & 74 & $\mathrm{~N} 095^{\circ} \mathrm{E}$ & $60^{\circ}-80^{\circ}$ \\
NIB & $100.03^{\circ} \mathrm{E}-100.86^{\circ} \mathrm{E}$ & 67 & $\mathrm{~N} 105^{\circ} \mathrm{E}$ & $40^{\circ}-55^{\circ}$ \\
$\mathrm{EIB}$ & $100.86^{\circ} \mathrm{E}-101.16^{\circ} \mathrm{E}$ & 23 & $\mathrm{~N} 095^{\circ} \mathrm{E}$ & $80^{\circ}-90^{\circ}$ \\
WBB & $101.16^{\circ} \mathrm{E}-101.53^{\circ} \mathrm{E}$ & 28 & $\mathrm{~N} 075^{\circ} \mathrm{E}$ & $80^{\circ}-90^{\circ}$ \\
NBB & $101.53^{\circ} \mathrm{E}-102.07^{\circ} \mathrm{E}$ & 50 & N115 $\mathrm{E}$ & $60^{\circ}$ \\
\hline
\end{tabular}

et al. 2010; Korschinek et al. 2010). Beryllium production rates have been calculated using the Stone (2000) scaling polynomial with a high-latitude sea level (SHL) spallation production rate of 4.49 at $\mathrm{g}^{-1} \mathrm{yr}^{-1}$. All calculations are performed using attenuation lengths of 160,1500 and $5300 \mathrm{~g} \mathrm{~cm}^{-2}$ with associated relative contributions to the total production rate of 97.85 per cent, 1.50 per cent and 0.65 per cent for neutrons, slow muons and fast muons, respectively (Braucher et al. 2003).

To estimate surface-exposure ages, we use both ${ }^{10} \mathrm{Be}$ concentrations at the surface and its distribution with depth (See Appendix A). Exposure ages are better defined using depth profiles, allowing the determination of denudation rate and inheritance (e.g. Repka et al. 1997). Exposure ages obtained from surficial samples were used only if ages given by depth profiles were poorly constrained. When sample concentrations appear to be at steady state, an integration of effective exposure time was determined (Lal 1991). The results for the ${ }^{10} \mathrm{Be}$ analysis are presented in Appendix A.

The slip rate ranges from minimum to maximum values corresponding to $v_{\min }=\left(\Delta_{x}-\sigma_{\Delta x}\right) /\left(\Delta_{t}+\sigma_{\Delta t}\right)$ and $v_{\max }=\left(\Delta_{x}+\sigma_{\Delta x}\right) /$ $\left(\Delta_{t}-\sigma_{\Delta t}\right)$ and, where $\Delta x$ is the measured offset of a geomorphic feature across the fault and $\Delta_{t}$ is the age estimate for the feature, with the corresponding errors $\sigma_{\Delta x}$ and $\sigma_{\Delta t}$, respectively. When the slip rate is estimated using offset terrace risers, the ages of the upper and lower terraces provide maximum and minimum ages for the risers, respectively (e.g. Hanks \& Thatcher 2006; Cowgill 2007; Gold et al. 2009).

\subsection{The West Ih Bogd segment}

\subsubsection{West Noyan Uul site}

The West Noyan Uul site is situated along the eastern part of the WIB segment within an area of lower relief (Fig. 1B). The rupture pattern of the Bogd Fault becomes more complex at this location, with several obliquely trending segments (Fig. 2A). As described by Kurushin et al. (1997), there are two branches of the fault at this location. The main fault is expressed as a west-trending, northfacing scarp, which cuts alluvial surfaces. Farther south, the second branch forms the northern boundary of the massif, and trends in a southwesterly direction for about $3 \mathrm{~km}$, and then curves towards the northwest for about $1.5 \mathrm{~km}$ before rejoining the main fault. This fault network forms a releasing bend (east side of Fig. 2A), which is consistent with the numerous normal fault scarps described by Kurushin et al. (1997) in this area. The region farther west, where the two faults strands rejoin may be described as a restraining bend, consistent with the thrust fault scarp in this area.

Estimating offsets. The West Noyan Uul site is located along the main EW trending fault where a system of alluvial terraces is left-laterally displaced with a small reverse component. Figs 2(B) and $(\mathrm{C})$ show the aerial photograph of the site and the corresponding digital elevation model (DEM) obtained from our kinematic Global Positioning Systems (GPS) survey. On the west bank of the stream, we identified a series of four displaced terraces (T3, T2, T1 and T0). T3 terrace has a flat morphology with some boulders standing above the surface. T2 and T1 terraces present similar morphology with relatively flat surfaces, above which stand large boulders encased in the alluvial sediments that underlie the surfaces. T0, the youngest terrace, is characterized by a well-preserved bar-and-swale morphology. South of the fault, we have subdivided the T0 surface into two subunits: T0-1 and T0-2. The T0-2 surface is more eroded and shows evidence of incision by $\mathrm{T} 0-1$. 

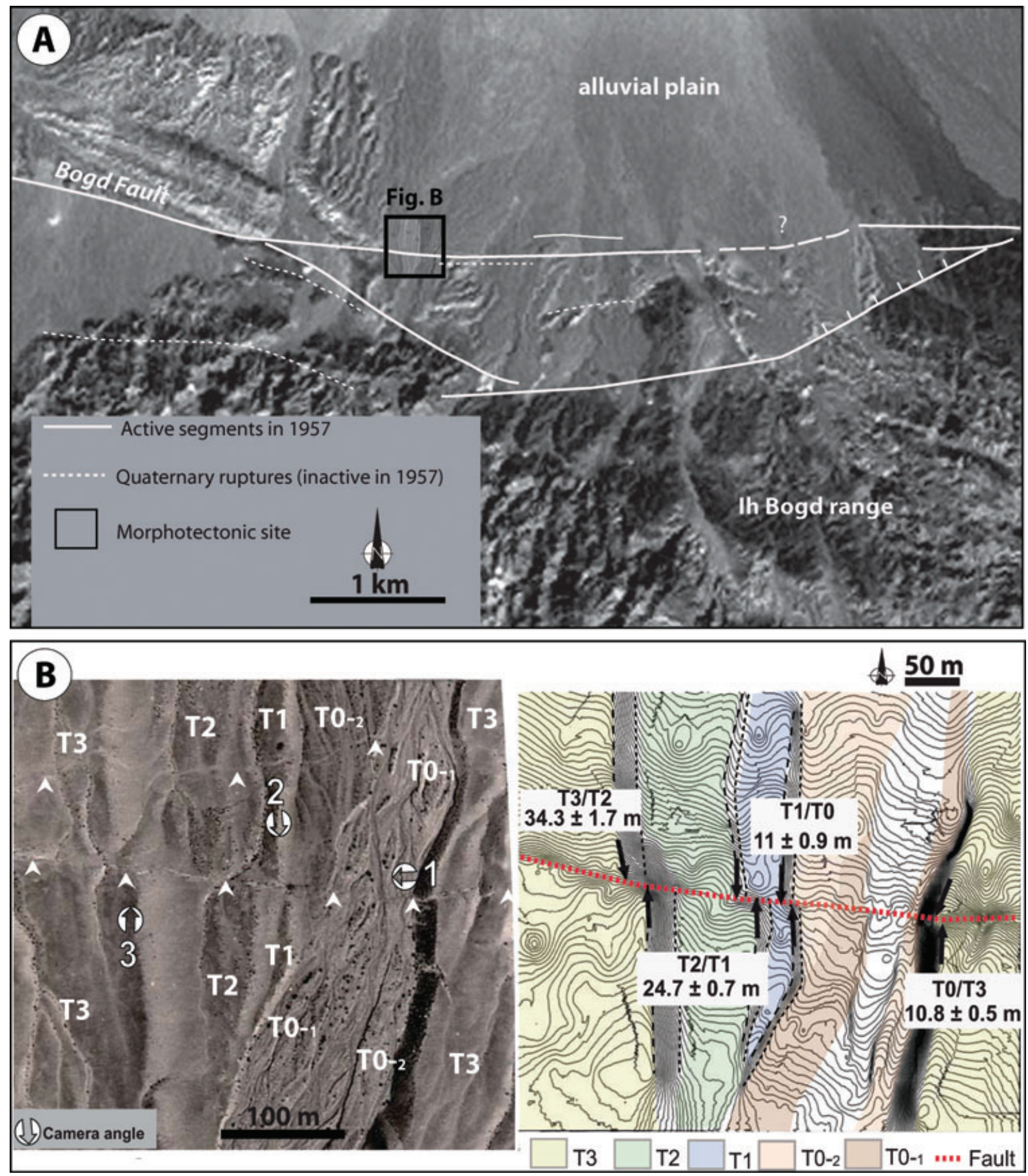

Figure 2. Morphological analyses at West Noyan Uul. (A) Hillshaded SRTM image (http://srtm.csi.cgiar.org) of the West Noyan Uul site, with 1957 surface ruptures mapped in white. The black box represents the study area. (B) Aerial photography (1958) showing the terraces T0, T1, T2 and T3 displaced along the Bogd Fault. Note that we subdivided the T0 terrace into two units $\mathrm{T}_{-1}$ and T0-2. The locations of field photos in Fig. 3 are shown here: (1) Fig. 3(A), (2) Fig. 3(B) and (3) Fig. 3(C). (C) Digital elevation model and the morphotectonic interpretations, based on aerial photographs and reconnaissance field mapping, with the piercing point used to measure the offset risers (black arrows).

On the west bank of the stream channel there is a series of three risers between the four terrace surfaces. Using the DEM that we generated from our survey, we estimate cumulative displacements of $34.3 \pm 1.7 \mathrm{~m}, 24.7 \pm 0.7 \mathrm{~m}$ and $11 \pm 0.9 \mathrm{~m}$ for T3/T2, T2/T1 and T1/T0 risers, respectively (see Fig. 2C). The east bank has experienced more severe erosion, and the only preserved terrace riser is between $\mathrm{T} 3$ (the highest and oldest terrace) and T0-1 (the youngest surface terrace). T2 and T1 terraces have been com- pletely removed. T3/T0-1 riser offset is $10.8 \pm 0.5 \mathrm{~m}$, similar to the T1/T0-2 riser offset measured on the west bank. This shows that the offset of the T3/T0 riser accumulated after that the lower terrace was abandoned.

Dating markers. To date the offset terrace risers, we measured ${ }^{10} \mathrm{Be}$ concentrations surface samples collected in the four alluvial terraces and one soil pit dug into the $\mathrm{T} 2$ terrace. Fig. 4(A) shows the results of ${ }^{10} \mathrm{Be}$ surface concentrations for the different 


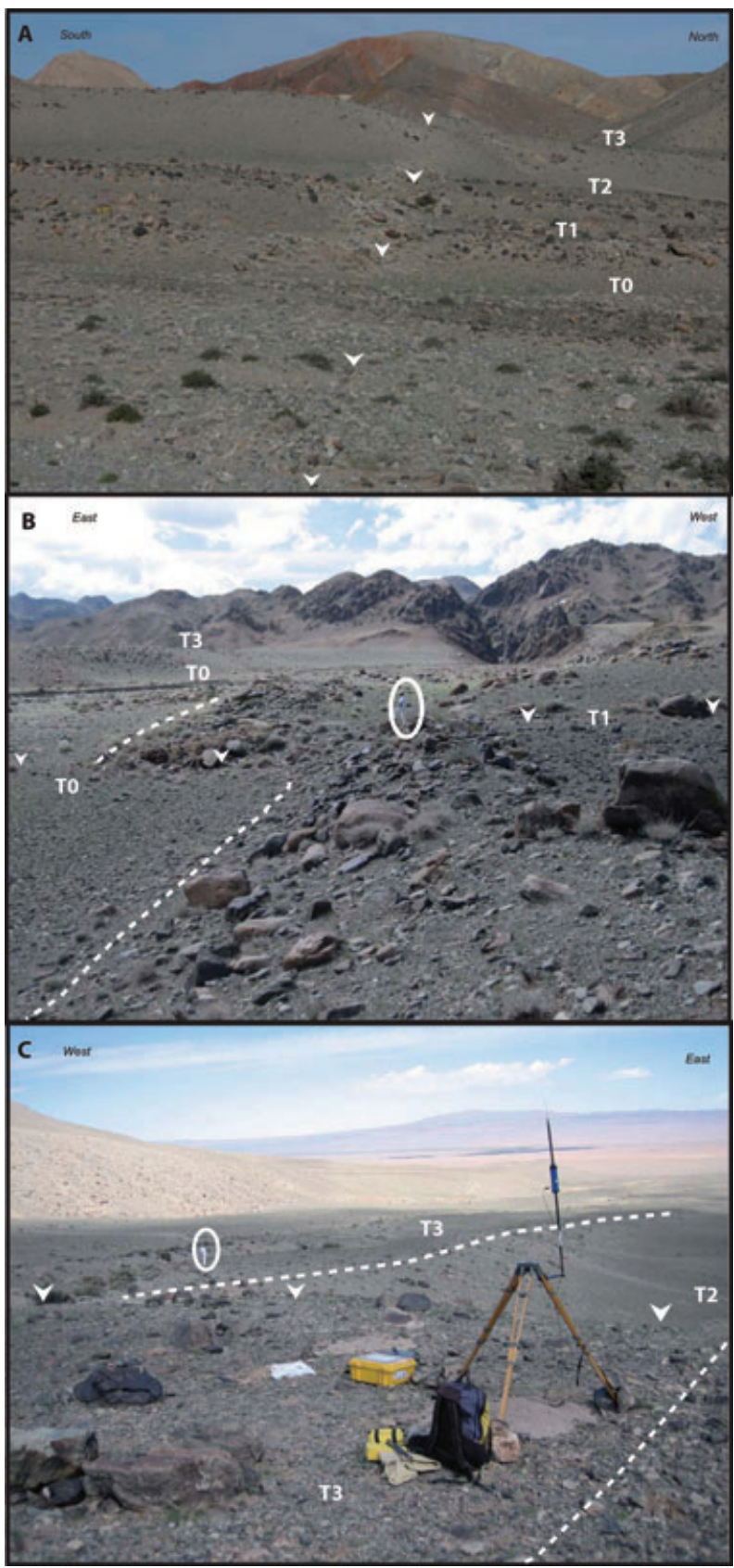

Figure 3. Photographs depicting field relationships at the West Noyan Uul site. (A) Field photo looking west from $\mathrm{T} 0$ terrace in the right bank showing the stepped terraces displaced along the 1957 rupture surface. (B) Field photo (looking south) from $\mathrm{T} 1$ terrace showing the $\mathrm{T} 0 / \mathrm{T} 1$ riser along the 1957 rupture, with piercing lines (white dashed lines) corresponding to the base of riser T0/T1. Note that a person making scale is surrounded by the white circle. (C) Field photo (looking north) from T3 terrace showing the T3/T2 riser along the 1957 rupture, with piercing lines corresponding to the top of riser T3/T2. Note that a person making scale is surrounded by the white circle.

terraces. For each surface, we collected pieces of rock samples from the tops of large quartz-rich boulders (diameter $>1 \mathrm{~m}$ ) and one amalgamated sample made of $\sim 40$ pebbles of quartz with centimetre size of $\sim 1-2 \mathrm{~cm}$ (i.e. Repka et al. 1997). The T3 terrace has the highest ${ }^{10} \mathrm{Be}$ concentrations, which range from $1.75 \pm 0.07$ Mat $\mathrm{g}^{-1}$ to $1.58 \pm 0.03 \mathrm{Mat}^{-1}$ (considering sample M07-01 as an outlier). The ${ }^{10} \mathrm{Be}$ concentrations in $\mathrm{T} 2$ terrace are between $1.61 \pm$
$0.02 \mathrm{Mat}^{-1}$ and $1.02 \pm 0.02 \mathrm{Mat}^{-1}$, considering sample M07-11 as an outlier. We found ${ }^{10} \mathrm{Be}$ concentrations between $0.96 \pm 0.03$ Mat $\mathrm{g}^{-1}$ and $0.49 \pm 0.04 \mathrm{Mat}^{-1}$ for $\mathrm{T} 1$, and ${ }^{10} \mathrm{Be}$ concentrations between $0.65 \pm 0.01 \mathrm{Mat}^{-1}$ and $0.25 \pm 0.01 \mathrm{Mat}^{-1}$, for T0 terraces (T0-1 and T0-2 surfaces and considering sample M07-26 as an outlier). T0, T1 and T2 terraces present high dispersions in the ${ }^{10} \mathrm{Be}$ surface concentrations that could be due to variable inheritances. ${ }^{10} \mathrm{Be}$ surface concentrations on $\mathrm{T} 3$ show less dispersion and are close to T2 concentrations, suggesting that T3 is approaching steady-state equilibrium.

Fig. 4(B) shows the depth distribution of ${ }^{10} \mathrm{Be}$ concentrations within the $\mathrm{T} 2$ terrace. Two different stratigraphical units are observed in the soil pit: a 1-m-thick debris flow unit made of quartzrich cobbles $(10-50 \mathrm{~cm}$ diameter) in a sandy-silty matrix and overlays a gravelly unit made of centimetre-scale clasts in a sandy-silty matrix. We collected at different depths one single clast (or fragment of clast) along a 130-cm-depth profile. The concentrations do not show an exponential decrease with the depth as expected. Starting at $1.00 \mathrm{Mat} \mathrm{g}^{-1}$ at the surface, the ${ }^{10} \mathrm{Be}$ concentration decreases rapidly with depth and reaches $0.6-0.7 \mathrm{Mat}^{-1}$ at the bottom of the first unit at $95 \mathrm{~cm}$ depth. The concentration then increases to 0.85 Mat $\mathrm{g}^{-1}$ at $130 \mathrm{~cm}$ in the second unit. This depth distribution of ${ }^{10} \mathrm{Be}$ concentrations is difficult to interpret, and is probably due to the fact that the concentrations correspond to individual rock samples (pebbles) and not amalgamated samples. The increase at $130 \mathrm{~cm}$ depth is consistent with the change observed in the stratigraphy at 100 $\mathrm{cm}$ depth, and can be interpreted either as pre-exposure before the deposition of the debris flow unit or as a different inheritance.

Taking into account that the surface samples and the profile present variable amount of inheritance, we use the lowest ${ }^{10} \mathrm{Be}$ concentrations for each surface to minimize the effect of exposure history prior to deposition (e.g. Vassallo et al. 2007a). We then determine minimum ages of $14.6 \pm 0.7 \mathrm{ka}, 28.7 \pm 2.4 \mathrm{ka}$ and $59.8 \pm 1.2 \mathrm{ka}$ for the T0, T1 and T2 terraces, respectively. For the T3 terrace, considering that the surface has reached a steadystate concentration, we calculate a maximum denudation rate of 8.6 $\mathrm{m} \mathrm{Myr}^{-1}$. We then determine an effective irradiation time $\left(T_{\text {eff }}\right)$ of $85.3 \mathrm{ka}$, that is the minimum time required to reach the steady state for a given denudation rate (Lal 1991).

Estimating slip rates. As mentioned in Section 2, a conservative approach to calculate the slip rates from offset terrace risers is to divide the offsets by the ages of the upper and lower terraces. We estimate maximum horizontal slip rates by dividing the riser offsets by the ages of the lower terraces. Offsets recorded by the T3/T2 $(34.3 \pm 1.7 \mathrm{~m}), \mathrm{T} 2 / \mathrm{T} 1(24.7 \pm 0.7 \mathrm{~m}), \mathrm{T} 1 / \mathrm{T} 0-2(11 \pm 0.9 \mathrm{~m})$ and T3/T0-2 $(10.8 \pm 0.5 \mathrm{~m})$ risers yield maximum slip rates of $0.57 \pm 0.04 \mathrm{~mm} \mathrm{yr}^{-1}, 0.87 \pm 0.1 \mathrm{~mm} \mathrm{yr}^{-1}, 0.76 \pm 0.1 \mathrm{~mm} \mathrm{yr}^{-1}$ and $0.74 \pm 0.07 \mathrm{~mm} \mathrm{yr}^{-1}$, respectively. We then estimate minimum slip rates by dividing the riser offsets by the ages of the upper terraces. Minimum slip rates of $0.39 \pm 0.07 \mathrm{~mm} \mathrm{yr}^{-1}, 0.13 \pm 0.01 \mathrm{~mm} \mathrm{yr}^{-1}$, $0.41 \pm 0.02 \mathrm{~mm} \mathrm{yr}^{-1}$ and $0.40 \pm 0.02 \mathrm{~mm} \mathrm{yr}^{-1}$ are calculated for the $\mathrm{T} 1 / \mathrm{T} 0-2, \mathrm{~T} 3 / \mathrm{T} 0-2, \mathrm{~T} 2 / \mathrm{T} 1$ and $\mathrm{T} 3 / \mathrm{T} 2$ risers, respectively. Note that the T3 surface is at steady state, and therefore the age is a minimum, and we have no maximum age estimate for this surface.

However, at West Noyan Uul, offset risers among the terrace pattern show that the offsets were recorded after the abandonment of the lower terraces. For instance the T1/T0 riser offset in the west bank is equal to the T3/T0 riser offset in the east bank showing that these offsets were recorded after the abandonment of T0. For these reasons, we give preference to our slip rate estimates using the ages of the lower terraces. 

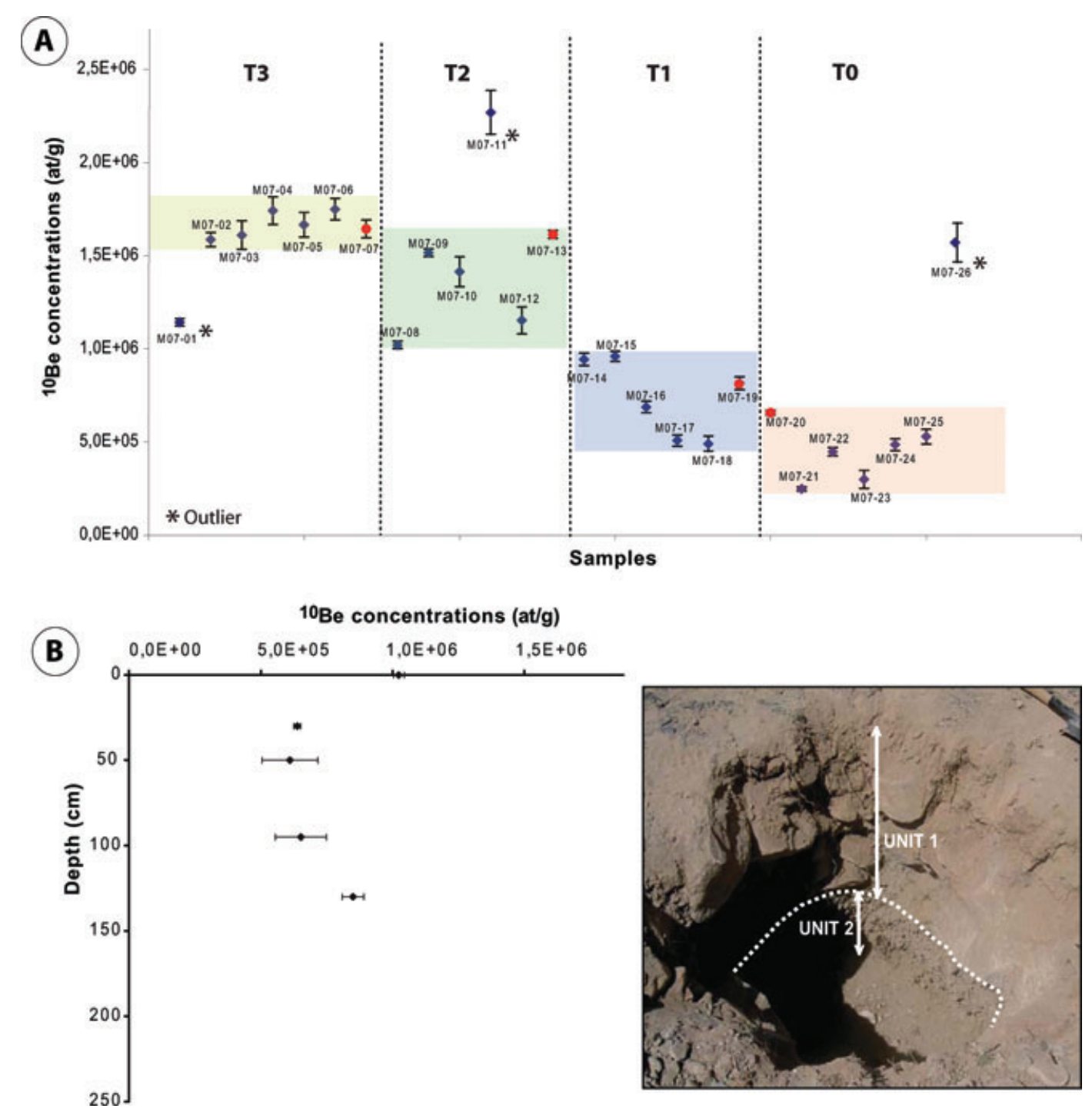

Figure 4. ${ }^{10} \mathrm{Be}$ analyses at West Noyan Uul. (A) ${ }^{10} \mathrm{Be}$ surface concentrations for the T3, T0, T2 and $\mathrm{T} 1$ terraces. The blue dots are for the boulders and red dots are for the amalgamated samples collected during the 2007 fieldtrip. (B) Depth distribution of ${ }^{10} \mathrm{Be}$ concentrations within T2 terrace, at West Noyan Uul site. Field photography of the soil pit within the T2 terrace at West Noyan Uul (taken in 2007). Two units have been identified by a stratigraphic contact, marked by the white dashed line.

\subsubsection{Noyan Uul site}

The Noyan Uul site is situated within the Noyony Nuruu massif, immediately west of the Ih Bogd massif(Fig. 1B). Here, the N095 ${ }^{\circ} \mathrm{E}$ trending Bogd Fault separates a mountainous area to the south from the alluvial plain to the north (Fig. 5A). Along the fault, three alluvial fan surfaces (S0, S1 and S2) are displaced. S0 surface, the youngest one, still shows a bar-and-swale morphology whereas the S1 and S2 surfaces are flatter, deeply incised and there are few remaining standing boulders. The incisions are deeper and more widely spaced on S2 than on S1. The overall pattern reflects the classic evolution of alluvial surfaces with a short-wavelength/lowamplitude topographic signal covered by boulder fields on S0, evolving towards long-wavelength/high-amplitude topographic signal on which the number of standing boulders diminishes gradually on S1 and S2 (e.g. Ritz et al. 2006). On the south side of the fault, within the canyon incision, we mapped remnant surfaces corresponding to S0, S1 and S2 surfaces (Fig. 5B).
Estimating offsets. Using 1:25 000 scale aerial photographs from a 1958 Russian-Mongolian airborne survey, Ritz et al. (1995; 2006) estimated the displacements of S1 and S2 surfaces to be $110 \pm 10$ $\mathrm{m}$ and $220 \pm 10 \mathrm{~m}$, respectively. To estimate more accurately the cumulative displacements, we surveyed the area with Real Time Kinematic (RTK) GPS to produce a DEM that we combine with aerial photographs (Fig. 5C). We estimated offsets using the offset risers observed on both sides of the fault. Using both tops and bottoms of $\mathrm{S} 1 / \mathrm{S} 0$ and $\mathrm{S} 2 / \mathrm{S} 1$ risers, we calculated mean values (see Fig. $2 \mathrm{~B}$, note that the riser $\mathrm{S} 2 / \mathrm{S} 1$ south of the fault is wider that $\mathrm{S} 1 / \mathrm{S} 0)$.

The riser between the $\mathrm{S} 0$ surface and the present streambed is offset by $19 \pm 1.0 \mathrm{~m}$ (Fig. 5C). Using the S1/S0 riser and the S2/S1 riser, we measured offsets of $51 \pm 6 \mathrm{~m}$ and $136 \pm 14 \mathrm{~m}$, respectively. To estimate the total offset of S1 and S2 surfaces, we also use their apices (defined by both the radial rill patterns incising the surfaces and the contours lines) with respect to the width of the catchment of 

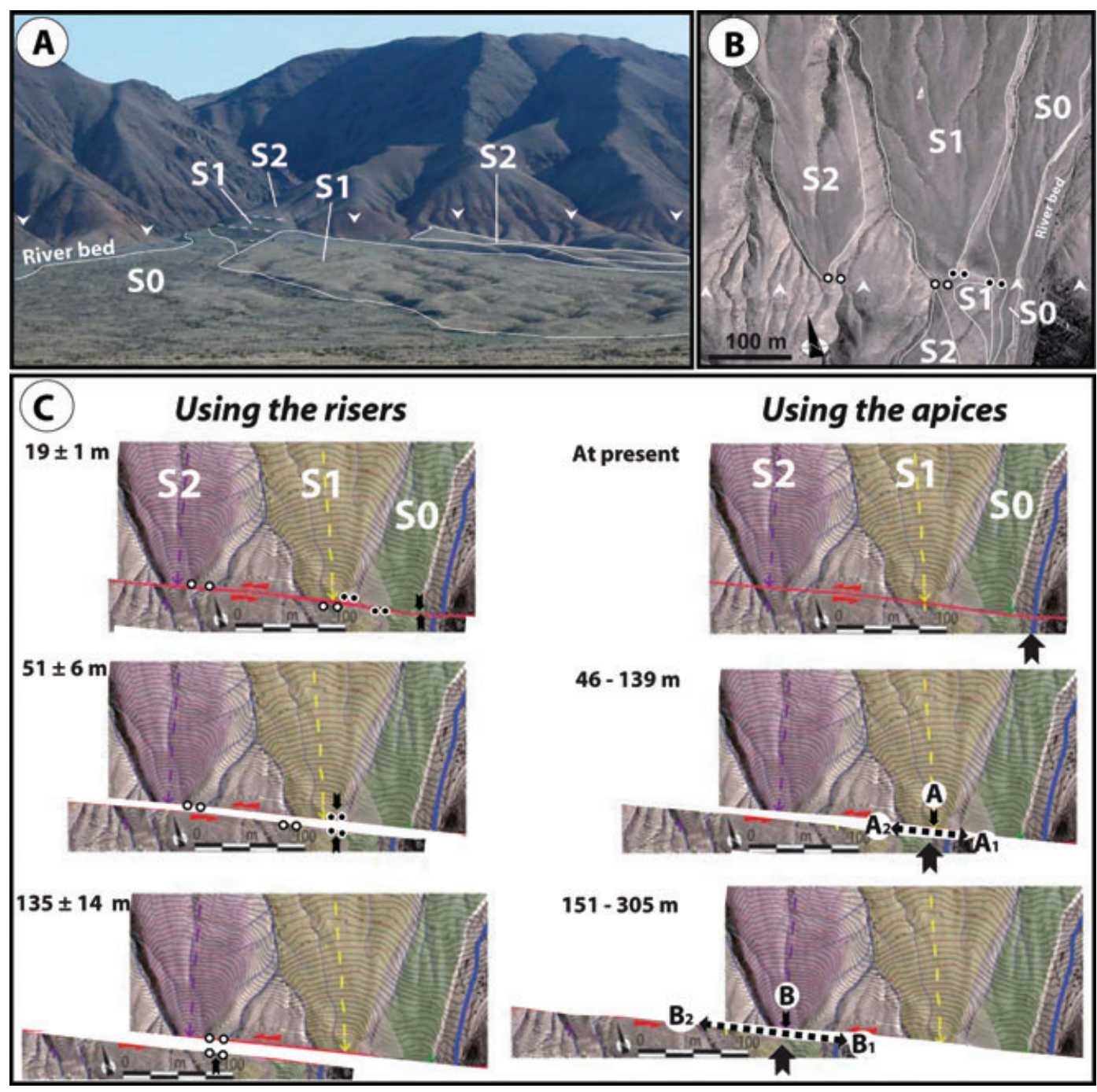

Figure 5. Morphological analyses at Noyan Uul. (A) Photography showing the Noyony Nuruu Massif and the three alluvial fans (S0, S1 and S2) at the Noyan Uul site. White triangles represent the fault line in the landscape. (B) Aerial photography (1958) showing the three alluvials fans displaced along the Bogd Fault. Three alluvials surfaces S0, S1 and S2 are in the north part of the fault while the remnant surface of S1 and S2 surfaces are identified in the western part of the canyon incision, south of the fault. Piercing points for the S1/S0 riser correspond to the white dots filled in black and the piercing points for the S2/S1 riser correspond to the black dots filled in white. (C) Digital elevation models and the morphotectonic reconstruction using the risers or apices of the alluvial fans. Note that the DEM was calculated by interpolation of 2671 data points.

the outlet axis. The maximum value is defined by the incision of the stream within the bedrock in the eastern part of the canyon, and the minimum value by the riser between alluvial surfaces in the western part of the canyon incision. Indeed, the centre of the drainage at the time of S1 deposition may have been located west of the presentday centre of the drainage, and the drainage may have incised along the eastern side of the S1 remnant surface fan. For the S1 surface, displacements range from $139 \mathrm{~m}$ to $46 \mathrm{~m}$ and correspond to the piercing points $A-A_{1}$ and $A-A_{2}$, respectively (Fig. 5C). For the $\mathrm{S} 2$ surface, displacements range from $305 \mathrm{~m}$ to $151 \mathrm{~m}$ and correspond to the piercing points $\mathrm{B}-\mathrm{B}_{1}$ and $\mathrm{B}-\mathrm{B}_{2}$, respectively.

Our estimate for the $\mathrm{S} 1$ surface displacement using the axis of incision is similar to the previously published estimate of $\sim 110 \mathrm{~m}$ (Ritz et al. 1995, 2006), but with higher uncertainties. This can be explained by the distortion of the aerial photographs that we corrected using the DEM. On the other hand, the previous estimate for $\mathrm{S} 2$ cumulative displacement was based on the offsets of two large stream incisions in the alluvial fans relative to streams upslope of the fault. Ritz et al. (1995, Fig. 2) considered these two large stream incisions as contemporaneous to $\mathrm{S} 2$ deposition.

Dating markers. To date the fan surfaces, we use in situ produced ${ }^{10} \mathrm{Be}$ data from Ritz et al. (1995) and Vassallo et al. (2005) for surfaces S1 and S2 together with new data from two amalgamated surface samples from S1 and S2 alluvial fans and one depth profile within S2 surface. These two amalgamated samples were made of $\sim 40$ quartz pebbles with centimetre size of $1-2 \mathrm{~cm}$. Fig. 6(A) shows that the ${ }^{10} \mathrm{Be}$ concentrations in $\mathrm{S} 1$ surface range

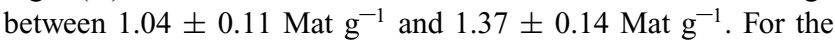
$\mathrm{S} 2$ surface, the ${ }^{10} \mathrm{Be}$ concentrations range between $1.56 \pm 0.17$ Mat $\mathrm{g}^{-1}$ and $1.83 \pm 0.12 \mathrm{Mat}^{-1}$, considering sample DVII- 1 as an outlier. The ${ }^{10} \mathrm{Be}$ concentrations for the two amalgamated samples are $1.49 \pm 0.04 \mathrm{Mat}^{-1}$ and $2.08 \pm 0.06 \mathrm{Mat}^{-1}$, on S1 and S2 surfaces, respectively. The offset of surface $\mathrm{S} 2$ being more than twice that of surface $\mathrm{S} 1$, the $\mathrm{S} 2$ concentration should be much larger than the $\mathrm{S} 1$ concentration if we assume a constant slip rate. However, the difference in ${ }^{10} \mathrm{Be}$ concentrations between $\mathrm{S} 1$ and $\mathrm{S} 2$ surfaces is only 

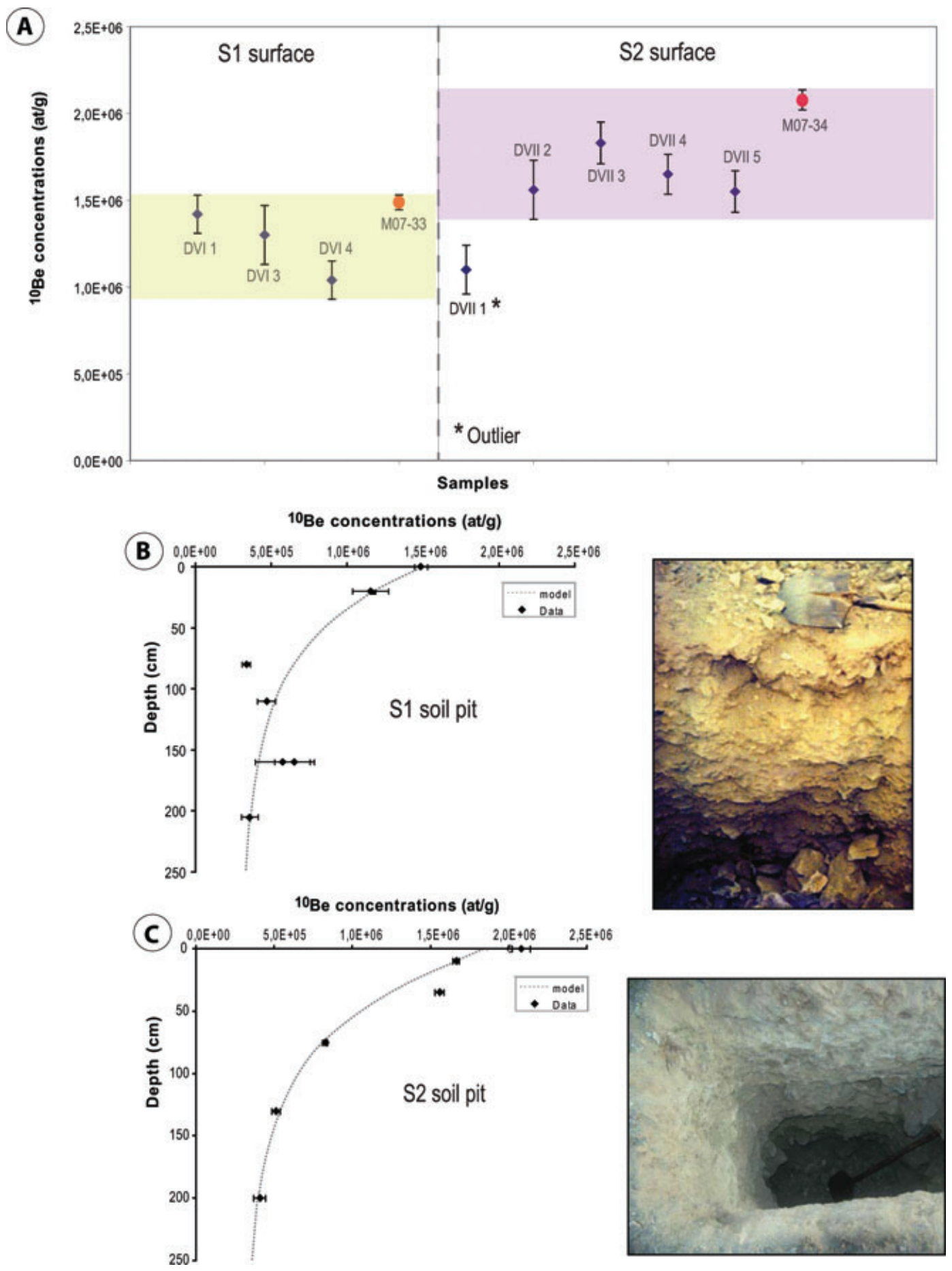

Figure 6. ${ }^{10} \mathrm{Be}$ analyses at Noyan Uul. (A) ${ }^{10} \mathrm{Be}$ surface concentrations for $\mathrm{S} 1$ and $\mathrm{S} 2$ surfaces. The blues dots are for the samples collected in 1995 (from Ritz et al. 1995) and restandardized here. The red dots are for the two amalgamated samples collected during the 2007 fieldtrip. (B) Depth distribution of ${ }^{10} \mathrm{Be}$ concentrations in S1surface. Black squares are for the data; the dashed lines represent the best fit using a chi-squared inversion. Field photography of the soil pit in the S1 fan surface (taken in 1997). (C) Depth distribution of ${ }^{10} \mathrm{Be}$ concentrations in S2 surface. Black squares are for the data; the dashed lines represent the best fit using a chi-squared inversion. Field photography of the soil pit in the S2 fan surface (taken in 2007).

0.38 Mat $^{-1}$ suggesting that $\mathrm{S} 2$ has probably reached steady-state equilibrium and that $\mathrm{S} 1$ may be approaching steady-state concentrations. Assuming surface concentrations at steady state, we calculate maximum denudation rates to be on the order of $8.2 \mathrm{~m} \mathrm{Myr}^{-1}$ and $6.8 \mathrm{~m} \mathrm{Myr}^{-1}$ for S1 and S2 surfaces, respectively.

Figs 6(B) and (C) show the depth distribution of ${ }^{10} \mathrm{Be}$ concentrations in samples from surfaces $\mathrm{S} 1$ and $\mathrm{S} 2$. We collected at different depths one single clast (or fragment of clast) along an $\sim 2 \mathrm{~m}$ depth profile. Both profiles show a decrease in ${ }^{10} \mathrm{Be}$ concentrations at depth reaching non-negligible ${ }^{10} \mathrm{Be}$ concentrations at $2 \mathrm{~m}$, attesting to an inheritance of $0.35-0.40 \mathrm{Mat}^{-1}$. Following the process described by Braucher et al. (2003, 2009) and Siame et al. (2004), we modelled the ${ }^{10} \mathrm{Be}$ distribution taking into account the denudation and the inheritance. We use a chi-squared inversion (see Appendix A 
for more details) to minimize the difference between observed and modelled ${ }^{10} \mathrm{Be}$ data, with the denudation and the inheritance free to vary. The best fit for $\mathrm{S} 1$ is for a denudation rate of $8.1 \pm 0.5$ $\mathrm{m} \mathrm{Myr}^{-1}$, and an inheritance of $0.56 \mathrm{Mat}^{-1}$ (Fig. 6B) with a surface at steady state. Note that $0.56 \mathrm{Mat}^{-1}$ corresponds to the inheritance at the time of deposition before subsequent exposure and denudation. After exposure and denudation, the concentration at 2 $\mathrm{m}$ depth becomes lower than the initial inheritance. The best fit for $\mathrm{S} 2$ gives a denudation rate of $6.8 \pm 0.2 \mathrm{~m} \mathrm{Myr}^{-1}$, and an inheritance of $0.44 \mathrm{Mat} \mathrm{g}^{-1}$ with a surface at steady state (Fig. 6C). Note that the denudation rates estimated using the ${ }^{10} \mathrm{Be}$ concentrations from the profiles are consistent with denudation rates estimated from the surficial samples. Both surfaces being at steady state and assuming constant denudation rates, the best we can do is to determine the effective irradiation time ( $\left.T_{\text {eff }}\right)$. The estimates of $T_{\text {eff }}$ are $108 \mathrm{ka}$ for $\mathrm{S} 1$ and $130 \mathrm{ka}$ for $\mathrm{S} 2$.

Estimating slip rates. Both S1 and S2 surfaces are approaching steady state, therefore the apparent exposure age calculated for the youngest surface (S1) is closer to the true age. To determine the slip rate, we consider only the $T_{\text {eff }}$ calculated for the $\mathrm{S} 1$ surface $(108 \mathrm{ka})$. This yields a maximum slip rate of $1.3 \pm 0.1 \mathrm{~mm} \mathrm{yr}^{-1}$ using the S2/S1 riser offset $(136 \pm 14 \mathrm{~m})$, and a minimum slip rate of $0.5 \pm 0.1 \mathrm{~mm} \mathrm{yr}^{-1}$ using the $\mathrm{S} 1 / \mathrm{S} 0$ riser offset $(51 \pm 6$ $\mathrm{m})$. These results are consistent with slip rate estimates using the $\mathrm{S} 1$ apex offset $(46-139 \mathrm{~m})$ that range between $0.4 \mathrm{~mm} \mathrm{yr}^{-1}$ and $1.3 \mathrm{~mm} \mathrm{yr}^{-1}$.

\subsection{North Ih Bogd segment}

Along the North Ih Bogd segment, we estimated the horizontal slip rate of the Bogd Fault at Bitut, a site located $40 \mathrm{~km}$ east of the the Noyan Uul site (Fig. 1B). There, a system of alluvial terraces at the outlet of the Bitut valley is displaced by the $\mathrm{N} 105^{\circ} \mathrm{E}$ striking Bogd Fault. The deformation is partitioned between a left-lateral strikeslip fault and a reverse fault located $\sim 1 \mathrm{~km}$ north of the strike-slip fault (Fig. 7A). Vassallo et al. (2007b) estimated a $\sim 0.1 \mathrm{~mm} \mathrm{yr}^{-1}$ vertical slip rate along the reverse segment. The horizontal slip rate was not estimated.

Estimating offsets. As observed at the West Noyan Uul site, the number of terraces is differed on either side of the canyon (Fig. 7). On the west bank, we identified a series of three displaced terraces (T2, T1 and T0). T2 and T1 surfaces show a flat morphology with some boulders standing above the surface and still encased in it. The flatness of the two surfaces is due to erosion dominantly by wind deflation (Ritz et al. 2006; Vassallo et al. 2007b). T0 surface is very different showing a bar-and-swale morphology with well-preserved boulders bars, attesting to a much younger age.

Using our DEM combined with aerial photographs, we mapped the offset terrace risers and other morphotectonic features (Figs 7D and E). A tributary channel flows along the fault zone and has deposited two small alluvial cones on top of the T1 and T0 surfaces. The channel and the cones have obscured the risers in the area and, to estimate where the risers intersect the fault, we have to project these piercing lines from a distance of $\sim 20-30 \mathrm{~m}$ to determine the offsets. We estimate cumulative displacements of $53.7 \pm 11.7 \mathrm{~m}$ and $46.7 \pm 5.1 \mathrm{~m}$ for T2/T1 riser and T1/T0 riser, respectively (Fig. 7E). On the right bank, only terraces $\mathrm{T} 2$ and $\mathrm{T} 0$ are preserved, while $\mathrm{T} 1$ has been removed by erosion. We estimate an offset of $9.1 \pm 0.5 \mathrm{~m}$ for $\mathrm{T} 2 / \mathrm{T} 0$ riser.

Dating markers. We used the ${ }^{10} \mathrm{Be}$ concentrations published in Vassallo et al. (2007b), which we recalculated using modern standards, to estimate the ages of the terraces. Additionally, we used luminescence dating techniques (Lian \& Roberts 2006; Wintle \& Murray 2006) to have independent age control. In Fig. 8(A), we present ${ }^{10} \mathrm{Be}$ concentrations of surficial boulders. Although we did not survey the T3 (oldest) terrace (location in Fig. 7A) with kinematic GPS, we collected samples for ${ }^{10} \mathrm{Be}$ analysis on the top of the remnant surface. T3 terrace has ${ }^{10} \mathrm{Be}$ concentrations ranging

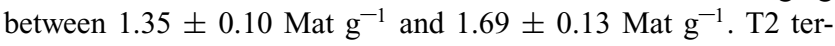
race, below T3, has concentrations ranging between $1.82 \pm 0.09$ Mat $\mathrm{g}^{-1}$ and $2.16 \pm 0.10 \mathrm{Mat}^{-1}$ with one outlier (MO-10). In T1 terrace ${ }^{10} \mathrm{Be}$ concentrations range between $1.26 \pm 0.23 \mathrm{Mat}^{-1}$ and $1.55 \pm 0.19 \mathrm{Mat}^{-1}$. In T0 terrace, the ${ }^{10} \mathrm{Be}$ concentrations range

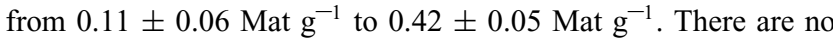
significant differences in ${ }^{10} \mathrm{Be}$ concentrations among $\mathrm{T} 3, \mathrm{~T} 2$ and $\mathrm{T} 1$. $\mathrm{T} 2$ concentrations being slightly higher than T3 (which is an older surface) suggests that both surfaces are at steady state with a denudation rate slightly higher for T3 (e.g. Vassallo et al. 2007b). T1 concentrations are slightly lower than $\mathrm{T} 2$ concentrations suggesting that this surface is also approaching the steady state.

Figs 8(A) and (B) present the depth distribution of ${ }^{10} \mathrm{Be}$ concentrations within $\mathrm{T} 1$ and $\mathrm{T} 2$ terraces, respectively. At $250 \mathrm{~cm}$ depth, the ${ }^{10} \mathrm{Be}$ concentration is very small showing that pre-exposure of alluvial material before deposition is negligible (Vassallo et al. 2007b). Using the chi-squared inversion procedure described earlier, we model the data with denudation and inheritance free to vary. For terrace T2, the best fit is obtained with a steady-state denudation rate of $5.7 \mathrm{~m} \mathrm{Myr}^{-1}$ and no inheritance, with a surface at steady state. Following Lal (1991), we calculate effective irradiation times $T_{\text {eff }}$ of $135.2 \mathrm{ka}$ for T2 terrace. For T1, the best fit is obtained with no denudation and no inheritance, yielding an age of $63.2 \pm 5 \mathrm{ka}$. However, as shown by the surface concentrations, the surface is approaching the steady state. Moreover, it is difficult to understand why erosion occurred on terrace T2 while no erosion would have affected terrace T1. As described earlier, both surfaces show evidence of denudation due to wind deflation. We therefore model the data using the same denudation rate determined for T2 $\left(5.7 \mathrm{~m} \mathrm{Myr}^{-1}\right)$ and allow the inheritance to vary. We obtain an age of $92.4 \pm 10 \mathrm{ka}$ for $\mathrm{T} 1$, which we consider as more realistic.

To estimate the age of $\mathrm{T} 0$ terrace from surface concentrations, we follow the same approach as developed in Vassallo et al (2007b). We consider that no significant denudation has occurred on $\mathrm{T} 0$ surface because it presents a well-preserved morphology and because the samples were collected from the tops of boulders resting on wellpreserved bars (see Ritz et al. 2006). We use the lowest concentration (M0-51) to minimize the pre-exposure, and assuming no denudation we calculate a minimum age of $5.1 \pm 0.9 \mathrm{ka}$.

For luminescence dating, we collected two samples. The first (M07-Bi-OSL-T2) was taken from a sand layer interstratified between $\mathrm{T} 2$ alluvium and the colluvium derived from the T3/T2 riser (Fig. 9) and the second was taken from beneath an alluvial surface $2 \mathrm{~km}$ to the west (Bi-OSL5, see location in Fig. 7A). At the second sample site, we measured a stream incision offset of $3.2 \pm$ $0.8 \mathrm{~m}$, consistent with the offset of the riser between T0 surface and the riverbed (Fig. 10), and presumed to represent the 1957 displacement. M07-Bi-OSL-T2 was analysed by infrared stimulated luminescence (IRSL) using the Multiple Aliquot Additive Dose (MAAD) procedure (Aitken 1998) on the fine-grained (4-11 $\mu \mathrm{m})$ polymineral sample (more details are provided in Appendix B). We used the IRSL dating technique because we anticipated older sample ages and quartz saturation: one sample had a very high dose rate, and also because the quartz within the area varies widely in its response to OSL dating due to possible albite contamination within the quartz grains (Hülle et al. 2010). Using the minimum equivalent 

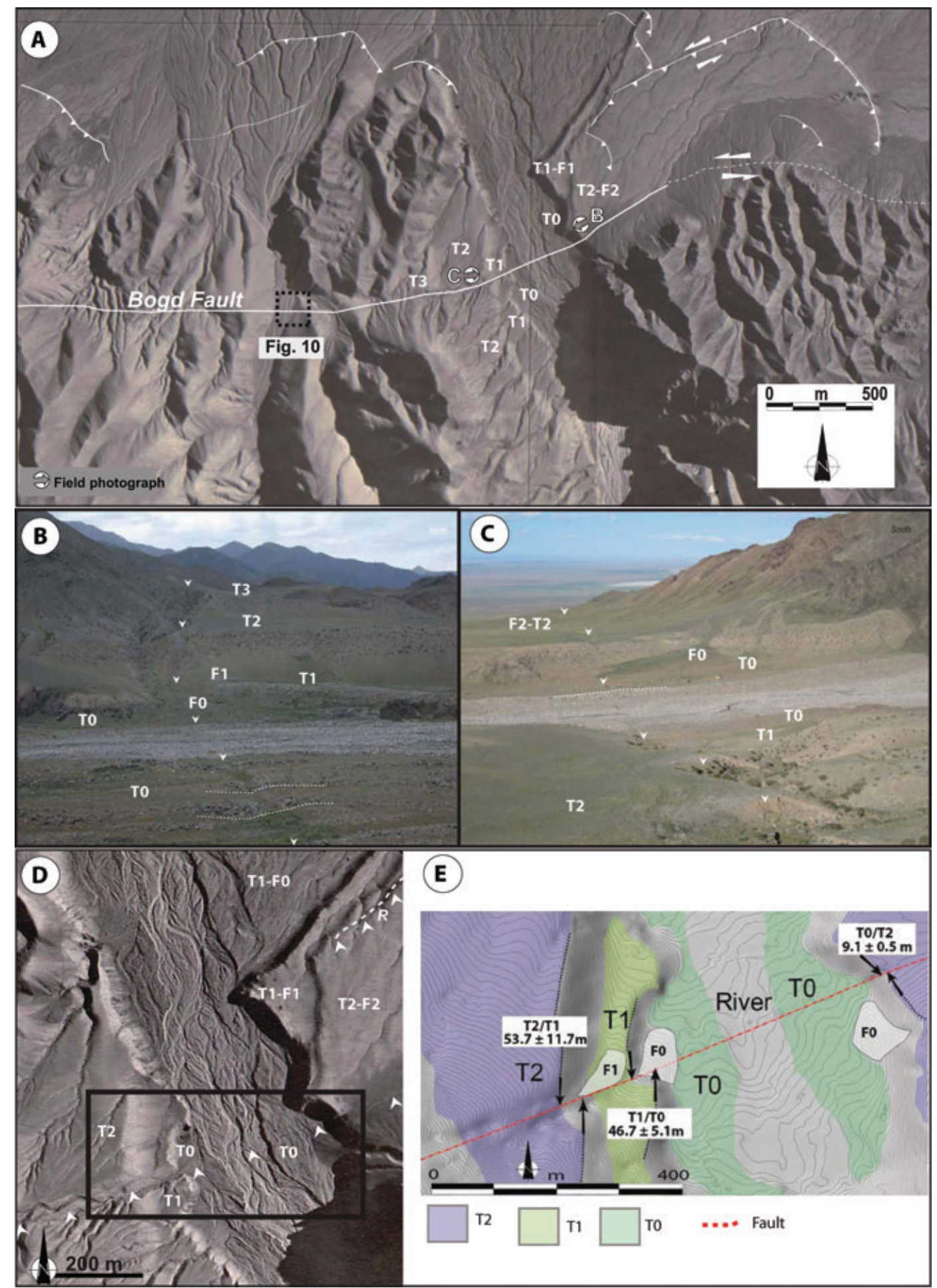

(E)

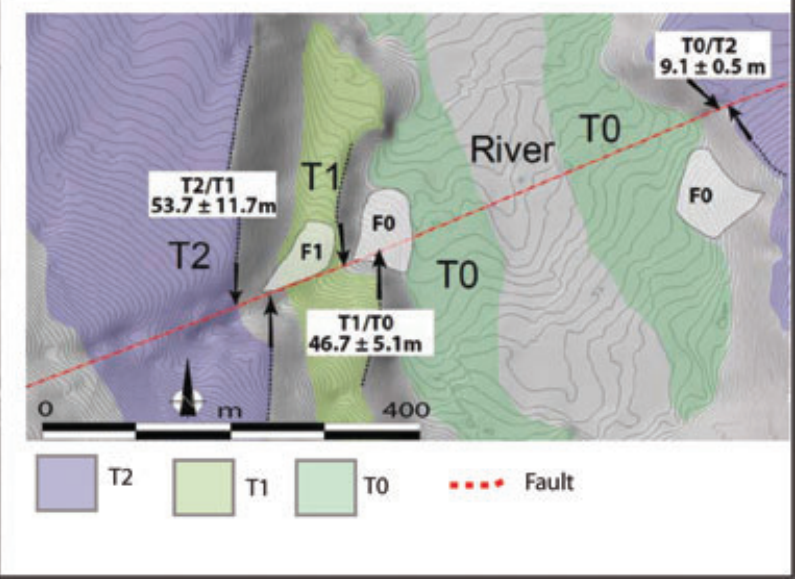

Figure 7. Morphological analyses at Bitut. (A) Aerial photo (1958) with a large view of the Bitut area. The surface ruptures associated with the 1957 event are mapped with white lines. (B) Aerial photography (1958) showing the terraces displaced along the Bogd Fault. The white triangles represent the 1957 surface rupture. (C) Digital elevation models and the morphotectonic interpretations with the piercing points used to measure the offset risers (black arrows). Note that T3 was not surveyed by the DEMs.

dose of $1100 \pm 200$ Grays (Gy), we calculate a minimum age of $210 \pm 50 \mathrm{ka}$ (Table 2). We consider this IRSL age estimate to be closer to the true age of T2 surface than the minimum age given from the steady state ${ }^{10} \mathrm{Be}$ concentration $\left(T_{\text {eff }} \sim 135 \mathrm{ka}\right)$. Bi-OSL5 was analysed using the blue light component of quartz and a Single Aliquot Regeneration protocol (Murray \& Wintle 2000). The central age model (CAM) gives an equivalent dose of $12.9 \pm 1.6$ Gy (details in Appendix B and in Table 2), which yields an age of $3.71 \pm 0.46 \mathrm{ka}$, consistent with the ${ }^{10} \mathrm{Be}$ age of surface $\mathrm{T} 0$ within the Bitut valley.

Estimating slip rates. To estimate the minimum horizontal slip rates, we used the displacements of the offset risers divided by the 

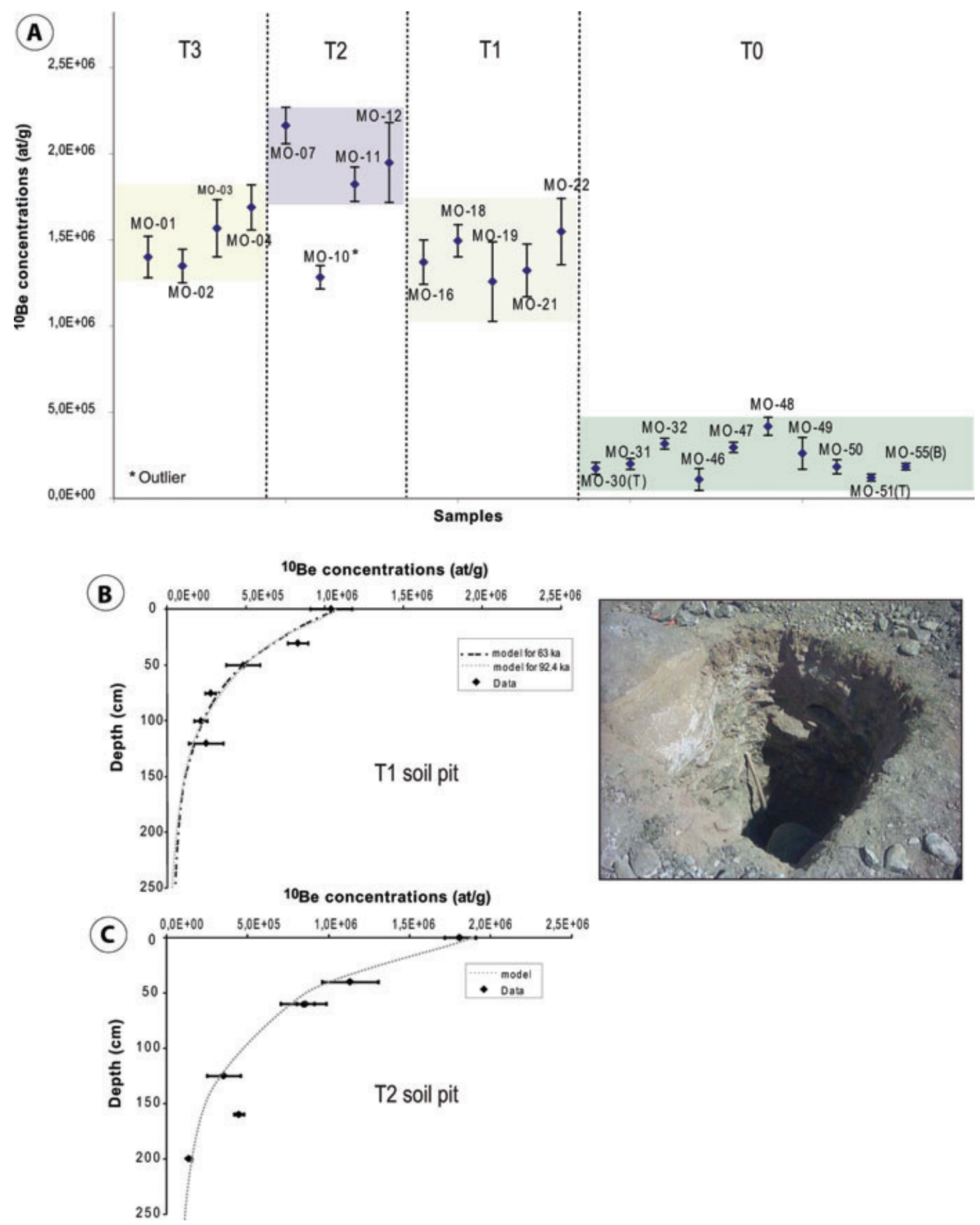

Figure 8. ${ }^{10} \mathrm{Be}$ analyses at Bitut. (A) ${ }^{10} \mathrm{Be}$ surface concentrations for the $\mathrm{T} 3, \mathrm{~T} 0, \mathrm{~T} 2$ and $\mathrm{T} 1$ terraces. (B) Depth distribution of ${ }^{10} \mathrm{Be}$ concentrations in $\mathrm{T} 1$ terrace. Black squares are for the data; the dashed lines represent the best fit using a chi-squared inversion. Field photography of the soil pit within the T1 terrace, (taken in 2005). (C) Depth distribution of ${ }^{10} \mathrm{Be}$ concentrations in $\mathrm{T} 2$ terrace. Black squares are for the data; the dashed lines represent the best fit using a chi-squared inversion.

ages of the upper surfaces. The offset of the T2/T1 riser $(53.7 \pm$ $11.7 \mathrm{~m})$ divided by the IRSL age $(210 \pm 50 \mathrm{ka})$ of $\mathrm{T} 2$ yields a minimum slip rate of $0.28 \pm 0.12 \mathrm{~mm} \mathrm{yr}^{-1}$. We can also obtain a maximum slip rate by dividing the offset of the riser by the age of the lower terrace. Dividing this same offset by the age $(92.4 \pm 10 \mathrm{ka})$ of $\mathrm{T} 1$ yields a maximum slip rate of $0.58 \pm 0.21 \mathrm{~mm} \mathrm{yr}^{-1}$. These two estimates constrain the slip rate rather tightly. The offset of the $\mathrm{T} 1 / \mathrm{T} 0$ riser $(46.7 \pm 5.1 \mathrm{~m})$ divided by the ${ }^{10} \mathrm{Be}$ age of the upper terrace $\mathrm{T} 1$, yields a minimum slip rate of $0.52 \pm 0.12 \mathrm{~mm} \mathrm{yr}^{-1}$. In this case, unfortunately, the maximum slip rate obtained by dividing this offset by the age ( $5 \mathrm{ka}$ ) of the lower terrace $\mathrm{T} 0$ is $\sim 9 \mathrm{~mm} \mathrm{yr}^{-1}$, which is valid as an upper bound but is not consistent with the maximum slip rate using T2/T1 riser offset or the maximum slip rate estimated at Noyan Uul $\left(1.4 \mathrm{~mm} \mathrm{yr}^{-1}\right)$. To summarize the results at Bitut, the average slip rate (over the past $\sim 200 \mathrm{kyr}$ ) ranges from 0.16 to $0.79 \mathrm{~mm} \mathrm{yr}^{-1}$. 


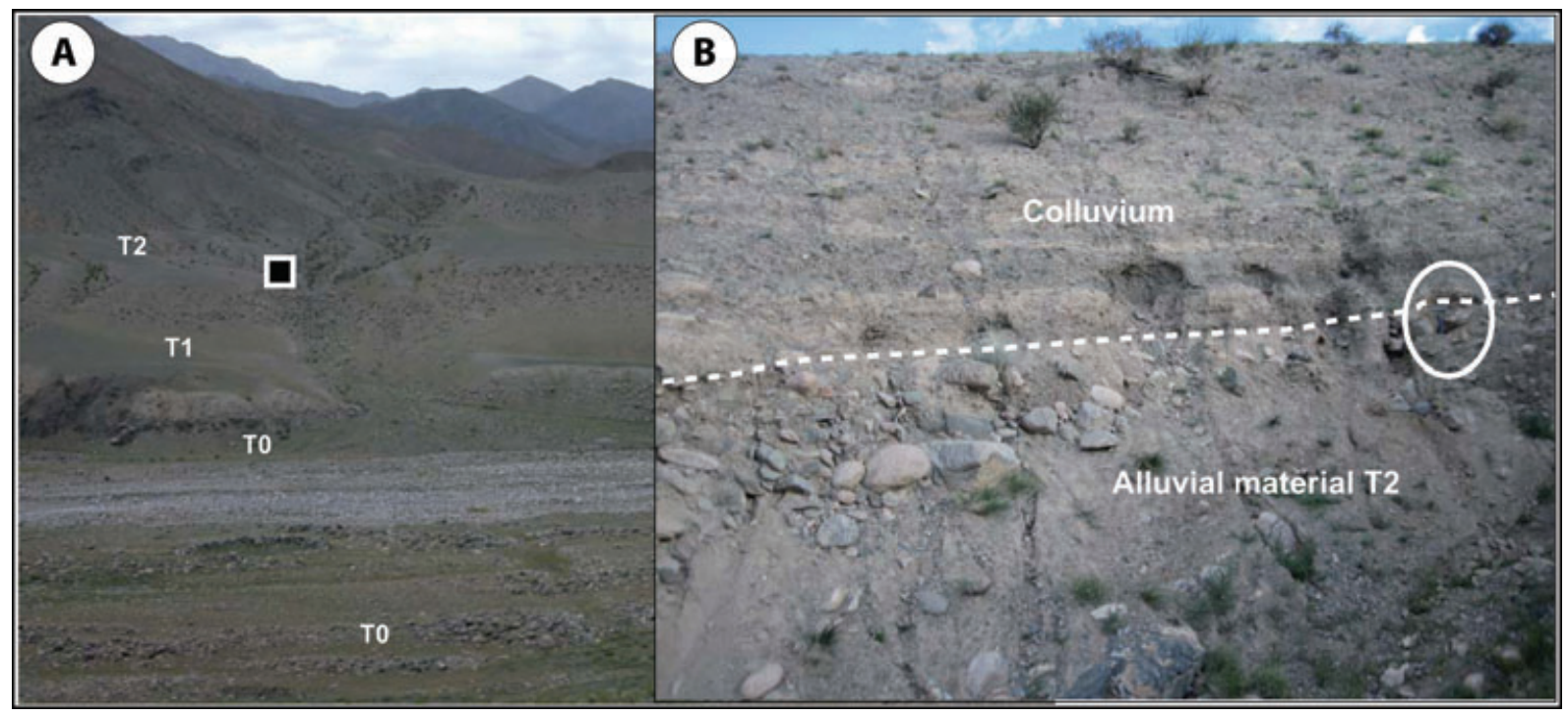

Figure 9. (A) Field photo showing the location of the IRSL sample M07-Bi-OSL-T2 in the Bitut terrace (Black square). (B) This sample is interstratified between the alluvial deposits of the T2 terrace and the colluviums from the T3 terrace. Sampling location is surrounded by the white circle.

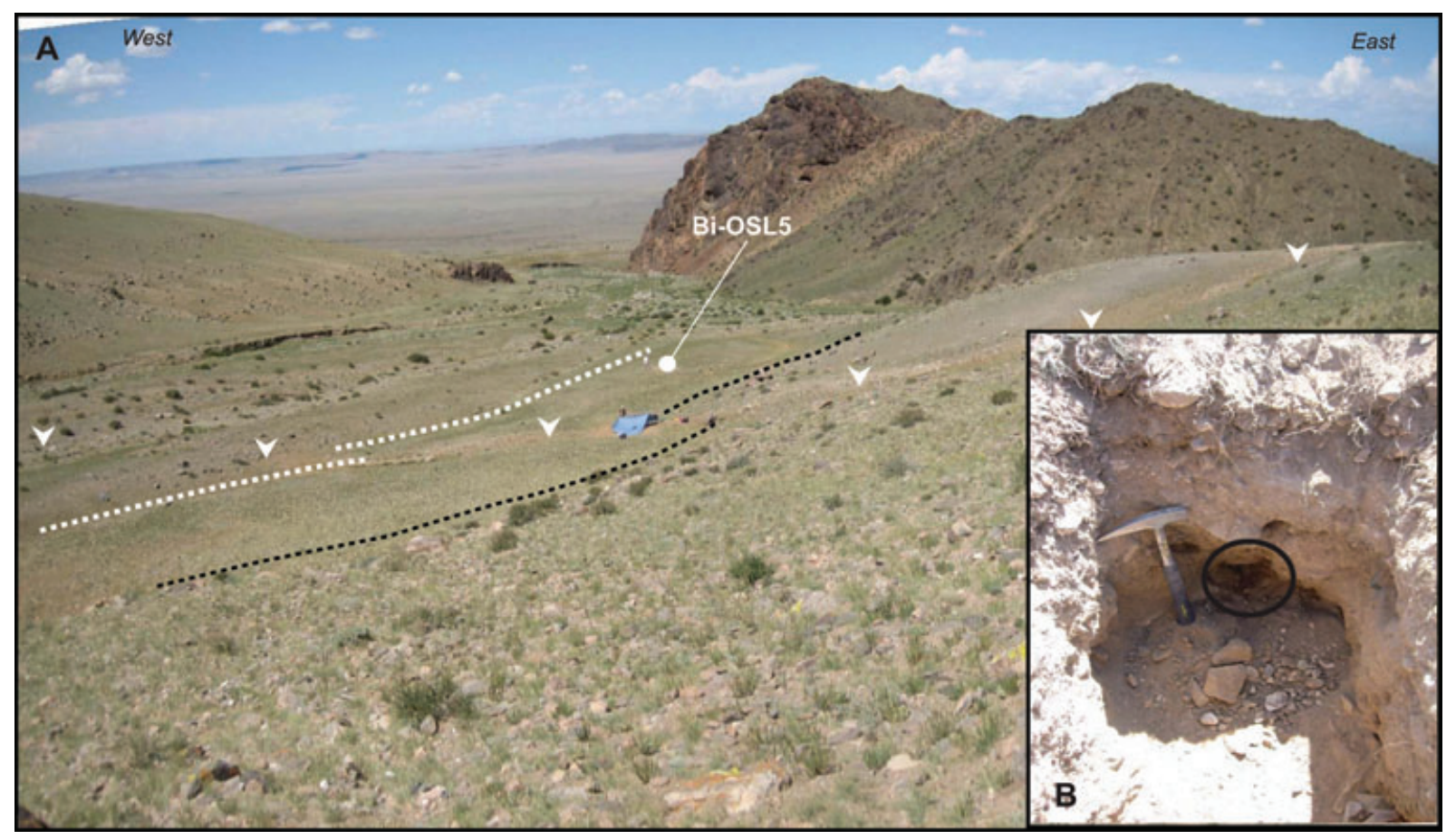

Figure 10. Field photo at the second site of Bitut area (looking north). (A) The white dashed lines represent the piercing lines used to define the offset ( $3 \mathrm{~m}$ ) within the T0 surface, corresponding to the 1957 coseismic offset. The black dashed lines are the piercing lines to measure the offset riser of S0/S1 surfaces. Location of the soil pit for Bi-OSL5 collecting is shown. (B) Field photo of the OSL collection pit with location of the sample (black open circle).

\subsection{The East Ih Bogd segment}

Along the East Ih Bogd segment, we estimated the horizontal slip rate of the Bogd Fault at Baast Uul, a site located $43 \mathrm{~km}$ east of the Bitut site (Fig. 1B). At this site, the Bogd Fault trends N095 E and separates the mountainous area to the south (the Dulaan Bogd Uul massif) from the alluvial plain to the north. In this area, the faulting pattern is complex showing evidence of partitioning between pure strike-slip faulting and reverse faulting (Fig. 11A). As has been described in several other places along the Bogd Fault system (i.e.
Bayasgalan et al. 1999b; Vassallo et al. 2007b), an old, inactive strike-slip fault is observed upslope within the Dulaan Bogd Uul massif.

Estimating offsets. The currently active trace of the Bogd Fault displaces two alluvial fan surfaces (S0 and S1) (Fig. 11C). The younger S0 surface shows bar-and-swale morphology with large boulders and shallow incision while the $\mathrm{S} 1$ is deeply incised with few remaining standing boulders. As described at Noyan Uul, the stream incisions are deeper and more broadly spaced on S1 than 
Table 2. Elemental concentrations, dose rate data and ages for the Bogd samples.

\begin{tabular}{|c|c|c|c|c|c|c|c|c|c|}
\hline $\begin{array}{l}\text { Sample } \\
\text { name }\end{array}$ & $\begin{array}{l}\text { Per cent water } \\
\text { content }^{a}\end{array}$ & $\mathrm{~K}(\text { per cent })^{b}$ & $\mathrm{Th}(\mathrm{ppm})^{b}$ & $\mathrm{U}(\mathrm{ppm})^{b}$ & $\begin{array}{c}\text { Cosmic dose }{ }^{c} \\
\text { additions }(\mathrm{Gy} / \mathrm{ka})\end{array}$ & $\begin{array}{l}\text { Total dose } \\
\text { rate }(\mathrm{Gy} / \mathrm{ka})\end{array}$ & $\begin{array}{l}\text { Equivalent } \\
\text { dose (Gy) }\end{array}$ & $n^{d}$ & Age (ka) \\
\hline M07-Bi-OSL-T2 & $1(24)$ & $2.66 \pm 0.09$ & $11.09 \pm 0.34$ & $2.70 \pm 0.34$ & $0.31 \pm 0.01$ & $5.18 \pm 0.13$ & $>1100 \pm 220$ & - & $>210 \pm 50^{e}$ \\
\hline Bi-OSL5 & $1(29)$ & $2.30 \pm 0.06$ & $11.50 \pm 0.35$ & $2.79 \pm 0.12$ & $0.27 \pm 0.01$ & $3.47 \pm 0.08$ & $12.9 \pm 1.60$ & $17(22)$ & $3.71 \pm 0.46^{e}$ \\
\hline BG09-1 & $1(17)$ & $3.90 \pm 0.50$ & $21.64 \pm 0.47$ & $5.02 \pm 0.20$ & $0.28 \pm 0.01$ & $10.30 \pm 0.16$ & $311.3 \pm 20.7$ & - & $39.0 \pm 2.66^{e, f}$ \\
\hline
\end{tabular}

Notes: ${ }^{a}$ Field moisture, with figures in parentheses indicating the full sample saturation per cent. Ages calculated using 30-35 per cent of saturation values

(i.e. 10 per cent when full saturation is 34 per cent).

${ }^{b}$ Analyses obtained using laboratory Gamma Spectrometry (low resolution NaI detector).

${ }^{c}$ Cosmic doses and attenuation with depth were calculated using the methods of Prescott \& Hutton (1994).

${ }^{d}$ Number of replicated equivalent dose (De) estimates used to calculate the mean equivalent dose. Figures in parentheses indicate total number of measurements made including failed runs with unusable data.

${ }^{e}$ Linear + exponential fit used on equivalent dose data, errors to one sigma. Only Bi-OSL5 is a quartz OSL SAR age.

${ }^{f}$ Anomalous Fading are reported on the calculated age at 5.5 per cent.

S0. The streams incised into S1 are displaced along the fault. S1 is bounded to the west by a deep stream incision showing a large cumulative left-lateral displacement. Along the eastern riser of the stream, we mapped two remnant bedrocks hills on both sides of the Bogd Fault, against which the alluvium associated with the S1 surface is accumulated. Detailed field mapping of the surface, including a topographic survey, allows us to estimate an offset of $18.6 \pm 1.9 \mathrm{~m}$ for the $\mathrm{S} 1 / \mathrm{S} 0$ riser (Fig. 11D). The depositional contact between $\mathrm{S} 1$ surface and the bedrock hills, and the deeply incised stream channel are offset left-laterally by $116 \pm 16 \mathrm{~m}$ (Fig. 11E).

Dating markers. We used luminescence dating to constrain the age of the S1 surface. We sampled the surface where its morphology is best preserved (see location, in Fig. 11C). The sampling protocol and preparation included manual extraction in a portable dark room (Rizza et al. 2011). We collected one sample (BG09-1) at $64 \mathrm{~cm}$ depth, within a stratified unit containing rounded gravels $(<5 \mathrm{~cm})$ in a sandy coarse matrix (Fig. 12). The sample was analysed using the fine-grained $(4-11 \mu \mathrm{m})$ polymineral sample. As we previously described, we anticipated that the quartz OSL would not provide a reliable equivalent dose analysis due to possible contamination in the quartz grains and also because the extremely high dose rate (see Table 2) would have saturated out the signal even if the sample had been deposited within the last 30-40 ka.

IRSL decay curves for the 4-11 $\mu \mathrm{m}$ grain size show saturation, with a minimum equivalent dose of $311.3 \pm 6.64$ Gy (details in Appendix B). Moreover, we performed anomalous fading tests on the stability of the IRSL signal (see the appendix for more details) that indicate large signal instability, with recording fades of $5.5 \pm 0.5$ per cent ( $g$-value of 4.16 per cent), which is in agreement with previously published fading tests in the Gobi-Altay area (i.e. Lehmkuhl \& Lang 2001; Hülle et al. 2010). Using the minimum equivalent dose and the fading value, we estimated a corrected minimum age of $39.0 \pm 2.66$ ka for sample BG09-1.

Estimating slip rate. Dividing the $\mathrm{S} 1$ displacement (116 $\pm 16 \mathrm{~m})$ by $\mathrm{S} 1$ minimum depositional age $(39.0 \pm 2.66 \mathrm{ka})$ yields a maximum horizontal slip rate of $3.01 \pm 0.63 \mathrm{~mm} \mathrm{yr}^{-1}$. This corresponds to a maximum bound for the slip rate because the luminescence sample is saturated, and therefore represents a minimum age. However, similarities among fan surface chronologies between Baast Uul, Bitut and Noyan Uul sites, suggest that these surfaces were deposited contemporaneously. In Noyan Uul, S1 surface is $108 \mathrm{ka}$, while in Bitut, T1 surface is $92.4 \pm 10 \mathrm{ka}$. These observations suggest that a major aggradational event occurred at $\sim 100$ ka within the Ih Bogd massif. Therefore, we suggest that the true age of surface S1 in Baast Uul is between $82.4 \mathrm{ka}$ and $108 \mathrm{ka}$. If this assumption is correct, this yields a minimum horizontal slip rate of $1.26 \pm 0.34 \mathrm{~mm} \mathrm{yr}^{-1}$.

\subsection{Variations of the horizontal slip rate within the western Bogd Fault}

Our study allows us to consider the evolution of the horizontal slip rate along the three western segments of the Bogd Fault. Along the WIB segment, at West Noyan Uul site, the horizontal slip rate increases from $0.57 \pm 0.04 \mathrm{~mm} \mathrm{yr}^{-1}$ for the past $60 \mathrm{ka}$ to $0.76 \pm$ $0.1 \mathrm{~mm} \mathrm{yr}^{-1}$ for the past $15 \mathrm{ka}$, suggesting an increase of the horizontal slip rate through time. This result has to be considered in the local context of this site, where the deformation is distributed over two fault strands forming a releasing bend. Considered together with the fact that both fault strands are active (they both ruptured in 1957), our result suggests that the deformation is distributed over the two branches and is gradually migrating from the southern branch that forms the main topographic scarp to the younger northern branch cutting through the pull-apart. A similar feature was described along the Jid Fault in Mongolia Altay (i.e. Walker et al. 2006). At Noyan Uul site, the horizontal slip rate estimated over the past $110 \mathrm{ka}$ ranges from $0.4 \mathrm{~mm} \mathrm{yr}^{-1}$ to $1.4 \mathrm{~mm} \mathrm{yr}^{-1}$, in agreement with previous estimates (Ritz et al. 1995; Ritz et al. 2006). Along the NIB segment, at Bitut site, the horizontal slip rate increases from $0.28 \pm 0.12 \mathrm{~mm} \mathrm{yr}^{-1}$ for the past $210 \mathrm{ka}$ to $0.52 \pm 0.12 \mathrm{~mm} \mathrm{yr}^{-1}$ for the past $100 \mathrm{ka}$, also showing an increase of the horizontal slip rate through time, as observed at West Noyan Uul. This evolution is consistent with observations by Vassallo et al. (2007b) suggesting that the deformation was distributed over two branches during the past 200-100 ka and progressively migrated from the southern, older branch $\sim 5 \mathrm{~km}$ within the Ih Bogd massif, to the northern younger branch that forms the present-day boundary of the massif. Along the EIB segment, at Baast Uul site, the horizontal slip rate is $1.26 \pm 0.34 \mathrm{~mm} \mathrm{yr}^{-1}$ assuming that the $120 \mathrm{~m}$ offset S1surface has the same age than the S1 surfaces in Noyan Uul and Bitut (82.4-108 ka).

Our results suggest that the horizontal slip rate decreases from the WIB segment to the NIB segment, then increases again along the EIB segment if we accept the slip rate determined at Baast Uul site based on an assumed age. The horizontal slip rate appears then to be constant at $\sim 1 \mathrm{~mm} \mathrm{yr}^{-1}$ along the $\mathrm{N} 095^{\circ} \mathrm{E}$ trending segments, while it decreases to $\sim 0.5 \mathrm{~mm} \mathrm{yr}^{-1}$ along the $\mathrm{N} 110^{\circ} \mathrm{E}$ trending segment. These differences in slip rate are consistent with the kinematic variations from purely left-lateral strike-slip faulting along the WIB and EIB segments to reverse-left-lateral faulting along the NIB segment, and consistent with the restraining bend geometry of the Bogd Fault. They also suggest that the total deformation is conserved along the western part of the Bogd Fault between Noyan Uul and Baast Uul. 

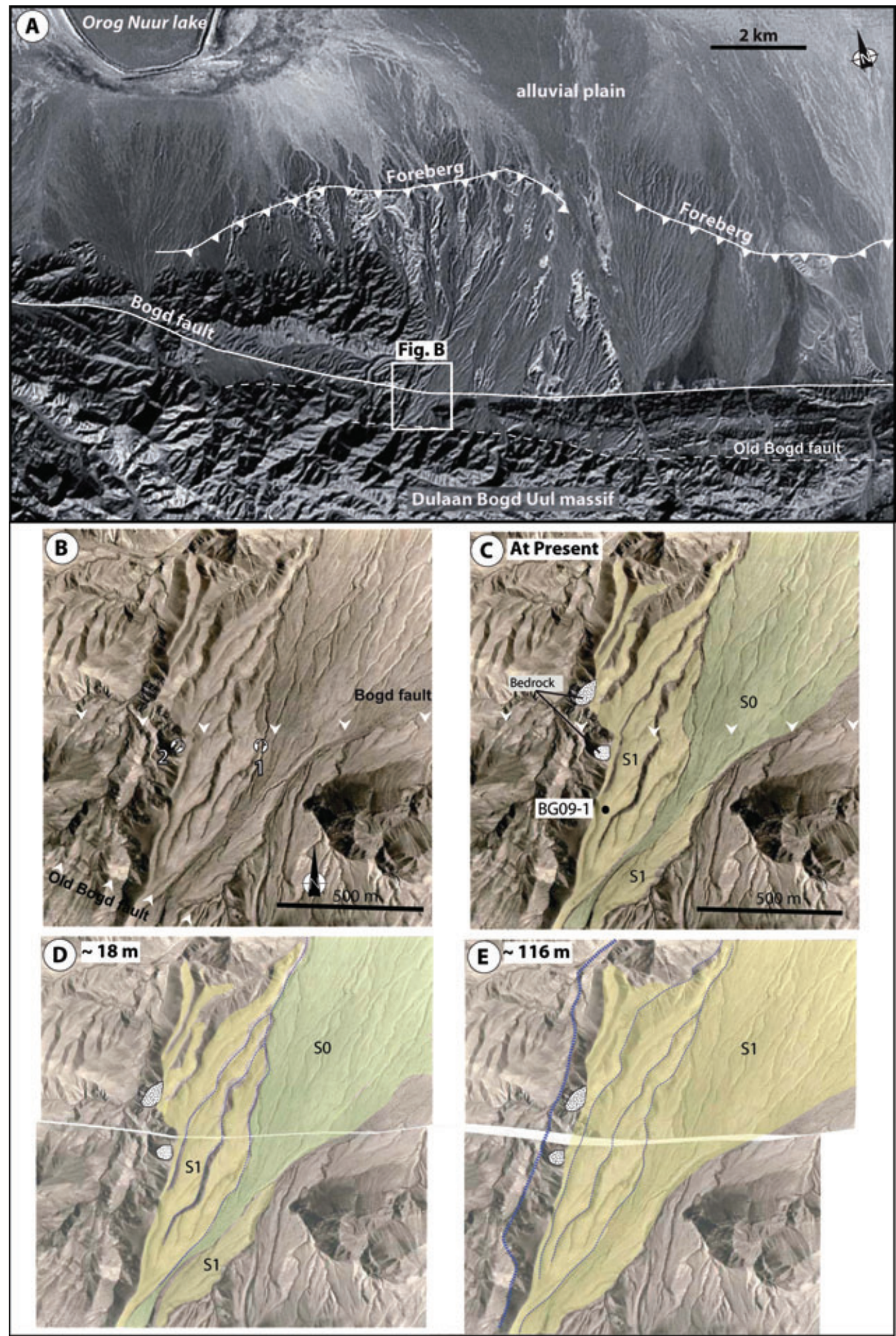

Figure 11. (A) Satellite image (source: http://www.earth.google.com) depicting the 1957 surface ruptures (white lines) in the Baast Uul area. The white dashed line represents the surface rupture of an old strand of the Bogd Fault, inactive during the 1957 earthquake. The white box is for the location of the study area. (B) Aerial photography (1958) showing the S0 and S1 alluvial fans displaced along the Bogd Fault. The locations of field photos are shown: (1) Fig. 16(A) (2) Fig. 16(B). (C) Morphotectonic interpretations based on aerial photographs and reconnaissance field mapping. The black dot is for the location of BG09-1 luminescence sample. (D) Morphotectonic reconstruction for an offset of $\sim 18 \mathrm{~m}$ using the riser S0/S1 of alluvial surfaces in the eastern part of the area. Note that thalwegs within S1 and S0 surfaces are connected across the fault. (E) Morphotectonic reconstruction for a compensation of $\sim 116 \mathrm{~m}$ using the riser of S1 alluvial surface in the western part of the area. The uncertainty in these offset measurements come from the reconstruction of the piercing lines (talwegs and risers) that range between a minimum $(100 \mathrm{~m})$ and maximum $(132 \mathrm{~m})$ values. In the western part of $\mathrm{S} 1 \mathrm{riser}$, the large thalweg is well connected with the other side of the incision. Note also that thalwegs within the S1 surface are connected across the fault, and that the west edge of the fan, where it is deposited onto local bedrock highs is also aligned across the fault. 

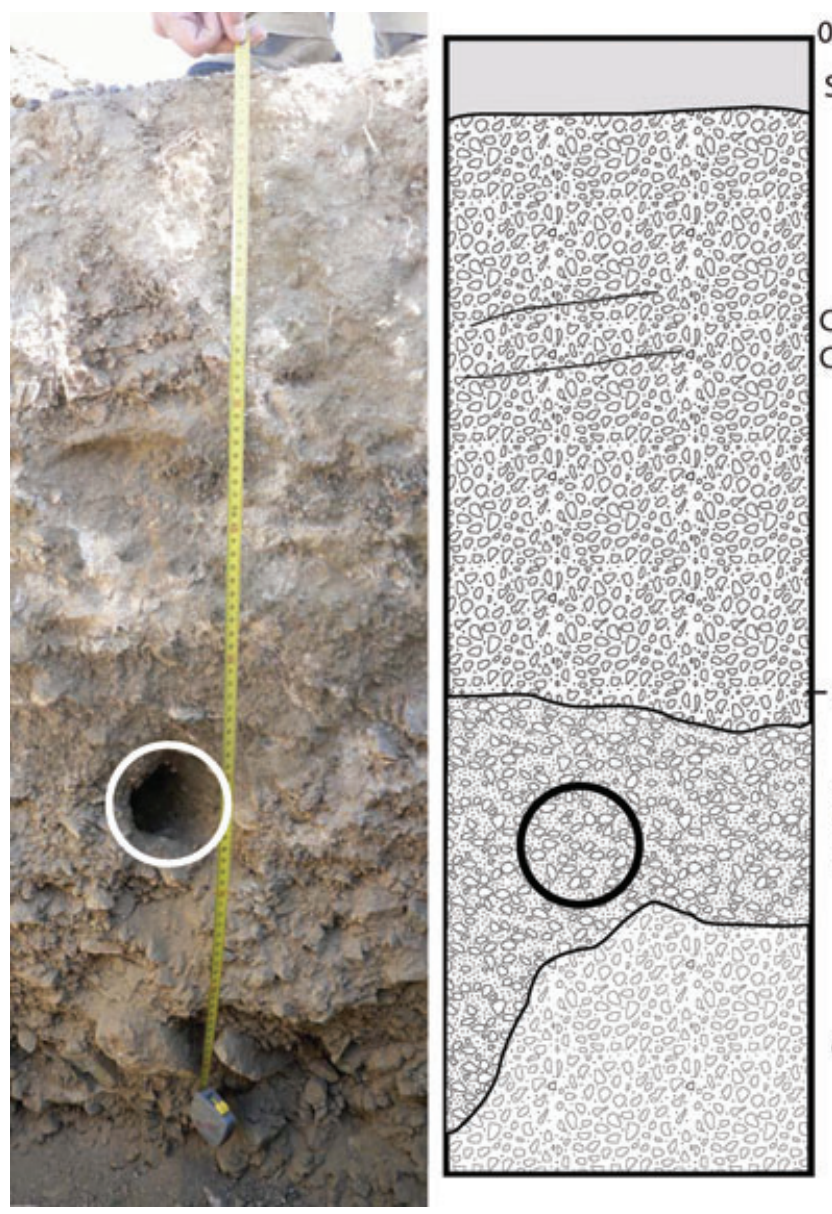

$0 \mathrm{~cm}$

Soil horizon

Clastic pebbles $($ size $\sim 10-20 \mathrm{~cm}$ )

Carbonate stage

$50 \mathrm{~cm}$

Stratified,

rounded peebles $($ size $\sim 10-30 \mathrm{~cm})$

with sandy matrix

Clastic pebbles $($ size $\sim 15-30 \mathrm{~cm})$

Figure 12. Field view showing the wall where BG09-1 was collected in a coarse matrix and the log interpretation of the profile. The OSL sample was collected within a palaeochannel incised into the fan deposits at $65 \mathrm{~cm}$ depth (black open dot is the location of the sampling).

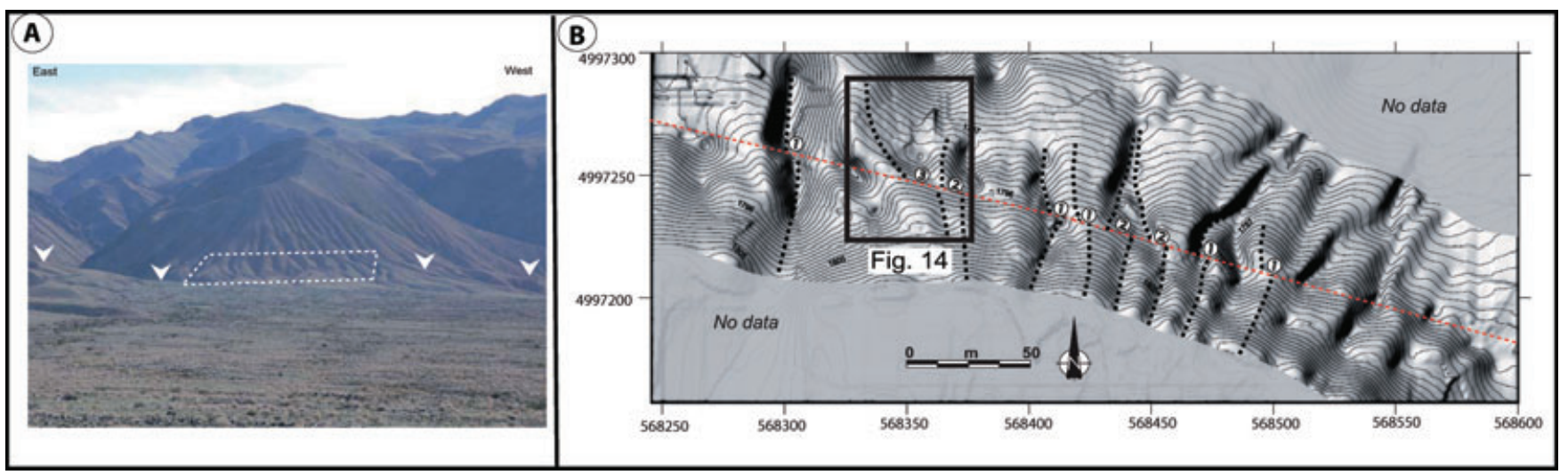

Figure 13. (A) Field view (looking south) showing the study area at Noyan Uul with the numerous thalwegs and ridgelines displaced along the Bogd Fault. The white dashed box represents the area surveyed with the kinematic GPS. (B) Digital elevation model showing the piercing lines (black dashed lines) used to calculate a mean horizontal offset along the Bogd Fault (red dashed line). (1) is for the 1957 offset, (2) and (3) are for larger offsets values. The coordinates are in Universal Transverse Mercator system, zone $48 \mathrm{~N}$. The contour interval is $1.0 \mathrm{~m}$.

\section{SLIP MAGNITUDES OF PAST EVENTS}

In this section, we consider the slip magnitude of past events by analysing the distribution of displacements along the Bogd Fault using kinematic GPS surveys. Comparing 1957 offsets with cumulative displacements allows us to consider the distribution of slip associated with past earthquakes. We focus our analyses on three of the four sites previously described (Noyan Uul, Bitut and
Baast Uul) in addition to a new site (Zadgay Sayhr) located $11 \mathrm{~km}$ east of Baast Uul (Fig. 1B).

Noyan Uul. In Noyan Uul, we surveyed a 340-m-long section of the Bogd Fault, located $500 \mathrm{~m}$ west of the site described in Section 2.1.1, using RTKs GPS methods. At this location, a series of narrow thalwegs are offset left-laterally (Fig. 13). We use the axes of these thalwegs and the crest lines of ridges separating them (interfluves) to estimate the horizontal displacements associated with the 1957 
Table 3. Details of the measured displacements along the Bogd Fault. Coordinates are in Universal Transverse, Mercator (UTM), zone 48. ( $X 1$; $Y 1)$ are the latitude and longitude coordinates for piercing point 1 , and $(X 2 ; Y 2)$ are the latitude and longitude coordinates for piercing point 2.

\begin{tabular}{|c|c|c|c|c|c|}
\hline & Coordinate $X 1(\mathrm{~m})$ & Coordinate $Y 1(\mathrm{~m})$ & Coordinate $X 2(\mathrm{~m})$ & Coordinate $Y 2(\mathrm{~m})$ & Offset (m) \\
\hline \multicolumn{6}{|l|}{ Noyan Uul } \\
\hline Thalweg & 568304,49 & 4997257,56 & 568299,82 & 4997257,83 & 4,68 \\
\hline Thalweg & 568412,30 & 4997234,21 & 568407,35 & 4997236,13 & 5,30 \\
\hline Crest & 568416,14 & 4997232,98 & 568420,26 & 4997231,60 & 4,34 \\
\hline Thalweg & 568446,49 & 4997219,93 & 568442,10 & 4997220,89 & 4,50 \\
\hline Thalweg & 568460,50 & 4997216,91 & 568456,52 & 4997218,97 & 4,48 \\
\hline Crest & 568497,86 & 4997205,78 & 568493,33 & $\begin{array}{c}4997205,92 \\
\text { mean }\end{array}$ & $\begin{array}{c}4,53 \\
4,6 \pm 0,3\end{array}$ \\
\hline Crest & 568331,13 & 4997251,65 & 568341,84 & 4997250,69 & 10,76 \\
\hline Crest & 568365,60 & 4997244,92 & 568374,53 & 4997242,73 & 9,19 \\
\hline Thalweg & 568435,23 & 4997225,70 & 568426,99 & $\begin{array}{c}4997228,99 \\
\text { mean }\end{array}$ & $\begin{array}{c}8,88 \\
9,6 \pm 1,0\end{array}$ \\
\hline thalweg & 568342,27 & 4997250,16 & 568365,60 & 4997243,77 & 24,19 \\
\hline thalweg & 568344,82 & 4997249,06 & 568366,63 & 4997241,87 & 22,97 \\
\hline thalweg & 568347,75 & 4997248,28 & 568367,89 & $\begin{array}{c}4997243,61 \\
\text { mean }\end{array}$ & $\begin{array}{c}20,67 \\
22,6 \pm 1,8\end{array}$ \\
\hline \multicolumn{6}{|l|}{ Bitut } \\
\hline Riser & 607499,54 & 4988439,45 & 607496,23 & 4988438,00 & 3,61 \\
\hline Riser & 607503,56 & 4988429,43 & 607505,96 & 4988430,43 & 2,60 \\
\hline Thalweg & 607490,89 & 4988435,77 & 607494,83 & 4988437,42 & 4,27 \\
\hline Thalweg & 607500,29 & 4988428,03 & 607502,65 & $\begin{array}{c}4988429,02 \\
\text { mean }\end{array}$ & $\begin{array}{c}2,56 \\
3,2 \pm 0,8\end{array}$ \\
\hline Riser S1/S0 & 607510,27 & 4988435,10 & 607516,89 & 4988437,67 & 7,10 \\
\hline Riser S1/S0 & 607507,94 & 4988439,67 & 607515,90 & $\begin{array}{c}4988442,61 \\
\text { mean }\end{array}$ & $\begin{array}{c}8,48 \\
7,8 \pm 0,9\end{array}$ \\
\hline Riverbed & 608621,48 & 608624,11 & 4988727,20 & 4988728,07 & 2,77 \\
\hline Riser T0 & 608629,66 & 608632,87 & 4988730,56 & 4988731,43 & 3,33 \\
\hline Bar 1 & 608648,49 & 608651,27 & 4988737,42 & 4988737,86 & 2,81 \\
\hline Bar 2 & 608657,84 & 608660,91 & 4988740,92 & 4988741,80 & 3,19 \\
\hline Bar 3 & 608694,78 & 608698,00 & 4988755,23 & 4988756,55 & 3,47 \\
\hline Bar 4 & 608719,90 & 608723,26 & 4988766,48 & $\begin{array}{c}4988767,65 \\
\text { mean }\end{array}$ & $\begin{array}{c}3,56 \\
3,2 \pm 0,3\end{array}$ \\
\hline \multicolumn{6}{|l|}{ Baast Uul } \\
\hline Top of riser S0 left bank & 651557,51 & 4978725,38 & 651562,15 & 4978724,29 & 4,77 \\
\hline Top of riser S0 left bank & 651558,20 & 4978726,49 & 651563,03 & 4978725,19 & 5,00 \\
\hline Base of riser S0 left bank & 651562,81 & 4978725,01 & 651566,11 & 4978723,70 & 3,55 \\
\hline Thalweg - incision & 651568,21 & 4978723,08 & 651565,43 & 4978723,69 & 2,85 \\
\hline Base of riser S0 right bank & 651572,87 & 4978722,13 & 651577,43 & 4978721,07 & 4,68 \\
\hline Top of riser S0 right bank & 651573,02 & 4978722,10 & 651577,72 & $\begin{array}{c}4978721,06 \\
\text { mean }\end{array}$ & $\begin{array}{c}4,81 \\
4,2 \pm 0,9\end{array}$ \\
\hline Riser S0/S1 - incision & 651541,12 & 4978728,80 & 651560,76 & 4978724,87 & 20,04 \\
\hline Riser S0/S1 - incision & 651544,69 & 4978728,20 & 651561,60 & $\begin{array}{c}4978724,75 \\
\text { mean }\end{array}$ & $\begin{array}{c}17,26 \\
18,6 \pm 1,9\end{array}$ \\
\hline Left riser & 651300,62 & 4978786,25 & 651319,44 & 4978781,70 & 19,36 \\
\hline Incision thalweg & 651307,42 & 4978784,00 & 651324,23 & 4978780,87 & 17,10 \\
\hline Incision thalweg & 651308,00 & 4978784,28 & 651324,11 & 4978780,59 & 16,53 \\
\hline Incision thalweg maximum & 651328,26 & 4978780,52 & 651307,95 & $\begin{array}{c}4978784,00 \\
\text { mean }\end{array}$ & $\begin{array}{c}20,60 \\
18,4 \pm 1,9\end{array}$ \\
\hline \multicolumn{6}{|l|}{ Zadgay Zayhr } \\
\hline Thalweg & 662517,71 & 4977946,67 & 662521,51 & 4977946,17 & 3,84 \\
\hline Thalweg & 662518,09 & 4977949,74 & 662521,94 & 4977949,08 & 3,90 \\
\hline Thalweg (1) & 662522,05 & 4977946,46 & 662518,31 & 4977947,49 & 3,88 \\
\hline Thalweg (1) & 662522,32 & 4977947,52 & 662518,08 & 4977948,74 & 4,42 \\
\hline Thalweg & 662549,01 & 4977944,34 & 662553,52 & 4977943,45 & 4,60 \\
\hline Thalweg & 662634,97 & 4977929,02 & 662639,87 & 4977928,07 & 4,99 \\
\hline Thalweg & 662639,34 & 4977927,13 & 662635,29 & 4977928,03 & 4,15 \\
\hline Thalweg & 662656,64 & 4977925,12 & 662661,54 & 4977924,29 & 4,97 \\
\hline Thalweg & 662672,02 & 4977922,39 & 662677,03 & $\begin{array}{c}4977921,44 \\
\text { mean }\end{array}$ & $\begin{array}{c}5,10 \\
4,4 \pm 0,5\end{array}$ \\
\hline Thalweg & 662463,33 & 4977959,49 & 662471,41 & 4977959,49 & 8,08 \\
\hline Thalweg & 662476,76 & 4977957,15 & 662485,34 & 4977955,59 & 8,72 \\
\hline Thalweg (2) & 662544,31 & 4977944,11 & 662553,31 & 4977942,31 & 9,18 \\
\hline Thalweg (2) & 662544,50 & 4977942,70 & 662553,27 & 4977940,88 & 8,95 \\
\hline Thalweg & 662757,70 & 4977907,13 & 662766,78 & $\begin{array}{c}4977905,51 \\
\text { mean }\end{array}$ & $\begin{array}{c}9,22 \\
8,8 \pm 0,5\end{array}$ \\
\hline Thalweg (3) & 662583,70 & 4977936,25 & 662596,10 & 4977934,76 & 12,49 \\
\hline Thalweg (3) & 662589,32 & 4977934,72 & 662575,11 & 4977936,78 & 14,36 \\
\hline Thalweg (3) & 662596,39 & 4977934,53 & 662583,60 & $\begin{array}{c}4977936,07 \\
\text { mean }\end{array}$ & $\begin{array}{c}12,89 \\
13,2 \pm 1,0\end{array}$ \\
\hline
\end{tabular}




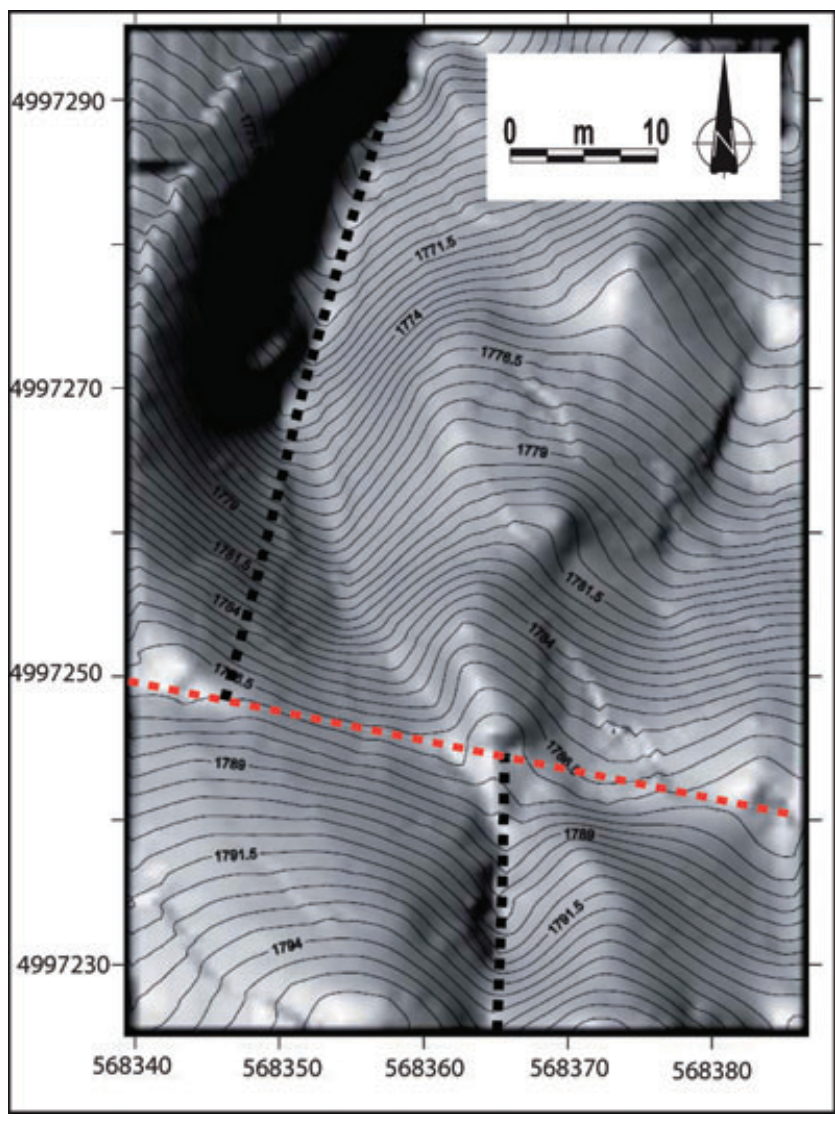

Figure 14. Digital elevation model showing the piercing lines (black dashed lines) used to calculate the mean cumulative horizontal offset $(22.6 \pm 1.8$ $\mathrm{m})$ along the Bogd Fault (red dashed line). The coordinates are in Universal Transverse Mercator system, zone 48 . The contour interval is $50 \mathrm{~cm}$.

earthquake and previous events. We calculate a mean value of $4.6 \pm$ $0.3 \mathrm{~m}$ for the 1957 dislocation and a mean cumulative displacement of $9.6 \pm 1.0 \mathrm{~m}$ (Table 3 ). Another topographic survey of an offset stream shows displacement of $22.6 \pm 1.8 \mathrm{~m}$ (Figs 13 and 14), while two offsets of $\sim 15 \mathrm{~m}$ are estimated farther west, using the aerial photography alone.

Bitut. In Bitut, we surveyed the offset bars associated with the lower terrace (T0) on the west bank of the Bitut River (Fig. 15). We measure a mean left-lateral horizontal offset of $3.2 \pm 0.3 \mathrm{~m}$, which is associated with the 1957 earthquake (Table 3). Two kilometres west of this site, we surveyed an offset stream (see Section 2.2) and an offset terrace with displacements of $3.2 \pm 0.8 \mathrm{~m}$ and $7.8 \pm$ $0.9 \mathrm{~m}$, respectively (Fig. 10). Between this site and the Bitut valley, Vassallo et al. (2007b) reported offset values of $3.0 \pm 0.5 \mathrm{~m}, 12 \pm$ $0.5 \mathrm{~m}$ and $22.5 \pm 2.5 \mathrm{~m}$.

Baast Uul. At Baast Uul, our GPS survey shows a mean coseismic offset of $4.2 \pm 0.9 \mathrm{~m}$ for the 1957 event using displaced streams incising the S0 surface, and cumulative offsets of $18.6 \pm 1.9 \mathrm{~m}$ and $18.4 \pm 1.9 \mathrm{~m}$ on the $\mathrm{S} 0 / \mathrm{S} 1$ riser (see Section 2.3) and a stream incising S1 surface, respectively (Fig. 16).

Zadgay Sayhr. This site is located $11 \mathrm{~km}$ east of the Baast Uul site, just west of the intersection of the Toromhon thrust fault and the Bogd Fault. Numerous thalwegs are left-laterally offset with several ranges of magnitudes. We surveyed a 345-m-long section from which we measure a mean displacement of $4.4 \pm 0.5 \mathrm{~m}$, which we interpret to have resulted during the 1957 earthquake and larger offsets of $8.8 \pm 0.5 \mathrm{~m}$ and $13.2 \pm 1.0 \mathrm{~m}$ (Fig. 17 and Table 3 ).
Analysing the slip distribution. In Fig. 18, we present a compilation of our displacement data and published offset measurements (Kurushin et al. 1997; Vassallo et al. 2007b). This compilation shows the horizontal slip distribution associated with the 1957 earthquake along the Bogd Fault and allows us to compare the 1957 displacements with older ones (Fig. 18). Horizontal offsets associated with the 1957 earthquake range between $6.4 \mathrm{~m}$ and 0.7 $\mathrm{m}$. The mean horizontal offset associated with the 1957 earthquake decreases from $5.2 \mathrm{~m}$ to $2.0 \mathrm{~m}$ from west to east. Along the WIB segment, the mean horizontal offset is $5.2 \pm 0.9 \mathrm{~m}$. Along the NIB segment, the mean 1957 horizontal offset is $3.1 \pm 0.7 \mathrm{~m}$, and varies from $3.9 \mathrm{~m}$ along the western part of this segment to $1.3 \mathrm{~m}$ along the eastern part. Along the EIB segment, the mean 1957 horizontal offset is $4.4 \pm 1.3 \mathrm{~m}$, increasing from $2.9 \mathrm{~m}$ on the western part of this segment to $4.6 \mathrm{~m}$ near the eastern end of the segment. Along the WBB segment, a single measurement of $3.0 \pm 1.0 \mathrm{~m}$ represents the 1957 horizontal offset. Along the NBB segment the mean horizontal offset is $2.0 \pm 0.1 \mathrm{~m}$, ranging from $3.3 \mathrm{~m}$ along the western part of this segment to $0.7 \mathrm{~m}$ near the eastern end.

Fig. 18A shows the left-lateral offsets measured for the 1957 earthquake and the larger displacements for cumulative earthquakes. For instance, at Noyan Uul (WIB), Bitut (NIB) and Zadgay Sayhr (EIB), cumulative offsets appear to represent at least two and three times the 1957 horizontal dislocation. We measure until four and five times the 1957 horizontal dislocation at Noyan Uul and Bitut, respectively. The ratio between these measured cumulative offsets and the multiple values of the 1957 offset is comprised between 85 per cent and 100 per cent (between 1 and 2 sigma). This observation suggests that the cumulative displacements observed along the Bogd Fault are multiples of the 1957 offset, and is consistent with a characteristic slip distribution (e.g. Schwartz \& Coppersmith 1984; Sieh 1996).

Fig. 18(B) shows that the distribution of the horizontal component is anticorrelated with the distribution of the vertical component. The horizontal component decreases along the NIB and NBB segments, while the vertical component increases. This evolution reflects the progressive change of kinematics from pure left-lateral strike-slip faulting to left-lateral-reverse faulting, consistent with the change of strike from the WIB segment to the NIB segment, and then from the EIB segment to the NBB segment.

\section{RE-ESTIMATING THE MOMENT MAGNITUDE OF THE 1957 GOBI-ALTAY EARTHQUAKE}

We use the coseismic offsets described in Section 3 to re-estimate the moment magnitude of the 1957 Gobi-Altay earthquake. We calculate the seismic moment using the relation $M_{0}=\mu$.A.SV with a shear modulus $(\mu)$ of $3.3 \times 10^{10} \mathrm{~N} \mathrm{~m}^{-2}$, and for each segments of the 1957 Bogd rupture, the mean slip vector (SV) with uncertainties, the surface rupture length and the fault dip (Table 4). We also assume that the rupture extended to a depth of $20 \mathrm{~km}$ as in Kurushin et al. (1997). We obtain a seismic moment $M_{0}$ constrained between $6.72 \times 10^{20} \mathrm{~N} \mathrm{~m}$ and $1.21 \times 10^{21} \mathrm{~N} \mathrm{~m}$. Then using the relation $M_{\mathrm{w}}=2 / 3 \times \log \left(M_{0}\right)-6.1$ (e.g. Hanks \& kanamori 1979), we estimate a moment magnitude $M_{\mathrm{w}}$ between 7.78 and 7.95 .

\section{RECURRENCE INTERVALS OF EARTHQUAKES}

Combining slip rate estimates and the slip distribution per event allows us to estimate the mean recurrence intervals of past 


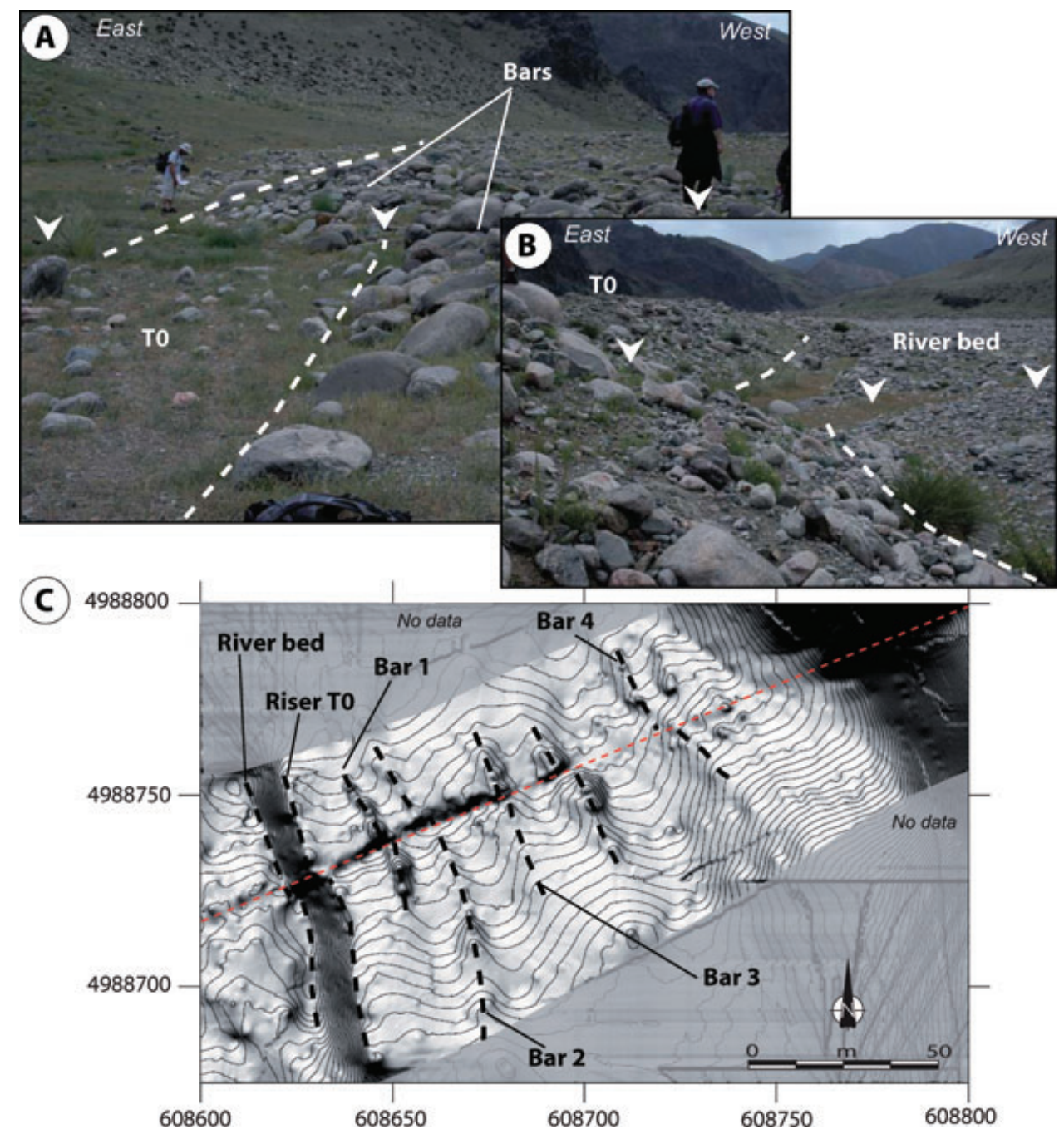

Figure 15. (A) Field view at Bitut (looking south) showing the bars and swale morphology in $T 0$ terrace displaced along the Bogd Fault. We measured an offset of $\sim 3$ m using the piercing lines represented by the white dashed lines. (B) Field view (looking south) showing bottom of riser between T0 terrace and the riverbed (white dashed lines). (C) Digital elevation model showing the piercing lines (black dashed lines) used to calculate a mean horizontal offset along the Bogd Fault (red dashed line). The coordinates are in Universal Transverse Mercator system, zone 48N. The contour interval is $25 \mathrm{~cm}$.

earthquakes along the different segments of the western Bogd Fault. Fig. 19 shows the mean recurrence interval estimates for large earthquakes along the WIB, NIB and EIB segments, determined by dividing the characteristic displacements observed at Noyan Uul, Bitut, Baast Uul and Gurvan Bulag site 2, by the long-term slip rate estimated at each of the three sites. These mean recurrence intervals are compared with the age of the penultimate event.

The mean recurrence intervals are between 3070 and $12250 \mathrm{yr}$ at Noyan Uul (WIB), between 3540 and $8750 \mathrm{yr}$ at Bitut (NIB) and between 2060 and $5540 \mathrm{yr}$ at Baast Uul (EIB), indicating that while the WIB and EIB segments have similar recurrence intervals, the NIB segment has slightly longer recurrence intervals. However, the mean interval at Bitut should be regarded as maximum bound because the slip rate there may be increasing through time (see Section 2.4). These intervals are similar to the age of the penultimate earthquake estimated from trenching investigations at Ulaan Bulag (Rizza 2010), a trench site located $33 \mathrm{~km}$ west of Noyan Uul, and from the ages of two surfaces $\left(5.1 \pm 0.9 \mathrm{ka}{ }^{10} \mathrm{Be}\right.$ and $3.71 \pm$ $0.46 \mathrm{ka}^{\mathrm{OSL}}$ ) only displaced by the 1957 earthquake at Bitut. They are also similar to the age of the penultimate event (Gurvan Bulag site 1) along the Gurvan Bulag thrust fault that bounds the Ih Bogd massif to the south (Prentice et al. 2002). The results are consistent with the idea that the segments of the western part of the Bogd Fault system (i.e. WIB, NIB, EIB segments + Gurvan Bulag thrust fault) have ruptured together in the past, and produces earthquakes with regular recurrence intervals. These results are in favour of a characteristic earthquake behaviour if the two eastern segments of the Bogd Fault system (WBB and NBB) show the same pattern.

\section{CONCLUSION AND DISCUSSIONS}

Our analysis of slip rate and slip magnitude of past events along the Bogd Fault leads us to draw a number of conclusions.

\subsection{Measuring horizontal slip rate}

Estimating horizontal slip rates from offset alluvial features can be difficult and interpretations of the age of offset features are often subject of debate. When offset markers are terrace risers, there is often ambiguity in whether the age of the offset corresponds to the age of the upper alluvial surface or the age of the lower surface or 

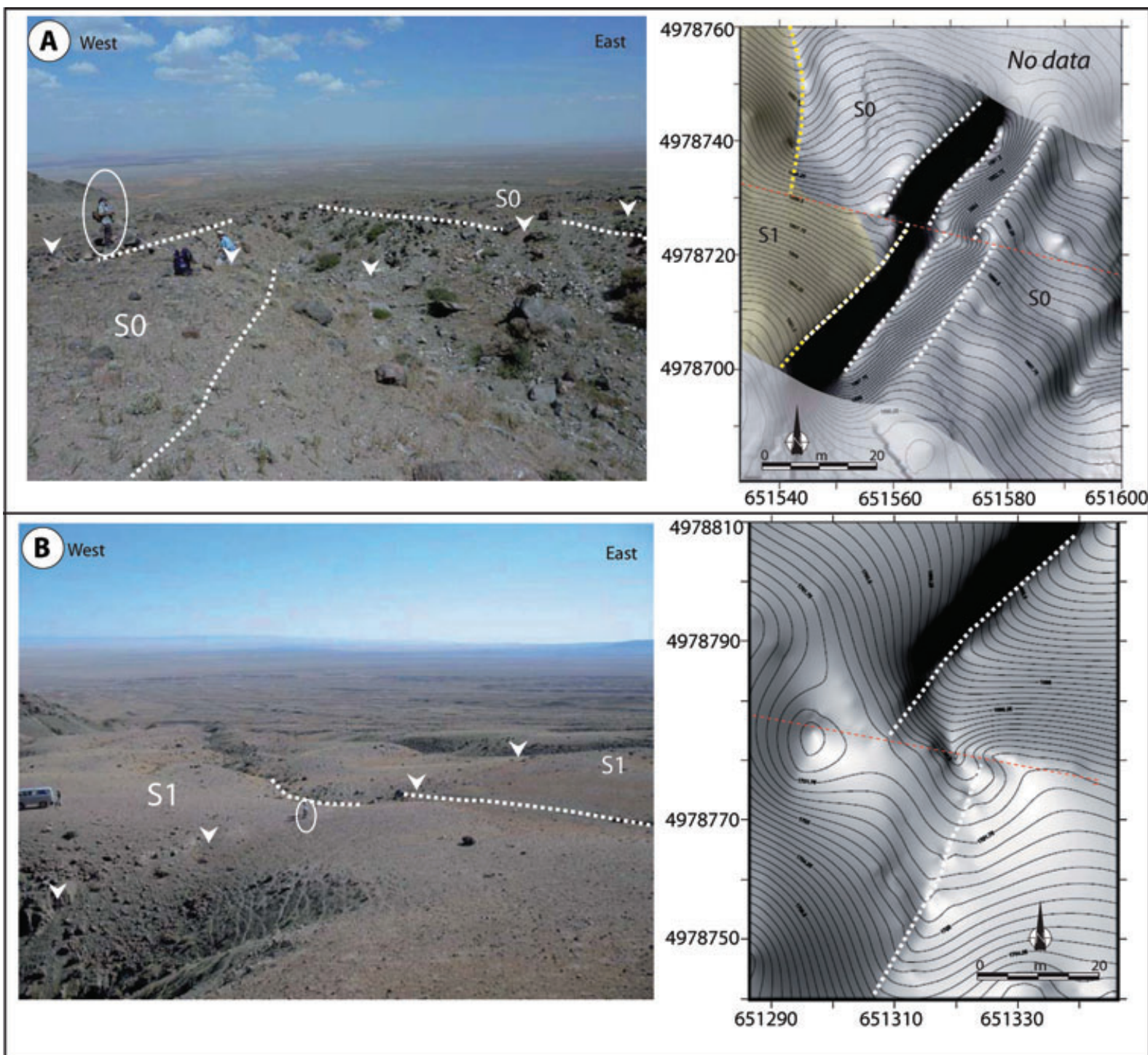

Figure 16. (A) Field view at Baast Uul (looking north) showing the piercing lines (white dashed lines) used to measure the thalweg within the S0 surface that has been displaced [state the amount of offset] along the Bogd Fault. Note that a person making scale is surrounded by the white circle. In the right part is the digital elevation model showing the piercing lines (white dashed lines) used to calculate the mean horizontal offset for the 1957 earthquake and one cumulative offset (yellow dashed lines, state the amount of offset) corresponding to the riser S0/S1. The coordinates are in Universal Transverse Mercator system, zone 48. The contour lines are spaced by $25 \mathrm{~cm}$. (B) Field view at Baast Uul (looking north) showing the piercing lines (white dashed lines) used to measure the cumulative offset of a gully incised within the $\mathrm{S} 1$ surface. In the right part is the digital elevation model showing the piercing lines (white dashed lines) used to calculate the mean cumulative horizontal offset along the Bogd Fault (red dashed line). The coordinates are in Universal Transverse Mercator system, zone $48 \mathrm{~N}$. The contour interval is $25 \mathrm{~cm}$.

something in between (e.g. Van der Woerd et al. 2000; Tapponnier et al. 2001; Meriaux et al. 2004; Hanks \& Thatcher 2006; Cowgill et al. 2007; Gold et al. 2009).

In this paper, we estimated slip rates within two different faulted alluvial settings. Where the offset feature is a fan deposit that is largely preserved, we prefer using the age of abandonment of that deposit itself (e.g. for S1 at Noyon Uul and at Baast Uul). At Noyon Uul the fan apex is well preserved and the offset measurement comes from restoring that apex to its most likely position within the source drainage. At Baast Uul, we are restoring the western edge of the S1 fan where it is deposited against local bedrock highs. This feature also is a depositional feature that has not been subject to younger erosion that could have reduced the apparent offset. Therefore we are justified in using only the date of the offset deposit itself (S1) and not the modern age of the alluvium within the deeply incised canyon to the west, which is also offset the same amount as the western edge of the S1 fan.

In a second setting, the fault is cutting through alluvial terraces within an alluvial piedmont. There the offset features are terrace risers, and we use the age of the upper terrace surface to obtain a minimum slip rate and the age of the lower terrace to obtain a maximum rate. In some cases these two methods provide relatively tight constraints on the slip rate (e.g. T2/T1 at Bitut, and T1/T0-2 at West Noyon Uul). In other cases, it is only possible to estimate either a minimum rate or a maximum rate (e.g. T3/T2 and T2/T1 at West Noyon Uul). In still other cases, the maximum and minimum rates are widely separated (e.g. T1/T0 at Bitut) and the geological context of the site as well as rates obtained from other sites along the fault 


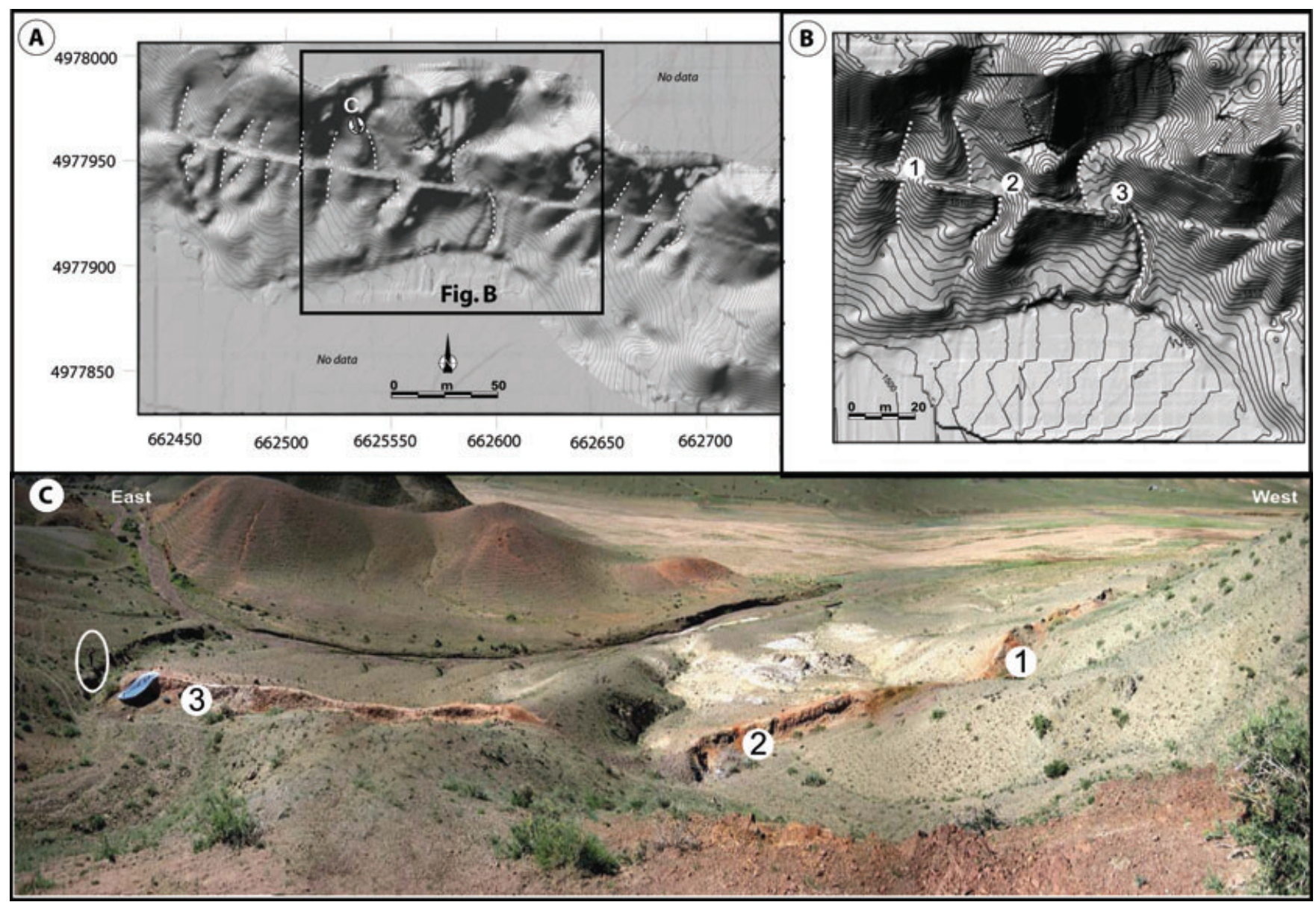

Figure 17. A) DEM, at Zadgay Zayhr site, showing the piercing lines (white dashed lines) used to calculate the mean horizontal offsets along the Bogd Fault. The coordinates are in Universal Transverse Mercator system, zone 48 . The contour interval is $25 \mathrm{~cm}$. The black box represents the detail mapping of the area presented in figure B. B) Digital elevation model showing the piercing lines (white dashed lines) used to calculate the horizontal offsets for the thalwegs labelled (1), (2) and (3) in Table 2. The coordinates are in Universal Transverse Mercator system, zone 48. The contour interval is $25 \mathrm{~cm}$. C) Field panorama (looking south) showing the thalwegs labeled (1), (2) and (3), displaced along the Bogd Fault. Note that a person making scale is surrounded by the white circle.

must be used to assess whether the true slip rate lies closer to the minimum bound or to the maximum bound. As other studies have concluded, our study shows therefore that there is not a standard way for estimating slip rate along a strike-slip fault, and each site must be evaluated individually.

\subsection{Slip rates}

Our analysis of laterally faulted markers and ages of alluvial surfaces, yields a mean horizontal slip rate of $\sim 1 \mathrm{~mm} \mathrm{yr}^{-1}$ along the N095 ${ }^{\circ}$ E trending strike-slip WIB and EIB segments of the Bogd Fault. Between these two segments, along the N110 ${ }^{\circ}$ trending NIB segment, the horizontal slip rate is $\sim 0.5 \mathrm{~mm} \mathrm{yr}^{-1}$. These variations are consistent with the geometry of the segments and their kinematic variation from mainly left-lateral strike-slip faulting along the WIB and EIB segments to reverse-left-lateral faulting along the NIB segment. They also suggest that the quantity of deformation is conserved along the three western segments of the Bogd Fault, between Noyan Uul and Baast Uul. The evolution of the horizontal slip rate through time at two sites (West Noyan Uul and Bitut) show also that the deformation can be distributed over several branches and gradually migrates from older branches to younger ones, as has been interpreted earlier (Bayasgalan et al. 1999b; Vassallo et al. 2007b).

\subsection{Climate and erosion}

The morphological analysis and the dating of alluvial surfaces along the western part of the Bogd Fault show that a major aggradational event occurred at $\sim 100 \mathrm{ka}$ at two different sites contemporaneously ( $\sim 108 \mathrm{ka}$ at Noyan Uul and $\sim 92.4 \pm 10 \mathrm{ka}$ at Bitut). This confirms that a major climatic pulse occurred at the glacial-interglacial transition MIS 6/5e within the Gurvan Bogd region (Ritz et al. 1995; Hanks et al. 1997; Ritz et al. 2003; Vassallo et al. 2005; Ritz et al. 2006) and was probably contemporaneous with a major aggradational event in Altay as well (e.g. Nissen et al. 2009a, 2009b). The analysis of the distribution of ${ }^{10} \mathrm{Be}$ concentrations along depth profiles confirms that alluvial surfaces in this region undergo a denudation rate between 6 and $9 \mathrm{~m} \mathrm{Myr}^{-1}$ as estimated elsewhere within the Gurvan Bulag mountain range (e.g. Vassallo et al. 2005; Vassallo 2006). This denudation rate is mainly due to wind deflation and is strong enough to limit the possibility of dating the alluvial surfaces in the Gobi-Altay area within the Upper Pleistocene period $(\sim 125 \mathrm{ka})$.

\subsection{Slip distribution}

Our study provides new estimates of the horizontal offset associated with the 1957 earthquake along the western part of the Bogd rupture, complementing Kurushin et al.'s (1997) study. Mean 

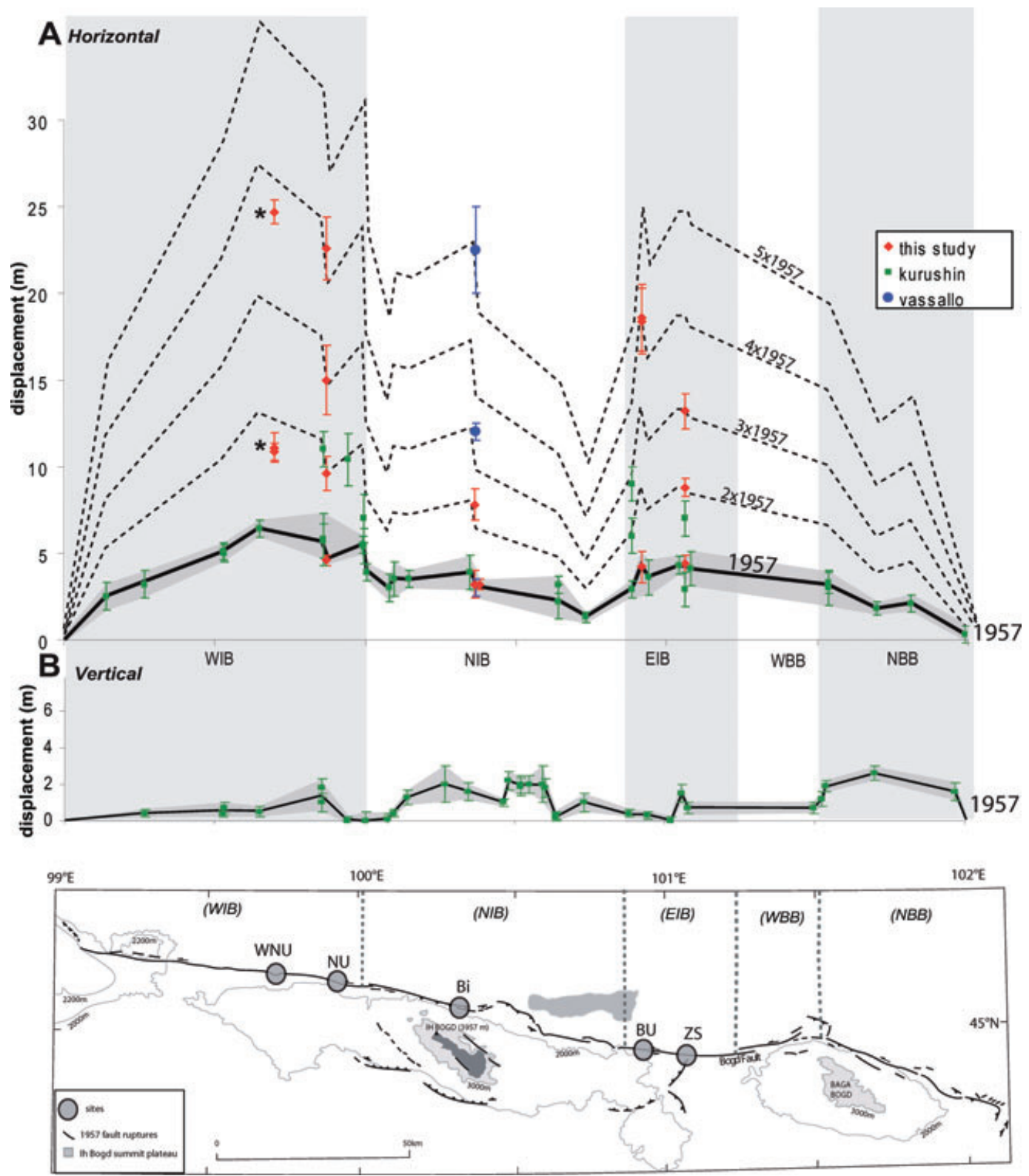

Figure 18. (A) Horizontal slip distribution along the WIB, NIB, EIB, WBB and NBB segments of the Bogd Fault. We combined our data, represented by the red diamonds (WNU : West Noyan Uul, NU : Noyan Uul, Bi: Bitut, BU: Baast uul, ZS: Zadgay Zayhr), together with Kurushin et al.'s (1997) data (green squares), and Vassallo et al.'s (2007b) data (blue dots). The black line represents the horizontal slip function for the 1957 earthquake along the Bogd Fault, and the grey area represents the uncertainty associated at each measure. $\left(^{*}\right)$ Note that at West Noyan Uul the cumulative offsets are in a pull apart basin, with distribution of the deformation between several branches. The black dashed lines are the multiples of the 1957 slip function. (B) Vertical slip distribution along the Bogd Fault using the vertical measures from Kurushin et al. (1997). The black line represents the vertical slip function for the 1957 earthquake along the Bogd Fault and the grey area, the uncertainty associated with each measure.

horizontal displacements at Noyan Uul (WIB), Bitut (NIB), Baast Uul (west EIB) and Zadgay Sayhr (east EIB) are $4.6 \pm 0.3 \mathrm{~m}$, $3.2 \pm 0.4 \mathrm{~m}, 4.2 \pm 0.9 \mathrm{~m}$ and $4.4 \pm 0.5 \mathrm{~m}$, respectively. Our data compiled together with published slip estimates (Kurushin et al. 1997; Vassallo et al. 2007b) provides a spectrum of the horizontal slip distribution along the Bogd Fault. The mean horizontal offset associated with the 1957 earthquake decreases progressively from $5.2 \mathrm{~m}$ to $2.0 \mathrm{~m}$ from west to east. The horizontal component is counter-correlated with the distribution of the vertical component reflecting the progressive change of kinematics from pure left-lateral strike-slip faulting to left-lateral-reverse faulting consistently with the geometry of the different Bogd Fault segments. Cumulative dis- placements display multiples of the 1957 offset and are consistent with a characteristic slip distribution along the Bogd left-lateral strike-slip fault, as it has been observed along other large strike-slip faults (i.e. Schwartz et al. 1984; Sieh \& Knopoff 1996; Rubin \& Sieh 1997; Klinger et al. 2003; Haibing et al. 2005; Klinger et al. 2011).

\subsection{Magnitude of the 1957 Gobi-Altay earthquake}

Our data about 1957 dislocations combined with Kurushin et al.'s (1997) data allow refining the slip vector magnitude along the different segments of the Bogd Fault which evolves from $5.2 \pm 1.0$ $\mathrm{m}$ on the west part of the fault to $3.0 \pm 1.1 \mathrm{~m}$ on the east part. 


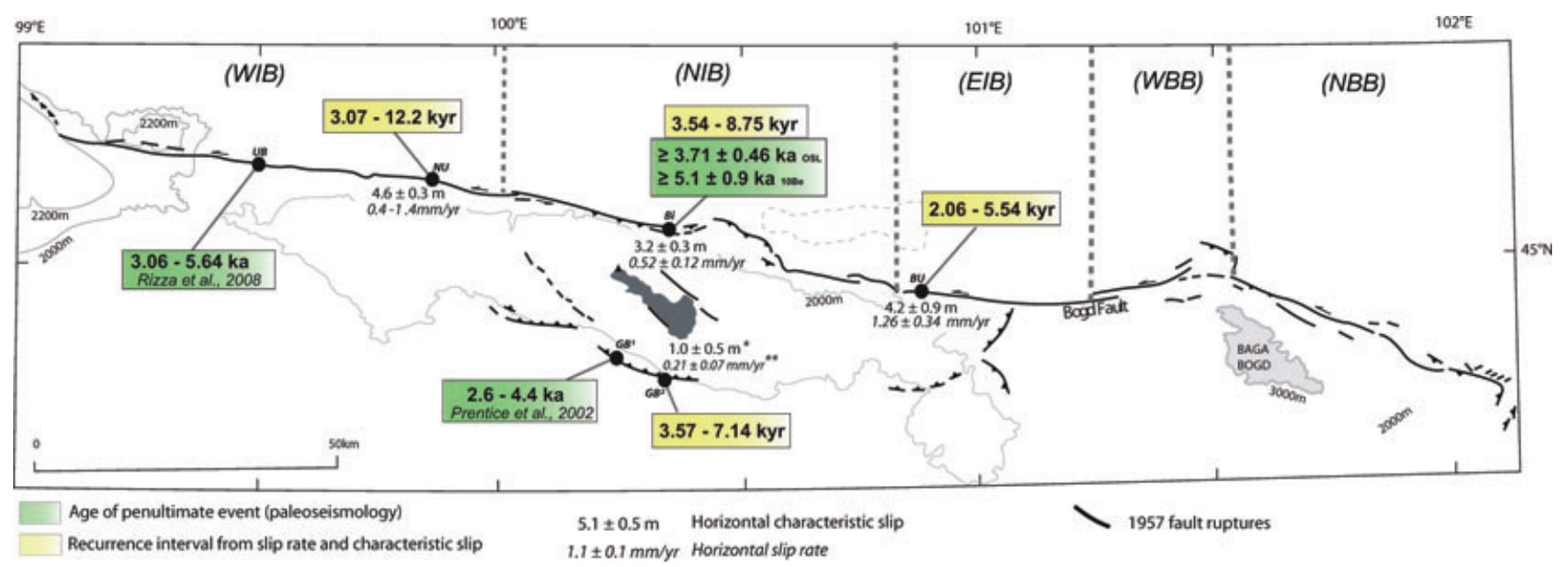

Figure 19. Recurrence intervals and ages of the penultimate earthquake along the three western segments of the Bogd Fault and the Gurvan Bulag thrust fault. UB, Ulaan Bulag; NU, Noyan Uul; Bi, Bitut; BU, Baast uul; GB ${ }^{1}$, Gurvan Bulag site 1; $\mathrm{GB}^{2}$, Gurvan Bulag site 2. Note that the slip rate at BU is estimated from an assumed age (see text for more details). The yellow boxes are the mean recurrence time calculated dividing the mean characteristic slip by the slip rate calculated at each site. Note that at $\mathrm{GB}^{2}$ (Gurvan Bulag thrust fault), the mean recurrence time has been calculated dividing the characteristic slip of $\sim 1$ $\mathrm{m}\left(*\right.$ Ritz et al. 2006) by the vertical slip rate of $0.21 \pm 0.07 \mathrm{~mm} \mathrm{yr}^{-1}$ (**Vassallo et al. 2005). The green boxes are for the ages of the penultimate earthquake along the Bogd Fault from palaeoseismic investigations. At Ulaan Bulag (UB), a trench opened in 2007 brackets the age of the penultimate earthquake using luminescence samples (Rizza et al. 2009). At Bitut (Bi), we used the age of the surfaces T0 only displaced by the 1957 earthquake (see Section 2.2). At Gurvan Bulag site $1\left(\mathrm{~GB}^{1}\right)$, we used the mean age of the penultimate earthquake bracketed by luminescence and radiocarbon samples from palaeoseismic investigations (Prentice et al. 2002).

Table 4. Length of rupture, dip, mean horizontal offset $(\Delta H)$, mean vertical offset projected along the fault $(\Delta V f)$ and total coseismic displacement (SV) along the different segments of the Gobi-Altay earthquake. Note that $\Delta H$ is for the mean horizontal offset estimated from the horizontal slip distribution presented in Fig. 18(A); $\Delta V f$ is for the mean vertical offset estimated from the vertical slip distribution presented in Fig. 18(B), and projected along the fault. The slip vector (SV) is calculated using the relation $\mathrm{SV}=$ $\sqrt{ }\left(\Delta H^{2}+\Delta V f^{2}\right)$.

\begin{tabular}{|c|c|c|c|c|c|}
\hline Segment & $\begin{array}{l}\text { Length } \\
(\mathrm{km})\end{array}$ & $\operatorname{Dip}\left({ }^{\circ}\right)$ & $\begin{array}{l}\Delta H \\
(\mathrm{~m})\end{array}$ & $\begin{array}{l}\Delta V f \\
(\mathrm{~m})\end{array}$ & $\begin{array}{l}\text { SV } \\
(\mathrm{m})\end{array}$ \\
\hline WIB & $74^{a}$ & $70^{b}$ & $5.2 \pm 0.9^{a}$ & $0.7 \pm 0.6^{a}$ & $5.2 \pm 1.0^{a}$ \\
\hline NIB & $67^{a}$ & $50^{b}$ & $3.1 \pm 0.7^{a}$ & $1.6 \pm 1.0^{a}$ & $3.5 \pm 1.0^{a}$ \\
\hline EIB & $23^{a}$ & $85^{b}$ & $4.4 \pm 1.6^{a}$ & $0.6 \pm 0.6^{a}$ & $4.7 \pm 1.6^{a}$ \\
\hline WBB & $28^{a}$ & $90^{b}$ & $3.0 \pm 1.0^{a}$ & $0.9 \pm 0.3^{a}$ & $3.1 \pm 1.0^{a}$ \\
\hline NBB & $50^{a}$ & $60^{b}$ & $2.0 \pm 1.0^{a}$ & $2.3 \pm 0.6^{a}$ & $3.0 \pm 1.1^{a}$ \\
\hline $\begin{array}{l}\text { Toromhon } \\
\text { north }\end{array}$ & $12^{b}$ & $45^{\mathrm{b}}$ & - & - & $5.0 \pm 1.0^{b}$ \\
\hline $\begin{array}{c}\text { Toromhon } \\
\text { central }\end{array}$ & $4^{b}$ & $60^{b}$ & - & - & $5.0 \pm 1.0^{b}$ \\
\hline $\begin{array}{l}\text { Toromhon } \\
\text { south }\end{array}$ & $5^{b}$ & $45^{b}$ & - & - & $0.3 \pm 0$ \\
\hline $\begin{array}{l}\text { Tsagaan } \\
\text { Uul east }\end{array}$ & $7^{b}$ & $45^{b}$ & - & - & $1.5 \pm 0.5^{b}$ \\
\hline $\begin{array}{c}\text { Tsagaan } \\
\text { Uul } \\
\text { central }\end{array}$ & $9^{b}$ & $45^{b}$ & - & - & $3.0 \pm 1.0^{b}$ \\
\hline $\begin{array}{l}\text { Tsagaan } \\
\text { Uul } \\
\text { west }\end{array}$ & $10^{b}$ & $45^{b}$ & - & - & $1.0 \pm 0.5^{b}$ \\
\hline $\begin{array}{l}\text { Gurvan } \\
\text { Bulag }\end{array}$ & $21^{c}$ & $50^{c}$ & - & - & $2.5 \pm 0.5^{c}$ \\
\hline Olziyt Uul & $18^{b}$ & $90^{b}$ & - & - & $3.0 \pm 1.0^{b}$ \\
\hline
\end{tabular}

Notes: ${ }^{a}$ This study.

${ }^{b}$ Kurushin et al. 1997.

${ }^{c}$ Prentice et al. 2002.
Using these data, we estimated the moment magnitude of the GobiAltay earthquake at $M_{\mathrm{w}}$ 7.78-7.95. From seismic waves, the moment magnitude had been estimated between $M_{\mathrm{w}} \sim 8.0$ and $M_{\mathrm{w}} \sim$ 8.3 (Okal 1976, Chen \& Molnar 1977; Pacheco \& Sykes 1992; Schlupp 1996). From surface ruptures, the moment magnitude had been estimated at $M_{\mathrm{w}} \sim 8.1$ with a surface rupture of $270 \mathrm{~km}$ long, $20 \mathrm{~km}$ width and with a coseismic slip of $8 \mathrm{~m}$ (Molnar \& Deng 1984). From their detailed rupture map, Kurushin et al. (1997) had re-estimated the moment magnitude at $M_{\mathrm{w}}=7.8-7.9$. Our result is consistent with this result and confirms that earlier $M_{\mathrm{w}}$ were probably over estimated, or that a greater amount of slip occurred at depth along some parts of the rupture than is observed at the surface, yielding higher moment estimates from seismologic methods than from geological methods.

\subsection{Recurrence intervals}

Combining our slip rate estimates and the slip distribution per event allowed us to determine mean recurrence intervals of $\sim 2500-5200$ yr for past earthquakes along the different segments of the western Bogd Fault. This is consistent with palaeoseismological data at Ulaan Bulag (west of Noyan Uul) where trenching investigation yielded a mean recurrence intervals of $4500 \pm 1400 \mathrm{yr}$ and a maximum average earthquake recurrence interval of 4200-5200 yr (Ritz et al. 2009; Rizza et al. 2009; Rizza 2010). These intervals are similar to the age of the penultimate event bracketed between 3060 and $5640 \mathrm{yr}$ at Ulaan Bulag (Ritz et al. 2009; Rizza et al. 2009; Rizza 2010) and between 2600 and 4400 yr at Gurvan Bulag $\left(\mathrm{GB}^{1}\right)$, a thrust fault located on the southern flank of Ih Bogd massif (Prentice et al. 2002). These results are consistent with the idea that the three western segments and the Gurvan Bulag thrust fault ruptured contemporaneously during the penultimate earthquake and also during earlier events.

Concerning the penultimate event, note that at Zadgahy Sayhr (EIB segment), a trench investigation showed that an event occurred between 800 and $2350 \mathrm{yr}$ cal BP (Bayasgalan 1999; Schwartz et al. 
2007). This result raises the question of the magnitude of this event since a characteristic slip of $4.4 \pm 0.5 \mathrm{~m}$ is observed along this fault segment. If this event produced a $4.4 \mathrm{~m}$ slip, as in 1957, the slip rate along this segment would be between two (i.e. $1.7 \mathrm{~mm} \mathrm{yr}^{-1}$ ) and five times (i.e. $6.2 \mathrm{~mm} \mathrm{yr}^{-1}$ ) larger than along the western part of the Bogd Fault. We believe therefore that this event was much smaller in magnitude than the 1957 event, and that the associated coseismic slip is included in the uncertainty $(0.5 \mathrm{~m})$ of the offset attributed to the 1957 earthquake $(4.4 \pm 0.5 \mathrm{~m})$. This event may be associated with the seismic rupture along the 23-km-long EIB segment that would produce, if it breaks individually, an $M_{\mathrm{w}} \sim 6.5$ earthquake with an average displacement of about $0.5 \mathrm{~m}$ following the statistical functions of Wells \& Coppersmith (1994).

\subsection{Characteristic earthquake}

Our overall results suggest that similar horizontal dislocations and similar recurrence times for large earthquakes $\left(M_{\mathrm{w}} \geq 7.5\right)$ occurred along the three western segments of the Bogd Fault. These results combined with those along the Gurvan Bulag thrust fault suggest that the western Bogd Fault system, including the Gurvan Bulag thrust fault, is usually rupturing during a same seismic event. If the two eastern segments of the Bogd Fault (WBB and NBB) were showing the same pattern, then the Bogd Fault could be described as a system able of producing characteristic earthquakes.

\section{ACKNOWLEDGMENTS}

This work was supported by the French INSU 3F ('Failles, Fluides, Flux') 2007 program. We would like to acknowledge our drivers and the RCAG colleagues for technical support, especially Ulzibat. Field assistance was provided by Baatarsuren, Ulzibat (MT's brother), Bayanmonh B., Javkhaa Otgonhuu and Thomas Guillot. We thank D. Schwartz and P. Vernant for fruitful discussions about geology of the Bogd Fault, and also R. Gold, T. Hanks, R. Walker and an anonymous reviewer to improve the manuscript. The new ${ }^{10} \mathrm{Be}$ measurements were performed at the ASTER AMS National Facility (CEREGE, Aix en Provence), which is supported by the INSU/CNRS, the French Ministry of Research and Higher Education, IRD and CEA.

\section{REFERENCES}

Aitken, M.J., 1985. Thermoluminescence Dating, Academic Press, London. Aitken, M.J., 1998. An Introduction to Optical Dating: The Dating of Quaternary Sediments by the Use of Photon-Stimulated Luminescence, Oxford University Press, London.

Arnold, M. et al., 2010. The French accelerator mass spectrometry facility ASTER: improved performance and developments. Nucl. Instr. Meth. Phys. Res., Sect. B: Beam Interact. Mater. At., 268, 1954-1959.

Auclair, M., Lamothe, M. \& Huot, S., 2003. Measurement of anomalous fading for feldspar IRSL using SAR, Radiat. Meas., 37, 487-492.

Baljinnyam, I. et al., 1993. Ruptures of major earthquakes and active deformation in Mongolia and its surroundings, Geol. Soc. Am., Mem., 181, 61.

Bayasgalan, A., 1999. Active tectonics of Mongolia, PhD thesis, Univ. of Cambridge.

Bayasgalan, A., Jackson, J., Ritz, J.-F. \& Carretier, S., 1999a. Field examples of strike-slip fault terminations in Mongolia, and their tectonic significance, Tectonics, 18, 394-411.

Bayasgalan, A., Jackson, J., Ritz, J.-F. \& Carretier, S., 1999b. 'Forebergs', flower structures, and the development of large intracontinental strike-slip faults: the Gurvan Bogd fault system in Mongolia, J. Struct. Geol., 21, 1285-1302.

Bierman, P.R., 1994. Using in situ produced cosmogenic isotopes to estimate rates of landscape evolution: a review from the geomorphic perspective, J. geophys. Res., 99, 13 885-13 896.
Braucher, R., Bourles, D.L., Colin, F., Oliveira, J., Vecchieto, A.B., \& Anonymous, 1998. Use of in situ-produced cosmogenic (super 10) Be for the study of Brazilian lateritic soil evolution, Mineral. Mag., 62A(1), 233-234.

Braucher, R., Brown, E.T., Bourles, D.L. \& Colin, F., 2003. In situ produced (super 10) Be measurements at great depths: implications for production rates by fast muons, Earth. planet. Sci. Lett., 211, 251-258.

Braucher, R., Del Castillo P., Siame L., Hidy, A.J. \& Bourlès D., 2009. Determination of both exposure time and denudation rate from an in-situ produced $10 \mathrm{Be}$ profile: a mathematical proof of uniqueness. Model sensivity and applications to natural cases, Quat. Geochronol., 4, 56-67.

Calais, E., Vergnolle, M., San'kov, V., Lukhnev, A., Miroshnitenko, A., Amarjargal, S. \& Déverchère, J., 2003. GPS measurements of crustal deformation in the Baikal-Mongolia Area (1994-2002): implications for current kinematics of Asia, J. geophys. Res., 108, 2501-2514.

Carretier, S., 2000. Cycle sismique et surrection de la chaîne de Gurvan Bogd (Mongolie). Approche de la géomorphologie quantitative, $P h D$ thesis, Univ. of Montpelier 2.

Carretier, S., Ritz, J.F., Jackson, J. \& Bayasgalan, A., 2002. Morphological dating of cumulative reverse fault scarps: examples from the Gurvan Bogd fault system, Mongolia, Geophys. J. Int., 148, 256-277.

Chen, W. P. \& Molnar, P., 1977. Seismic moments of major earthquakes and the average rate of slip in Central Asia, J. geophys. Res., 82, 2945-2969.

Chery, J., Carretier, S. \& Ritz, J.-F., 2001. Postseismic stress transfer explains time clustering of large earthquakes in Mongolia, Earth. planet. Sci. Lett., 194, 277-286.

Chmeleff, J., von Blanckenburg, F., Kossert, K. \& Jakob, D. 2010. Determination of the 10Be half-life by multicollector ICP-MS and liquid scintillation counting, Nucl. Instr. Methods Phys. Res., Sect. B: Beam Interact. Mater. At., 268, 192-199.

Cowgill, E., 2007. Impact of riser reconstructions on estimation of secular variation in rates of strike-slip faulting: revisiting the Cherchen River site along the Altyn Tagh Fault, NW China, Earth. planet. Sci. Lett., 254, 239-255.

Cowgill, E., Gold, R., Chen, X., Wang, X. \& Arrowsmith, R., 2007. Implications of uniform slip rate along the central Altyn Tagh Fault at millennial, centennial, and decadal time-scales on the classical debate between microplate vs. continuum views of continental deformation, Geol. Soc. Am. Abstracts with Programs, 39, 262.

Cunningham, W.D., 1998. Lithospheric controls on late Cenozoic construction of the Mongolian Altai, Tectonics, 17, 891-902.

Cunningham, D., 2005. Active intracontinantal tranpressional mountain building in the Mongolian Altai: defining a new class of orogen, Earth planet. Sci. Lett., 240, 436-444.

Florensov, N.A. \& Solonenko, 1965. The Gobi-Altai Earthquake, U.S. Department of Commerce, Washington, D. C., 424pp

Forman, S.L. \& Pierson, J., 2002. Late Pleistocene luminescence chronology of loess deposition in the Missouri and Mississippi River valleys, United States, Palaeogeog. Palaeoclimat. Palaeoecol., 186, 25-46.

Galbraith, R.F., Roberts, R.G., Laslett, G.M., Yoshida, H. \& Olley, J.M., 1999. Optical dating of single and multiple grains of quartz from Jinmium rock shelter, Northern Australia. Part 1: experimental design and statistical models, Archaeometry, 41, 339-364.

Gold, R.D., Cowgill, E., Arrowsmith, J.R., Gosse, J., Chen, X. \& Wang, X., 2009. Riser diachroneity, lateral erosion, and uncertainty in rates of strikeslip faulting: A case study from Tuzidun along the Altyn Tagh Fault, NW China, J. geophys. Res., 114, B04401, doi:10.1029/2008JB005913.

Haibing, L., Van Der Woerd, J., Tapponnier, P., Klinger, Y., Qi, X., Yang, J. \& Zhu, Y., 2005. Slip rate on the Kunlun Fault at Hongshui Gou, and recurrence time of great events comparable to the 14/11/2001, Mw approximately 7.9 Kokoxili earthquake, Earth. planet. Sci. Lett., 237, 285-299.

Hanks, T.C. \& Kanamori, H., 1979. A moment magnitude scale, J. geophys. Res., 84, 2348-2350.

Hanks, T.C. \& Thatcher, W., 2006. The slip-rate discrepancy for the Altyn Tagh Fault: an example of epistemic uncertainty, Presented at Fall Meet Am. Geophys. Union, San Francisco (Abstr.) 
Hanks, T.C., Ritz, J.F., Kendrick, K., Finkel, B. \& Garvin, C.D., 1997. Uplift rates in a continental interior: faulting offsets of a $\sim 100 \mathrm{ka}$ abandonned fan along the Bogd fault, southern Mongolia, Proceedings of the Penrose Conference on the Tectonics of Continentals Interiors, pp. 23-28, 1997 September, Cedar City.

Hülle, D., Hilgers, A., Radtke, U., Stolz, C., Hempelmann, N., Grunert, J., Felauer, T. \& Lehmkuhl, F., 2010. OSL dating of sediments from the Gobi desert, Southern Mongolia, Quat. Geochronol, 5, 107-113.

Huntley, D.J. \& Lamothe, M., 2001. Ubiquity of anomalous fading in Kfeldspars and the measurement and correction for it in optical dating, Can. J. Earth Sci, Rev. Can. des Sci. de la Terre, 38, 1093-1106.

Jolivet, M. et al., 2007. Mongolian summits: an uplifted, flat, old but still preserved erosion surface, Geology, 35, 871-874.

Klinger, Y. et al., 2003. Paleoseismic evidence of characteristic slip on the western segment of the North Anatolian Fault, Turkey, Bull. Seismological Soc. Am., 93, 2317-2332.

Klinger, Y., Etchebes, M., Tapponnier, P. \& Narteau, C., 2011. Characteristic slip for five great earthquakes along the Fuyun fault in China, Nature Geosci., 4(6), 389-392, doi:10.1038/NGEO1158.

Korschinek, G. et al., 2010. A new value for the half-life of 10Be by HeavyIon Elastic Recoil Detection and liquid scintillation counting, Nucl. Instr. Meth. Phys. Res., Sect. B: Beam Interact. Mater. At., 268, 187-191.

Kurushin, R.A., Bayasgalan, A., Olziybat, M., Enhtuvshin, B., Molnar, P., Bayarsayhan, C., Hudnut, K.W. \& Lin, J., 1998. Geol. Soc. Am. Special Papers, 320, 144pp., doi:10.1130/0-8137-2320-5.1.

Lal, D., 1991. Cosmic ray labeling of erosion surfaces: in situ nuclide production rates and erosion models, Earth. planet. Sci. Lett., 104, 424-439.

Lang, A., 1994. Infra-red stimulated luminescence dating of Holocene reworked silty sediments, Quat. Sci. Rev., 13, 525-528.

LeDortz, K. et al., 2009. Holocene right-slip rate determined by cosmogenic and OSL dating on the Anar fault, Central Iran. Geophys. J. Int., 179, $700-710$.

Lehmkuhl, F. \& Lang, A., (2001). Geomorphological investigations and luminescence dating in the southern part of the Khangay and the Valley of the Gobi Lakes (Central Mongolia), J. Quat. Sci., 16, 69-87.

Lian \& Roberts, R.G., 2006. Dating the Quaternary: progress in luminescence dating of sediments, Quat. Sci. Rev., 25, 2449-2468.

Meriaux, A.S., Ryerson, F.J., Tapponnier, P., Van Der Woerd, J., Finkel, R. C., Xu, X., Xu, Z. \& Caffee, M.W., 2004. Rapid slip along the central Altyn Tagh Fault: morphochronologic evidence from Cherchen He and Sulamu Tagh, J. geophys. Res., 109, B0640, doi:10.1029/2003JB002558.

Molnar, P. \& Deng, Q., 1984. Faulting associated with large earthquakes and the average rate of deformation in central and eastern Asia, J. geophys. Res., 89, 6203-6227.

Molnar, P., Chen, W.P., Fitch, T.J., Tapponnier, P., Warsi, W.E.K. \& Wu, F.T., 1977. Structure and tectonics of the Himalaya: a brief summary of relevant geophysical observations, Himalaya, 269-294.

Murray, A.S. \& Wintle, A.G., 2000. Luminescence dating of quartz using an improved single-aliquot regenerative-dose protocol, Radiat. Meas., 32, $57-73$.

Murray, A.S., Marten, R., Johnson, A. \& Martin, P., 1987. Analysis for naturally occurring radionuclides at environmental concentrations by gamma spectrometry, J. Radioanal. Nucl. Chem. Art., 115, 263-288.

Nissen, E., Walker, R., Molor, E., Fattahi, M. \& Bayasgalan, A., 2009a. Late Quaternary rates of uplift and shortening at Baatar Hyarhan (Mongolian Altai) with optically stimulated luminescence, Geophys. J. Int., 177, 259-278.

Nissen, E. et al., 2009b. The late Quaternary slip-rate of the Har-Us-Nuur Fault (Mongolian Altai) from cosmogenic (super 10) Be and luminescence dating, Earth. planet. Sci. Lett, 286, 467-478.

Okal, E.A., 1976. A surface-wave investigation of the rupture mechanism of the Gobi-Altai (December 4, 1957) earthquake, Phys. Earth planet. Inter., 12, 319-328.

Pacheco, J.F. \& Sykes, L.R., 1992. Seismic moment catalog of large shallow earthquakes, 1900 to 1989, Bull. Seismol. Soc. Am., 82, 1306-1349.

Pollitz, F., Vergnolle, M. \& Calais, E., 2003. Fault interaction and stress triggering of twentieth century earthquakes in Mongolia, J. geophys. Res., 108, 2503, doi:10.1029/2002JB002375.
Prentice, C. S., Kendrick, K., Berryman, K., Bayasgalan, A., Ritz, J.-F. \& Spencer, J.Q., 2002. Prehistoric ruptures of the Gurvan Bulag fault, Gobi Altay, Mongolia. J. geophys. Res., 107, 2321-2339.

Prescott, J.R. \& Hutton, J.T., 1994. Cosmic-ray contributions to dose-rates for luminescence and ESR dating-large depths and long-term time variations, Radiat. Meas., 23, 497-500.

Raisbeck, G.M. \& Yiou, F., 1987. Geomagnetic reversals, polar ice and cosmic spherules: some recent measurements with a small dedicated accelerator mass-spectrometry facility, Philos. Trans. R. Soc. London, Ser. A., 323, 101-102.

Repka, J.L., Anderson, R.S. \& Finkel, R.C., 1997. Cosmogenic dating of fluvial terraces, Fremont River,Utah, Earth planet. Sci. Lett., 152, 59-73.

Richardson, C.A., McDonald, E.V. \& Busacca, A.J., 1997. Luminescence dating of loess from the Northwest United States, Quat. Sci. Rev., 16, 403-415.

Ritz, J.-F., Brown, E.T., Bourlès, D.L., Philip, H., Schlupp, A., Raisbeck, G.M., Yiou, F. \& Enkhtuvshin, B., 1995. Slip rates along active faults estimated with cosmic-ray-exposure dates: application to the Bogd fault, Gobi-Altaï, Mongolia, Geology, 23, 1019-1024.

Ritz, J.-F. et al., 2003. Late Pleistocene to Holocene slip rates for the Gurvan Bulag thrust fault (Gobi-Altay, Mongolia) estimated with $10 \mathrm{Be}$ dates, $J$. geophys. Res., 108, 2162-2178.

Ritz, J.-F., Vassallo, R., Braucher, R., Brown, E.T., Carretier, S. \& Bourlès, D. L., 2006. Using in situ produced $10 \mathrm{Be}$ to quantify active tectonics in the Gurvan Bogd mountain range (Gobi-Altay, Mongolia), Geol. Soc. Am. Special Papers, 415, 87-110.

Ritz, J.-F., Rizza, M., Prentice, C. \& Schwartz, D., 2009. Détermination de l'aléa sismique: approche paléosismologique, Géochronique, 110, 25-26.

Rizza, M., 2010. Analyses des vitesses et déplacements co-sismiques sur des failles décrochantes en Mongolie et en Iran: approche morphotectonique et paléosismologique. PhD thesis, University Montpellier.

Rizza, M. et al., 2009. Age and slip distribution of Past earthquakes along the Bogd Fault (Mongolia), Seismol. Res. Lett., 80, 358.

Rizza, M., Mahan S., Ritz, J., Nazari, H., Hollinsgworth, J. \& Salamati, R., 2011. Using luminescence dating of coarse matrix material to estimate fault slip-rate of the Astaneh Fault (Iran), Quat. Geochronol., 6, 390406.

Rubin, C.M. \& Sieh, K., 1997. Long dormancy, low slip rate, and similar slip-per-event for the Emerson Fault, eastern California shear zone, $J$. geophys. Res., 102, 15 319-15 333.

Schlupp, A., 1996. Néotectonique de la Mongolie Occidentale analysée à partir de données de terrain, sismologiques et satellitaires, $P h D$ thesis, University Louis Pasteur, Strasbourg.

Schwartz, D.P., Coppersmith, K.J. \& Anonymous. (1984). Fault behavior and characteristic earthquakes: examples from the Wasatch and San Andreas fault zones, J. geophys. Res., 89, 5681-5698.

Schwartz, D.P., Hanks, T.C., Prentice, C.S., Bayasgalan, A., Dolan, J.F., Rockwell, T.K., Molnar, P. \& Hermann, R.B., (1996). The 1957 GobiAltay earthquake $(\mathrm{M}=8.1)$; complex: long recurrence (?) interval faulting in the middle of a continent, Seismol. Res. Lett., 67, 54.

Schwartz, D.P. et al., 2007. Paleoseismic investigations of the 1957 GobiAltay surface ruptures, in 50th Anniversary Earthquake Conference Commemorating the 1957 Gobi-Altay Earthquake, Mongolia.

Siame, L.L., Braucher, R. \& Bourles, D.L., 2000. Les nucleides cosmogeniques produits in-situ: de nouveaux outils en geomorphologie quantitative. Cosmogenic nuclides produced in situ; new applications in quantitative geomorphology, Bull. de la Soc. Geologique de Fr., 171, 383396.

Siame, L., Regis, B., Bourles, D. \& Anonymous, 2004. Cosmic ray exposure modeling of concentration depth-profiles: methodology and limitations, Int. Geol. Congr., Abstr. Congres Geologique Int., Resumes, 32(Part 2), 923-924.

Sieh, K. \& Knopoff, L., 1996. The repetition of large-earthquake ruptures, Proc. Natl. Acad. Sci. USA, 93, 3764-3771.

Singhvi, A.K., Sharma, Y.P. \& Agrawal, D.P., 1982. Thermoluminescence dating of sand dunes in Rajasthan, India, Nature, 295, 313-314.

Stone, J.O., 2000. Air pressure and cosmogenic isotope production. J. geophys. Res., 105, 23 753-23 759. 
Tapponnier, P. \& Molnar, P., 1979. Active faulting and Cenozoic tectonics of the Tien Shan, Mongolia, and Baykal regions, J. geophys. Res., 84, 3425-3459

Tapponnier, P., Ryerson, F.J., Van Der Woerd, J., Meriaux, A.-S. \& Lasserre, C., 2001. Long-term slip rates and characteristic slip; keys to active fault behaviour and earthquake hazard, C.R. Acad. Sci., 333, 483-494.

Van Der Woerd, J. et al., 2000. Uniform slip-rate along the Kunlun Fault: implications for seismic behaviour and large-scale tectonics, Geophys. Res. Lett., 27, 2353-2356.

Vassallo, R., 2006. Chronologie et évolution des reliefs dans la région Mongolie-Sibérie: approche morphotectonique et géochronologique, PhD thesis, Univ. of Montpelier 2.

Vassallo, R., Ritz, J.-F., Braucher, R. \& Carretier, S., 2005. Dating faulted alluvial fans with cosmogenic 10Be in the Gurvan Bogd mountain range (Gobi-Altay, Mongolia): climatic and tectonic implications, Terra Nova, 17, 278-285.

Vassallo, R., Jolivet, M., Ritz, J. F., Braucher, R., Larroque, C., Sue, C., Todbileg, M. \& Javkhlanbold, D., 2007a. Uplift age and rates of the Gurvan Bogd System (Gobi-Altay) by apatite fission track analysis, Earth planet. Sci. Lett., 259, 333-346.

Vassallo, R. et al., 2007b. Transpressional tectonics and stream terraces of the Gobi-Altay, Mongolia, Tectonics, 26, doi:10.1029/2006TC002081.

Vergnolle, M., 2003. Rhéologie et déformation de la lithosphère continentale: apport de mesures GPS en Asie et de modèles numériques, $P h D$ thesis, Univ. Nice-Sophia Antipolis.

Vergnolle, M., Pollitz, F. \& Calais, E., 2003. Constraints on the viscosity of the continental crust and mantle from GPS measurements and postseismic deformation models in western Mongolia, J. geophys. Res., 108, 14.

Vermeesch, P., 2007. CosmoCalc: an Excel add-in for cosmogenic nuclide calculations, Geochem. Geophys. Geosyst., 8, doi:10.1029/2006GC001530, Q08003.

Walker, R.T. et al., 2006. Geomorphology and structure of the Jid rightlateral strike-slip fault in the Mongolian Altay Mountains, J. Struct. Geol., 28, 1607-1622.

Wells, D.L. \& Coppersmith, K.J., 1994. New empirical relationships among magnitude, rupture length, rupture width, rupture area, and surface displacement, Bull. seism. Soc. Am., 84, 974-1002.

Wintle, A.G. \& Murray, A.S., 2006. A review of quartz optically stimulated luminescence characteristics and their relevance in single-aliquot regeneration dating protocols, Radiat. Meas., 41, 369-391.

\section{APPENDIX A: ${ }^{10}$ Be DATING}

\section{A1. Sampling strategy}

The concentration of in situ cosmogenic ${ }^{10} \mathrm{Be}$ is directly related to the time when alluviation ended, or when the subsequent incision led to the abandonment of the fan surface. The sampling strategy consisted in collecting pieces of large boulders $(>1 \mathrm{~m})$, which allowed minimizing the effects of post-depositional surface deflation (Carretier 2000; Ritz et al. 2006; Vassallo et al. 2007b, Fig. A1).

\section{A2. Experimental details}

The samples from 1995 and 2003 fieldwork were analysed at Tandetron in Gif-sur-Yvette, France. Samples from 2005, 2007 and 2009 field collecting were prepared and analysed by AMS at the CEREGE, Aix-en-Provence, France (Table A1).

To estimate exposure ages from boulders as well as both denudation rates and exposure ages from depth profiles, the following eq. (A1) was used:

$$
\begin{aligned}
C(x, \varepsilon, t)= & C_{\text {inh }} \mathrm{e}^{-\lambda t}+\frac{P_{0} P_{n}}{\frac{\varepsilon}{\Lambda_{n}}+\lambda} \mathrm{e}^{-\frac{x}{\Lambda_{n}}}\left[1-\mathrm{e}^{-t\left(\frac{\varepsilon}{\Lambda_{n}}+\lambda\right)}\right] \\
& +\frac{P_{0} P_{\mu s}}{\frac{\varepsilon}{\Lambda_{n}}+\lambda} \mathrm{e}^{-\frac{x}{\Lambda_{\mu s}}}\left[1-\mathrm{e}^{-t\left(\frac{\varepsilon}{\Lambda \mu s}+\lambda\right)}\right] \\
& +\frac{P_{0} P_{\mu f}}{\frac{\varepsilon}{\Lambda_{\mu f}}+\lambda} \mathrm{e}^{-\frac{x}{\Lambda_{\mu f}}}\left[1-\mathrm{e}^{-t\left(\frac{\varepsilon}{\Lambda_{\mu f}}+\lambda\right)}\right],
\end{aligned}
$$



Figure A1. Boulders used for ${ }^{10} \mathrm{Be}$ dating during fieldwork in 2007 at West Noyan Uul. 
Table A1. Location, elevation, pressure bar using CosmoCalc (Vermeesch 2007), density and thickness for samples used in this study. The samples shown in italics are data never published.

\begin{tabular}{|c|c|c|c|c|c|c|c|}
\hline & $\begin{array}{l}\text { Samples } \\
\text { Names }\end{array}$ & $\begin{array}{c}\text { Latitude WGS84 } \\
\text { deg min }\end{array}$ & $\begin{array}{c}\text { Longitude WGS84 } \\
\text { deg min }\end{array}$ & $\begin{array}{l}\text { Altitude } \\
\mathrm{m}\end{array}$ & $\begin{array}{c}\text { Pressure } \\
\text { mbar }\end{array}$ & $\begin{array}{l}\text { Density } \\
\mathrm{g} \mathrm{cm}^{-3}\end{array}$ & $\begin{array}{c}\text { Thickness } \\
\mathrm{cm}\end{array}$ \\
\hline \multicolumn{8}{|c|}{ NOYAN UUL site } \\
\hline S1 profile & NU42 & $45^{\circ} 8,24$ & $99^{\circ} 53,68$ & 1565 & 836 & 2.40 & 3.00 \\
\hline S1 profile & NU45 & $45^{\circ} 8,24$ & $99^{\circ} 53,68$ & 1565 & 836 & 2.40 & 3.00 \\
\hline Sl profile & NU47 & $45^{\circ} 8,24$ & $99^{\circ} 53,68$ & 1565 & 836 & 2.40 & 3.00 \\
\hline S1 profile & NU49 HF4 & $45^{\circ} 8,24$ & $99^{\circ} 53,68$ & 1565 & 836 & 2.40 & 3.00 \\
\hline S1 profile & NU51 & $45^{\circ} 8,24$ & $99^{\circ} 53,68$ & 1565 & 836 & 2.40 & 3.00 \\
\hline S1 profile & NU52A & $45^{\circ} 8,24$ & $99^{\circ} 53,68$ & 1565 & 836 & 2.40 & 3.00 \\
\hline S1 profile & NU45HF4 & $45^{\circ} 8,24$ & $99^{\circ} 53,68$ & 1565 & 836 & 2.40 & 3.00 \\
\hline$S 1$ & DVI 1 & $45^{\circ} 7,48$ & $99^{\circ} 53,14$ & 1730 & 822 & 2.65 & 3.00 \\
\hline SI & DVI 3 & $45^{\circ} 7,48$ & $99^{\circ} 53,14$ & 1730 & 822 & 2.65 & 3.00 \\
\hline$S 1$ & DVI 4 & $45^{\circ} 7,48$ & $99^{\circ} 53,14$ & 1730 & 822 & 2.65 & 3.00 \\
\hline$S 1$ & DVI 5 & $45^{\circ} 7,48$ & $99^{\circ} 53,14$ & 1730 & 822 & 2.65 & 3.00 \\
\hline$S 2$ & DVII 1 & $45^{\circ} 7,48$ & $99^{\circ} 53,14$ & 1750 & 820 & 2.65 & 3.00 \\
\hline$S 2$ & DVII 2 & $45^{\circ} 7,48$ & $99^{\circ} 53,14$ & 1750 & 820 & 2.65 & 3.00 \\
\hline$S 2$ & DVII 3 & $45^{\circ} 7,48$ & $99^{\circ} 53,14$ & 1750 & 820 & 2.65 & 3.00 \\
\hline$S 2$ & DVII 4 & $45^{\circ} 7,48$ & $99^{\circ} 53,14$ & 1750 & 820 & 2.65 & 3.00 \\
\hline$S 2$ & DVII 5 & $45^{\circ} 7,48$ & $99^{\circ} 53,14$ & 1750 & 820 & 2.65 & 3.00 \\
\hline Amalgam S1 & M07-33 & $45^{\circ} 7,91$ & $99^{\circ} 53,28$ & 1666 & 828 & 2.65 & 3.00 \\
\hline Amalgam $S 2$ & M07-34 & $45^{\circ} 7,51$ & $99^{\circ} 53,28$ & 1735 & 821 & 2.65 & 3.00 \\
\hline S2 profile & M07-35 & $45^{\circ} 7,51$ & $99^{\circ} 53,13$ & 1735 & 821 & 2.40 & 3.00 \\
\hline S2 profile & $M 07-37$ & $45^{\circ} 7,52$ & $99^{\circ} 53,13$ & 1735 & 821 & 2.40 & 3.00 \\
\hline S2 profile & M07-39 & $45^{\circ} 7,53$ & $99^{\circ} 53,13$ & 1735 & 821 & 2.40 & 3.00 \\
\hline$S 2$ profile & $M 07-40$ & $45^{\circ} 7,54$ & $99^{\circ} 53,13$ & 1735 & 821 & 2.40 & 3.00 \\
\hline S2 profile & $M 07-41$ & $45^{\circ} 7,55$ & $99^{\circ} 53,13$ & 1735 & 821 & 2.40 & 3.00 \\
\hline \multicolumn{8}{|c|}{ WEST NOYAN UUL site } \\
\hline$T 3$ & M07-01 & $45^{\circ} 7,90$ & $99^{\circ} 41,69$ & 1618 & 833 & 2.60 & 3.00 \\
\hline$T 3$ & M07-02 & $45^{\circ} 7,96$ & $99^{\circ} 41,75$ & 1609 & 834 & 2.60 & 3.00 \\
\hline$T 3$ & M07-03 & $45^{\circ} 8,05$ & $99^{\circ} 41,76$ & 1606 & 835 & 2.60 & 3.00 \\
\hline$T 3$ & M07-04 & $45^{\circ} 8,09$ & $99^{\circ} 41,79$ & 1592 & 836 & 2.60 & 3.00 \\
\hline$T 3$ & M07-05 & $45^{\circ} 8,00$ & $99^{\circ} 41,76$ & 1608 & 834 & 2.60 & 3.00 \\
\hline$T 3$ & M07-06 & $45^{\circ} 8,01$ & $99^{\circ} 41,71$ & 1607 & 835 & 2.60 & 3.00 \\
\hline T3 right bank & $M 07-26$ & $45^{\circ} 7,95$ & $99^{\circ} 42,00$ & 1607 & 835 & 2.60 & 3.00 \\
\hline amalgam $T 3$ & M07-07 & $45^{\circ} 8,00$ & $99^{\circ} 41,82$ & 1605 & 835 & 2.60 & 3.00 \\
\hline$T 2$ & M07-08 & $45^{\circ} 7,96$ & $99^{\circ} 41,83$ & 1598 & 835 & 2.60 & 3.00 \\
\hline$T 2$ & M07-09 & $45^{\circ} 7,96$ & $99^{\circ} 41,83$ & 1597 & 836 & 2.60 & 3.00 \\
\hline$T 2$ & M07-10 & $45^{\circ} 7,96$ & $99^{\circ} 41,89$ & 1597 & 836 & 2.60 & 3.00 \\
\hline$T 2$ & M07-11 & $45^{\circ} 8,01$ & $99^{\circ} 41,81$ & 1594 & 836 & 2.60 & 3.00 \\
\hline$T 2$ & $M 07-12$ & $45^{\circ} 8,06$ & $99^{\circ} 41,81$ & 1587 & 837 & 2.60 & 3.00 \\
\hline amalgam $T 2$ & M07-13 & $45^{\circ} 7,60$ & $99^{\circ} 41,84$ & 1598 & 835 & 2.60 & 3.00 \\
\hline$T 1$ & M07-14 & $45^{\circ} 7,98$ & $99^{\circ} 41,86$ & 1592 & 836 & 2.60 & 3.00 \\
\hline$T 1$ & $M 07-15$ & $45^{\circ} 7,99$ & $99^{\circ} 41,86$ & 1591 & 836 & 2.60 & 3.00 \\
\hline$T 1$ & M07-16 & $45^{\circ} 8,00$ & $99^{\circ} 41,87$ & 1593 & 836 & 2.60 & 3.00 \\
\hline$T 1$ & M07-17 & $45^{\circ} 8,00$ & $99^{\circ} 41,87$ & 1592 & 836 & 2.60 & 3.00 \\
\hline$T 1$ & M07-18 & $45^{\circ} 8,09$ & $99^{\circ} 41,87$ & 1587 & 837 & 2.60 & 3.00 \\
\hline amalgam T1 & M07-19 & $45^{\circ} 7,80$ & $99^{\circ} 41,87$ & 1590 & 836 & 2.60 & 3.00 \\
\hline amalgam T0 & $M 07-20$ & $45^{\circ} 7,80$ & $99^{\circ} 41,94$ & 1583 & 837 & 2.60 & 3.00 \\
\hline TO & $M 07-21$ & $45^{\circ} 7,98$ & $99^{\circ} 41,89$ & 1590 & 836 & 2.60 & 3.00 \\
\hline TO & M07-22 & $45^{\circ} 7,98$ & $99^{\circ} 41,89$ & 1593 & 836 & 2.60 & 3.00 \\
\hline TO & M07-23 & $45^{\circ} 8,05$ & $99^{\circ} 41,91$ & 1582 & 837 & 2.60 & 3.00 \\
\hline TO & $M 07-24$ & $45^{\circ} 8,06$ & $99^{\circ} 41,93$ & 1583 & 837 & 2.60 & 3.00 \\
\hline TO & $M 07-25$ & $45^{\circ} 8,06$ & $99^{\circ} 41,83$ & 1580 & 837 & 2.60 & 3.00 \\
\hline T2 profile & $M 07-27$ & $45^{\circ} 8,00$ & $99^{\circ} 41,83$ & 1597 & 836 & 2.40 & 3.00 \\
\hline T2 profile & $M 07-28$ & $45^{\circ} 8,00$ & $99^{\circ} 41,84$ & 1597 & 836 & 2.40 & 3.00 \\
\hline T2 profile & $M 07-29$ & $45^{\circ} 8,00$ & $99^{\circ} 41,84$ & 1597 & 836 & 2.40 & 3.00 \\
\hline T2 profile & $M 07-30$ & $45^{\circ} 8,00$ & $99^{\circ} 41,84$ & 1597 & 836 & 2.40 & 3.00 \\
\hline T2 profile & $M 07-31$ & $45^{\circ} 8,00$ & $99^{\circ} 41,84$ & 1597 & 836 & 2.40 & 3.00 \\
\hline
\end{tabular}


Table A1. (Continued.)

\begin{tabular}{|c|c|c|c|c|c|c|c|}
\hline & $\begin{array}{l}\text { Samples } \\
\text { names }\end{array}$ & $\begin{array}{l}\text { Latitude WGS84 } \\
\text { deg min }\end{array}$ & $\begin{array}{c}\text { Longitude WGS84 } \\
\text { deg min }\end{array}$ & $\begin{array}{l}\text { Altitude } \\
\mathrm{m}\end{array}$ & $\begin{array}{c}\text { Pressure } \\
\text { mbar }\end{array}$ & $\begin{array}{l}\text { Density } \\
\mathrm{g} \mathrm{cm}^{-3}\end{array}$ & $\begin{array}{c}\text { Thickness } \\
\mathrm{cm}\end{array}$ \\
\hline \multicolumn{8}{|l|}{ BITUT site } \\
\hline T3 (boulder) & MO-03-01 & $45^{\circ} 2,78$ & $100^{\circ} 22,28$ & 1720 & 823 & 2.70 & 3.00 \\
\hline T3 (boulder) & MO-03-02 & $45^{\circ} 2,79$ & $100^{\circ} 22,28$ & 1720 & 823 & 2.70 & 3.00 \\
\hline T3 (boulder) & MO-03-03 & $45^{\circ} 2,79$ & $100^{\circ} 22,28$ & 1720 & 823 & 2.70 & 3.00 \\
\hline T3 (boulder) & MO-03-04 & $45^{\circ} 2,80$ & $100^{\circ} 22,28$ & 1720 & 823 & 2.67 & 3.00 \\
\hline T3 (boulder) & MO-03-05 & $45^{\circ} 2,80$ & $100^{\circ} 22,28$ & 1720 & 823 & 2.67 & 3.00 \\
\hline T2 (boulder) & MO-03-07 & $45^{\circ} 2,70$ & $100^{\circ} 22,44$ & 1690 & 826 & 2.67 & 3.00 \\
\hline T2 (boulder) & MO-03-10 & $45^{\circ} 2,60$ & $100^{\circ} 22,59$ & 1690 & 826 & 2.67 & 3.00 \\
\hline T2 (boulder) & MO-03-11 & $45^{\circ} 2,60$ & $100^{\circ} 22,59$ & 1690 & 826 & 2.62 & 3.00 \\
\hline T2 (boulder) & MO-03-12 & $45^{\circ} 2,60$ & $100^{\circ} 22,59$ & 1690 & 826 & 2.62 & 3.00 \\
\hline T2 (boulder) & MO-03-12 0cm & $45^{\circ} 2,60$ & $100^{\circ} 22,59$ & 1690 & 826 & 2.62 & 3.00 \\
\hline T2 (boulder) & MO-03-12 40cm & $45^{\circ} 2,60$ & $100^{\circ} 22,59$ & 1690 & 826 & 2.62 & 3.00 \\
\hline T2 (boulder) & MO-03-12 $60 \mathrm{~cm}$ & $45^{\circ} 2,60$ & $100^{\circ} 22,59$ & 1690 & 826 & 2.62 & 3.00 \\
\hline T2 profile & MO-03-T2-TOP & $45^{\circ} 2,60$ & $100^{\circ} 22,59$ & 1690 & 826 & 2.62 & 3.00 \\
\hline T2 profile & M0-03-T2-40 & $45^{\circ} 2,60$ & $100^{\circ} 22,59$ & 1690 & 826 & 2.60 & 3.00 \\
\hline T2 profile & MO-03-T2-60 & $45^{\circ} 2,60$ & $100^{\circ} 22,59$ & 1690 & 826 & 2.60 & 3.00 \\
\hline T2 profile & MO-03-T2-125 & $45^{\circ} 2,60$ & $100^{\circ} 22,60$ & 1690 & 826 & 2.60 & 3.00 \\
\hline T2 profile & MO-03-T2-160 & $45^{\circ} 2,60$ & $100^{\circ} 23,80$ & 1690 & 826 & 2.60 & 3.00 \\
\hline T2 profile & MO-03-T2-200 & $45^{\circ} 2,60$ & $100^{\circ} 23,81$ & 1690 & 826 & 2.60 & 3.00 \\
\hline T2 (boulder) & MO-03-14 & $45^{\circ} 2,68$ & $100^{\circ} 24,23$ & 1713 & 824 & 2.60 & 3.00 \\
\hline T1 (boulder) & MO-03-16 & $45^{\circ} 2,69$ & $100^{\circ} 23,70$ & 1650 & 830 & 2.60 & 3.00 \\
\hline T1 (boulder) & MO-03-17 & $45^{\circ} 2,69$ & $100^{\circ} 22,60$ & 1650 & 830 & 2.60 & 3.00 \\
\hline T1 (boulder) & MO-03-18 & $45^{\circ} 3,19$ & $100^{\circ} 22,60$ & 1650 & 830 & 2.60 & 3.00 \\
\hline T1 (boulder) & MO-03-19 & $45^{\circ} 3,16$ & $100^{\circ} 22,60$ & 1650 & 830 & 2.60 & 3.00 \\
\hline T1 (boulder) & MO-03-21 & $45^{\circ} 3,25$ & $100^{\circ} 22,60$ & 1650 & 830 & 2.60 & 3.00 \\
\hline T1 (boulder) & MO-03-22 & $45^{\circ} 3,10$ & $100^{\circ} 22,60$ & 1650 & 830 & 2.60 & 3.00 \\
\hline T1 profile & MO-03-T3-30 & $45^{\circ} 2,68$ & $100^{\circ} 22,60$ & 1650 & 830 & 2.60 & 3.00 \\
\hline T1 profile & MO-03-T3-50 & $45^{\circ} 2,68$ & $100^{\circ} 22,69$ & 1650 & 830 & 2.60 & 3.00 \\
\hline T1 profile & MO-03-T3-75 & $45^{\circ} 2,68$ & $100^{\circ} 22,69$ & 1650 & 830 & 2.60 & 3.00 \\
\hline T1 profile & MO-03-T3-100 & $45^{\circ} 2,68$ & $100^{\circ} 22,66$ & 1650 & 830 & 2.60 & 3.00 \\
\hline T1 profile & MO-03-T3-120 & $45^{\circ} 2,68$ & $100^{\circ} 22,66$ & 1650 & 830 & 2.60 & 3.00 \\
\hline TO (boulder) & $\mathrm{MO}-03-30(\mathrm{~T})$ & $45^{\circ} 2,54$ & $100^{\circ} 22,56$ & 1640 & 831 & 2.67 & 3.00 \\
\hline TO (boulder) & MO-03-31 (B) & $45^{\circ} 2,54$ & $100^{\circ} 22,56$ & 1640 & 831 & 2.67 & 3.00 \\
\hline TO (boulder) & MO-03-32 & $45^{\circ} 2,51$ & $100^{\circ} 22,56$ & 1640 & 831 & 2.67 & 3.00 \\
\hline T0 (valley) & MO-03-46 & $44^{\circ} 59,64$ & $100^{\circ} 22,56$ & 2100 & 785 & 2.67 & 3.00 \\
\hline TO (valley) & MO-03-47 & $44^{\circ} 59,64$ & $100^{\circ} 22,56$ & 2100 & 785 & 2.67 & 3.00 \\
\hline T0 (valley) & MO-03-48 & $44^{\circ} 59,64$ & $100^{\circ} 22,56$ & 2100 & 785 & 2.67 & 3.00 \\
\hline T0 (valley) & MO-03-49 & $44^{\circ} 59,64$ & $100^{\circ} 22,56$ & 2100 & 785 & 2.67 & 3.00 \\
\hline TO (valley) & MO-03-50 & $44^{\circ} 59,64$ & $100^{\circ} 22,56$ & 2100 & 785 & 2.67 & 3.00 \\
\hline T0 (valley) & MO-03-51(T) & $44^{\circ} 59,64$ & $100^{\circ} 22,56$ & 2100 & 785 & 2.67 & 3.00 \\
\hline TO (valley) & MO-03-55(B) & $44^{\circ} 59,64$ & $100^{\circ} 22,56$ & 2100 & 785 & 2.67 & 3.00 \\
\hline
\end{tabular}

where:

(1) $C(x, \varepsilon, t)$ is the ${ }^{10} \mathrm{Be}$ concentration function of depth $x$ $\left(\mathrm{g} \mathrm{cm}^{-2}\right)$, denudation rate $\varepsilon\left(\mathrm{g} \mathrm{cm}^{-2} \mathrm{yr}^{-1}\right)$ and exposure time $t$ (yr).

(2) $\Lambda_{n}(160), \Lambda_{\mu s}(1500)$ and $\Lambda_{\mu f}(5300)$ are the effective apparent attenuation lengths $\left(\mathrm{g} \mathrm{c}^{\mathrm{m}-2}\right)$, for neutrons, slow muons and fast muons, respectively.

(3) $P_{n}, P_{\mu s}$ and $P_{\mu f}$ are the relative contributions to the ${ }^{10} \mathrm{Be}$ production rate of the three reactions $\left(P_{n}+P_{\mu s}+P_{\mu f}=100\right.$ per cent). The relative contributions to the total surface production rate are 97.85 per cent for the neutrons, 1.50 per cent for slow muons, and 0.65 per cent for the fast muons. These values are based on field-calibrated measurement by Braucher et al. (2003).

(4) $P_{0}$ is the production rate at the surface taken from Stone (2000).

(5) $C_{\text {inh }}$ represents the ${ }^{10} \mathrm{Be}$ concentration potentially acquired by the sample during exposure to cosmic rays prior to emplacement in their sampling position.
Because denudation processes are complex, in a first step, exposure ages were determined using negligible denudation. In that case, the exposure ages are minimum. However, when it was possible, exposure ages were better defined using depth profiles allowing the determination of denudation rate and inheritance using a chi-square inversion (Braucher et al. 2003).

Chi - square $=\sum_{i=1}^{n}\left[\frac{C_{i}-C_{(x, \varepsilon, t)}}{\sigma_{i}}\right]^{2}$,

where

(1) $C_{i}$ is the measured ${ }^{10} \mathrm{Be}$ concentration at depth $x_{i}$.

(2) $C(x, \varepsilon, t)$ is the theoretical ${ }^{10} \mathrm{Be}$ concentration determined using eq. (A1).

(3) $\sigma_{i}$ is the analytical uncertainty at depth $i$, and $n$ the total number of samples in the profile.

The ages obtained from surficial samples were used only if ages given by depth profiles were poorly constrained. When the surface 

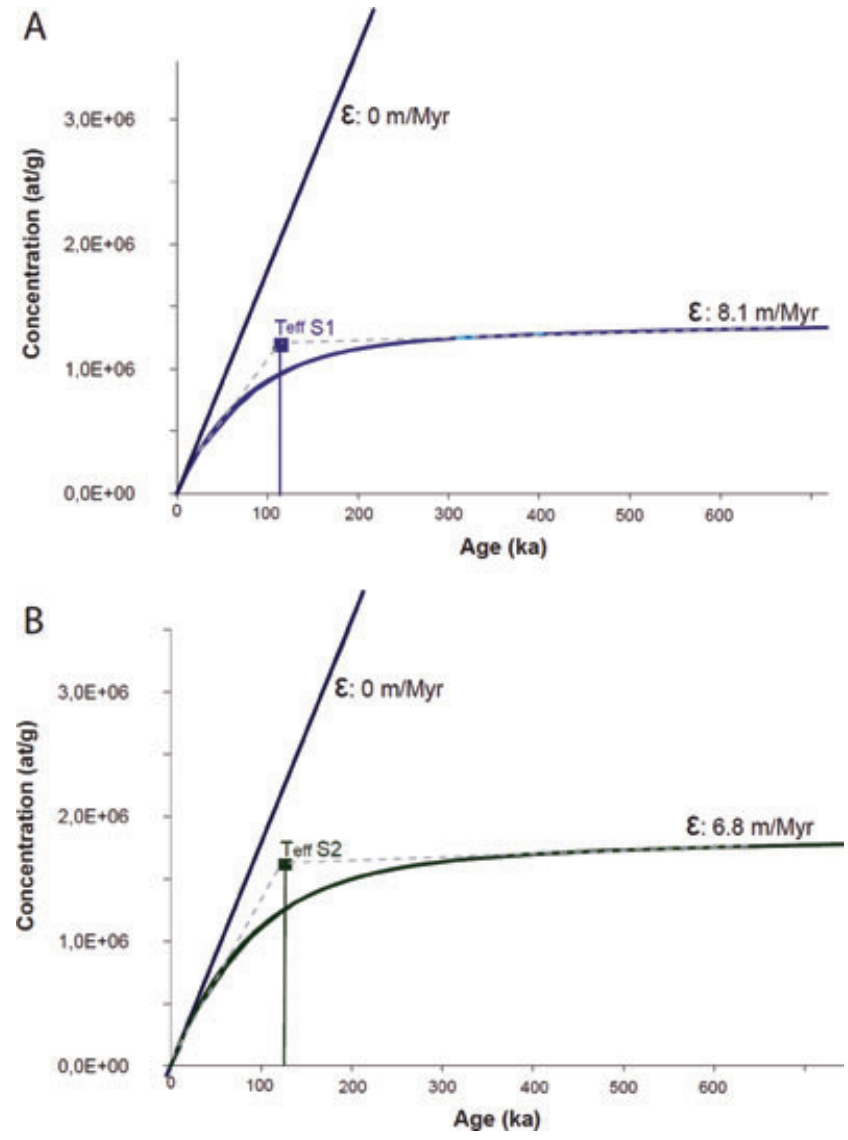

Figure A2. Effective irradiation times deduced from the ${ }^{10} \mathrm{Be}$ concentrations and the denudation rate calculated for S1 (A) and S2 (B) surfaces. The blue and green curves represent the modelled evolution of the ${ }^{10} \mathrm{Be}$ surface concentration versus the time at the measured denudation rates $(\varepsilon)$ for each surface. The grey dashed lines define the linear increase in concentration and the linear evolution at steady state. The squares are the intersection between the straight lines and represent minimum time required to reach steady state $\left(T_{\text {eff }}\right)$ for $\mathrm{S} 1$ and S2 surfaces. Since both of these surfaces are inferred to have reached steady state, these ages also represent minimum ages of abandonment.

concentration was at steady state, we determined a denudation rate and an effective irradiation time (Lal 1991). Fig. A2 shows the Teff deduced from the variation of ${ }^{10} \mathrm{Be}$ concentrations for S1 and S2 versus time using the modelled denudation rate. Effective irradiation times $T_{\text {eff }}$ are determined by intersecting straight lines defining the linear increase in concentration when production is larger than losses, and the asymptote at steady state.

\section{APPENDIX B: LUMINESCENCE DATING}

\section{B1. OSL collecting protocol}

\section{B1.1. Bitut}

At Bitut, the samples were carved into a pedestal fitting the shape of an aluminum container that was $6-7 \mathrm{~cm}$ in diameter. These containers were sealed and stored in dark plastic bags until transport to an OSL processing lab. We kept only the material in the centre of the block after removing the light-exposed edges. The block edges were painted in the lab, the paint was allowed to dry, and then the edges were rigorously trimmed off to get to the centre. If any paint showed up in the sieves during the prep process, the sample fraction was thrown away and a new portion was used.

\section{B1.2. Baast Uul}

At Baast Uul, the main stratigraphic deposits in the alluvial surfaces are clastic limestone pebbles supported by sand matrix, stratified and poorly sorted. We decided that, to collect only the matrix, we would need to build ourselves a 'portable' dark room as the foundation area that would enable us to dig out suitable OSL samples. Our samples were collected by using the field protocol detailed in Rizza et al. (2011), covering the pits with several layers of black plastic and cover blankets, such that we could be confident that during the manual extraction and collection, there was not any light exposure at the time of sampling.

\section{B2. Experimental details}

\section{B2.1. Dosimetry}

Around $600 \mathrm{~g}$ of bulk sample were dried, sealed in a plastic planchets (Murray et al. 1987) and placed in a gamma-ray spectrometer to measure the concentration of radiogenic Thorium (Th), Potassium (K) and Uranium (U). Dose rates for each sample were calculated using radioisotope concentration, burial depth, elevation, geomagnetic latitude (Prescott \& Hutton 1994) and present-day moisture. Alpha and beta attenuation contributions were corrected for grainsize attenuation (Aitken, 1985) if fine grains were used for dating (i.e. IRSL). All elemental concentrations and dose rates are shown in Table 1.

\section{B2.2. Sample preparation protocol}

In the OSL laboratory the middle portion of sediment within the aluminium cans were used for equivalent dose analyses (final mineral was either quartz sand or polymineral silt grains). After standard quartz separation, the samples was resieved to save the pure quartz grains and to discard the broken, and thus smaller, plagioclase grains that survived the hydrofluoric etch process. Within the samples, plagioclase was very plentiful and difficult to separate from the quartz. Only HF or intensive Frantz magnetic separation could achieve a reasonable grains separation. For this reason we believe there are probably inclusions of albite in some quartz grains. The largest sand size fraction was used for these samples because it was the dominant fraction ( $>50$ per cent) within usable OSL grain sizes.

B2.2.1. Quartz dating The quartz grains from the Bitut sample (BiOSL5) were analysed with the Single Aliquot Regeneration (SAR) procedures (Murray \& Wintle 2000) and run as aliquots with a size of 1-2 mm (Fig. B1). Extended descriptions of the machine and protocols used can be found in the Table B1.

B2.2.2. Feldspar dating We used IRSL, which is the emissions from the potassium-Feldspar silt fractions. The IRSL samples M07-Bi-OS1-T2 and BG09-1 were analysed using the MAAD procedure (Aitken 1998). The fine-grained (4-11 $\mu \mathrm{m})$ polymineral sample splits for three samples were analysed using the total-bleach MAAD method for IRSL (Singhvi et al. 1982; Lang 1994; Richardson et al. 1997; Forman \& Pierson 2002). Specific details for this 
Table A2. Depth, elevation, ${ }^{10}$ Be concentrations and their associated incertitude (two sigma error bars), production rate calculated using Stone (2000), and laboratory location for this study. The samples shown in italics are data never published.

\begin{tabular}{|c|c|c|c|c|c|c|c|}
\hline & Samples & Depth (cm) & Altitude (m) & ${ }^{10} \mathrm{Be}\left(\right.$ at $\left.\mathrm{g}^{-1}\right)$ & ${ }^{10} \mathrm{Be}$ error $\left(\right.$ at $\left.\mathrm{g}^{-1}\right)$ & Production (at $\mathrm{g}^{-1} \mathrm{yr}^{-1}$ ) & Measured at \\
\hline \multicolumn{8}{|l|}{ NOYAN UUL } \\
\hline S1 profile & NU42 & 205 & 1565 & $3,578 \mathrm{E}+05$ & $5,600 \mathrm{E}+04$ & 16,44 & TANDETRON \\
\hline S1 profile & NU45 & 160 & 1565 & $6,534 \mathrm{E}+05$ & $1,308 \mathrm{E}+05$ & 16,44 & TANDETRON \\
\hline S1 profile & NU47 & 110 & 1565 & $4,696 \mathrm{E}+05$ & $5,935 \mathrm{E}+04$ & 16,44 & TANDETRON \\
\hline S1 profile & NU49 HF4 & 80 & 1565 & $3,358 \mathrm{E}+05$ & $2,772 \mathrm{E}+04$ & 16,44 & TANDETRON \\
\hline S1 profile & NU51 & 20 & 1565 & $1,155 \mathrm{E}+06$ & $1,184 \mathrm{E}+05$ & 16,44 & TANDETRON \\
\hline S1 profile & NU52A & 0 & 1565 & $1,917 \mathrm{E}+06$ & $1,966 \mathrm{E}+05$ & 16,44 & TANDETRON \\
\hline S1 profile & NU45HF4 & 160 & 1565 & $5,746 \mathrm{E}+05$ & $1,818 \mathrm{E}+05$ & 16,44 & TANDETRON \\
\hline $\mathrm{S} 1$ & DVI 1 & 0 & 1730 & $1,420 \mathrm{E}+06$ & $1,100 \mathrm{E}+05$ & 18,22 & TANDETRON \\
\hline $\mathrm{S} 1$ & DVI 3 & 0 & 1730 & $1,300 \mathrm{E}+06$ & $1,700 \mathrm{E}+05$ & 18,22 & TANDETRON \\
\hline $\mathrm{S} 1$ & DVI 4 & 0 & 1730 & $1,040 \mathrm{E}+06$ & $1,100 \mathrm{E}+05$ & 18,22 & TANDETRON \\
\hline $\mathrm{S} 1$ & DVI 5 & 0 & 1730 & $1,370 \mathrm{E}+06$ & $1,400 \mathrm{E}+05$ & 18,22 & TANDETRON \\
\hline $\mathrm{S} 2$ & DVII 1 & 0 & 1750 & $1,100 \mathrm{E}+06$ & $1,400 \mathrm{E}+05$ & 18,49 & TANDETRON \\
\hline $\mathrm{S} 2$ & DVII 2 & 0 & 1750 & $1,560 \mathrm{E}+06$ & $1,700 \mathrm{E}+05$ & 18,49 & TANDETRON \\
\hline $\mathrm{S} 2$ & DVII 3 & 0 & 1750 & $1,830 \mathrm{E}+06$ & $1,200 \mathrm{E}+05$ & 18,49 & TANDETRON \\
\hline $\mathrm{S} 2$ & DVII 4 & 0 & 1750 & $1,650 \mathrm{E}+06$ & $1,400 \mathrm{E}+05$ & 18,49 & TANDETRON \\
\hline $\mathrm{S} 2$ & DVII 5 & 0 & 1750 & $1,550 \mathrm{E}+06$ & $1,200 \mathrm{E}+05$ & 18,49 & TANDETRON \\
\hline Amalgam S1 & M07-33 & 0 & 1666 & $1,488 E+06$ & $4,277 E+04$ & 17,22 & ASTER \\
\hline Amalgam $S 2$ & M07-34 & 0 & 1735 & $2,078 E+06$ & $5,785 E+04$ & 18,33 & ASTER \\
\hline S2 profile & M07-35 & 200 & 1735 & $4,067 E+05$ & $3,640 E+04$ & 18,33 & ASTER \\
\hline S2 profile & M07-37 & 130 & 1735 & $5,108 E+05$ & $2,625 E+04$ & 18,33 & ASTER \\
\hline$S 2$ profile & M07-39 & 75 & 1735 & $8,257 E+05$ & $1,533 E+04$ & 18,33 & ASTER \\
\hline S2 profile & M07-40 & 35 & 1735 & $1,556 E+06$ & $2,721 E+04$ & 18,33 & ASTER \\
\hline S2 profile & M07-41 & 10 & 1735 & $1,663 E+06$ & $1,896 E+04$ & 18,33 & $A S T E R$ \\
\hline \multicolumn{8}{|c|}{ WEST NOYAN UUL } \\
\hline$T 3$ & M07-01 & 0 & 1618 & $1,143 E+06$ & $2,024 E+04$ & 17,24 & ASTER \\
\hline$T 3$ & M07-02 & 0 & 1609 & $1,587 E+06$ & $3,769 E+04$ & 17,13 & ASTER \\
\hline$T 3$ & M07-03 & 0 & 1606 & $1,611 E+06$ & $7,633 E+04$ & 17,09 & ASTER \\
\hline$T 3$ & M07-04 & 0 & 1592 & $1,742 E+06$ & $7,445 E+04$ & 16,92 & ASTER \\
\hline$T 3$ & M07-05 & 0 & 1608 & $1,666 E+06$ & $6,606 E+04$ & 17,12 & ASTER \\
\hline$T 3$ & M07-06 & 0 & 1607 & $1,749 E+06$ & $5,795 E+04$ & 17,10 & ASTER \\
\hline T3 right bank & $M 07-26$ & 0 & 1607 & $1,571 E+06$ & $1,048 E+05$ & 17,10 & ASTER \\
\hline amalgam T3 & M07-07 & 0 & 1605 & $1,644 E+06$ & $4,771 E+04$ & 17,08 & ASTER \\
\hline$T 2$ & M07-08 & 0 & 1598 & $1,022 E+06$ & $1,988 E+04$ & 16,99 & ASTER \\
\hline$T 2$ & M07-09 & 0 & 1597 & $1,516 E+06$ & $2,106 E+04$ & 16,98 & ASTER \\
\hline$T 2$ & M07-10 & 0 & 1597 & $1,414 E+06$ & $8,056 E+04$ & 16,98 & ASTER \\
\hline$T 2$ & M07-11 & 0 & 1594 & $2,269 E+06$ & $1,175 E+05$ & 16,94 & ASTER \\
\hline$T 2$ & M07-12 & 0 & 1587 & $1,153 E+06$ & $7,229 E+04$ & 16,85 & ASTER \\
\hline amalgam $T 2$ & M07-13 & 0 & 1598 & $1,614 E+06$ & $2,081 E+04$ & 16,99 & ASTER \\
\hline$T 1$ & M07-14 & 0 & 1592 & $9,429 E+05$ & $3,379 E+04$ & 16,91 & ASTER \\
\hline$T 1$ & $M 07-15$ & 0 & 1591 & $9,603 E+05$ & $2,740 E+04$ & 16,90 & ASTER \\
\hline$T 1$ & $M 07-16$ & 0 & 1593 & $6,882 E+05$ & $3,122 E+04$ & 16,94 & ASTER \\
\hline$T 1$ & M07-17 & 0 & 1592 & $5,082 E+05$ & $2,999 E+04$ & 16,91 & ASTER \\
\hline$T 1$ & M07-18 & 0 & 1587 & $4,910 E+05$ & $4,039 E+04$ & 16,85 & ASTER \\
\hline amalgam $T 1$ & $M 07-19$ & 0 & 1590 & $8,163 E+05$ & $3,470 E+04$ & 16,89 & ASTER \\
\hline amalgam T0 & M07-20 & 0 & 1583 & $6,578 E+05$ & $1,247 E+04$ & 16,80 & ASTER \\
\hline TO & M07-21 & 0 & 1590 & $2,487 E+05$ & $1,132 E+04$ & 16,89 & ASTER \\
\hline TO & $M 07-22$ & 0 & 1593 & $4,485 E+05$ & $2,188 E+04$ & 16,93 & ASTER \\
\hline TO & $M 07-23$ & 0 & 1582 & $2,998 E+05$ & $4,865 E+04$ & 16,79 & ASTER \\
\hline TO & M07-24 & 0 & 1583 & $4,861 E+05$ & $3,244 E+04$ & 16,80 & ASTER \\
\hline TO & $M 07-25$ & 0 & 1580 & $5,295 E+05$ & $4,064 E+04$ & 16,80 & ASTER \\
\hline T2 profile & M07-27 & 0 & 1597 & $2,323 E+05$ & $1,930 E+04$ & 16,98 & ASTER \\
\hline T2 profile & M07-28 & 30 & 1597 & $6,363 E+05$ & $1,284 E+04$ & 16,98 & ASTER \\
\hline T2 profile & $M 07-29$ & 50 & 1597 & $6,084 E+05$ & $1,059 E+05$ & 16,98 & $A S T E R$ \\
\hline T2 profile & M07-30 & 95 & 1597 & $6,502 E+05$ & $9,694 E+04$ & 16,98 & ASTER \\
\hline T2 profile & M07-31 & 130 & 1597 & $8,473 E+05$ & $4,123 E+04$ & 16,98 & ASTER \\
\hline \multicolumn{8}{|l|}{ BITUT } \\
\hline T3 (boulder) & MO-03-01 & 0 & 1720 & $1,401 \mathrm{E}+06$ & $1,205 \mathrm{E}+05$ & 18,07 & ASTER \\
\hline T3 (boulder) & MO-03-02 & 0 & 1720 & $1,349 \mathrm{E}+06$ & $9,779 \mathrm{E}+04$ & 18,07 & ASTER \\
\hline T3 (boulder) & MO-03-03 & 0 & 1720 & $1,569 \mathrm{E}+06$ & $1,661 \mathrm{E}+05$ & 18,07 & ASTER \\
\hline T3 (boulder) & MO-03-04 & 0 & 1720 & $1,690 \mathrm{E}+06$ & $1,311 \mathrm{E}+05$ & 18,07 & ASTER \\
\hline T3 (boulder) & MO-03-05 & 0 & 1720 & $1,173 \mathrm{E}+06$ & $8,101 \mathrm{E}+04$ & 18,07 & ASTER \\
\hline
\end{tabular}


Table A2. (Continued.)

\begin{tabular}{|c|c|c|c|c|c|c|c|}
\hline & Samples & Depth $(\mathrm{cm})$ & Altitude (m) & ${ }^{10} \mathrm{Be}\left(\right.$ at g $\left.^{-1}\right)$ & ${ }^{10}$ Be error $\left(\right.$ at g $\left.^{-1}\right)$ & Production $\left(\right.$ at $\left.^{-1} \mathrm{yr}^{-1}\right)$ & Measured at \\
\hline T2 (boulder) & MO-03-07 & 0 & 1690 & $2,164 \mathrm{E}+06$ & $1,053 E+05$ & 17,68 & ASTER \\
\hline T2 (boulder) & MO-03-10 & 0 & 1690 & $1,284 \mathrm{E}+06$ & $6,773 \mathrm{E}+04$ & 17,67 & ASTER \\
\hline T2 (boulder) & MO-03-11 & 0 & 1690 & $1,824 \mathrm{E}+06$ & $9,974 \mathrm{E}+04$ & 17,67 & ASTER \\
\hline T2 (boulder) & MO-03-12 & 0 & 1690 & $1,949 \mathrm{E}+06$ & $2,322 \mathrm{E}+05$ & 17,67 & ASTER \\
\hline T2 (boulder) & MO-03-12 0cm & 0 & 1690 & $1,809 \mathrm{E}+06$ & $9,576 \mathrm{E}+04$ & 17,67 & ASTER \\
\hline T2 (boulder) & MO-03-12 40cm & 40 & 1690 & $2,622 \mathrm{E}+06$ & $8,295 \mathrm{E}+05$ & 17,67 & ASTER \\
\hline T2 (boulder) & MO-03-12 60cm & 60 & 1690 & $8,457 \mathrm{E}+05$ & $6,867 \mathrm{E}+04$ & 17,67 & ASTER \\
\hline $\mathrm{T} 2$ profile & MO-03-T2-TOP & 0 & 1690 & $1,759 \mathrm{E}+06$ & $1,452 \mathrm{E}+05$ & 17,67 & ASTER \\
\hline $\mathrm{T} 2$ profile & M0-03-T2-40 & 40 & 1690 & $1,133 \mathrm{E}+06$ & $1,410 \mathrm{E}+05$ & 17,67 & ASTER \\
\hline $\mathrm{T} 2$ profile & MO-03-T2-60 & 60 & 1690 & $8,558 \mathrm{E}+05$ & $1,714 \mathrm{E}+05$ & 17,67 & ASTER \\
\hline $\mathrm{T} 2$ profile & MO-03-T2-125 & 125 & 1690 & $3,528 \mathrm{E}+05$ & $5,331 \mathrm{E}+04$ & 17,67 & ASTER \\
\hline $\mathrm{T} 2$ profile & MO-03-T2-160 & 160 & 1690 & $4,468 \mathrm{E}+05$ & $1,026 \mathrm{E}+05$ & 17,67 & ASTER \\
\hline $\mathrm{T} 2$ profile & MO-03-T2-200 & 200 & 1690 & $1,385 E+05$ & $3,181 \mathrm{E}+04$ & 17,67 & ASTER \\
\hline T2 (boulder) & MO-03-14 & 0 & 1713 & $8,275 \mathrm{E}+05$ & $8,005 E+04$ & 17,98 & ASTER \\
\hline T1 (boulder) & MO-03-16 & 0 & 1650 & $1,371 \mathrm{E}+06$ & $1,281 \mathrm{E}+05$ & 17,16 & ASTER \\
\hline T1 (boulder) & MO-03-17 & 0 & 1650 & $7,790 \mathrm{E}+05$ & $2,755 \mathrm{E}+05$ & 17,15 & ASTER \\
\hline T1 (boulder) & MO-03-18 & 0 & 1650 & $1,496 \mathrm{E}+06$ & $9,360 \mathrm{E}+04$ & 17,17 & ASTER \\
\hline T1 (boulder) & MO-03-19 & 0 & 1650 & $1,259 \mathrm{E}+06$ & $2,302 \mathrm{E}+05$ & 17,17 & ASTER \\
\hline T1 (boulder) & MO-03-21 & 0 & 1650 & $1,324 \mathrm{E}+06$ & $1,534 \mathrm{E}+05$ & 17,17 & ASTER \\
\hline T1 (boulder) & MO-03-22 & 0 & 1650 & $1,549 \mathrm{E}+06$ & $1,928 \mathrm{E}+05$ & 17,17 & ASTER \\
\hline $\mathrm{T} 1$ profile & MO-03-T3-30 & 30 & 1650 & $8,290 \mathrm{E}+05$ & $6,339 \mathrm{E}+04$ & 17,16 & ASTER \\
\hline $\mathrm{T} 1$ profile & MO-03-T3-50 & 50 & 1650 & $4,820 \mathrm{E}+05$ & $1,079 \mathrm{E}+05$ & 17,16 & ASTER \\
\hline $\mathrm{T} 1$ profile & MO-03-T3-75 & 75 & 1650 & $2,757 \mathrm{E}+05$ & $3,330 \mathrm{E}+04$ & 17,16 & ASTER \\
\hline $\mathrm{T} 1$ profile & MO-03-T3-100 & 100 & 1650 & $2,129 \mathrm{E}+05$ & $4,263 \mathrm{E}+04$ & 17,16 & ASTER \\
\hline $\mathrm{T} 1$ profile & MO-03-T3-120 & 120 & 1650 & $2,462 E+05$ & $1,102 \mathrm{E}+05$ & 17,16 & ASTER \\
\hline T0 (boulder) & MO-03-30(T) & 0 & 1640 & $1,745 \mathrm{E}+05$ & $3,494 \mathrm{E}+04$ & 17,04 & ASTER \\
\hline T0 (boulder) & MO-03-31 (B) & 0 & 1640 & $2,004 \mathrm{E}+05$ & $3,175 \mathrm{E}+04$ & 17,04 & ASTER \\
\hline T0 (boulder) & MO-03-32 & 0 & 1640 & $3,179 \mathrm{E}+05$ & $3,163 \mathrm{E}+04$ & 17,04 & ASTER \\
\hline T0 (valley) & MO-03-46 & 0 & 2100 & $1,103 \mathrm{E}+05$ & $6,368 \mathrm{E}+04$ & 23,66 & ASTER \\
\hline T0 (valley) & MO-03-47 & 0 & 2100 & $2,963 \mathrm{E}+05$ & $2,964 \mathrm{E}+04$ & 23,66 & ASTER \\
\hline T0 (valley) & MO-03-48 & 0 & 2100 & $4,184 \mathrm{E}+05$ & $5,247 \mathrm{E}+04$ & 23,66 & ASTER \\
\hline T0 (valley) & MO-03-49 & 0 & 2100 & $2,622 \mathrm{E}+05$ & $9,275 \mathrm{E}+04$ & 23,66 & ASTER \\
\hline T0 (valley) & MO-03-50 & 0 & 2100 & $1,839 \mathrm{E}+05$ & $4,117 \mathrm{E}+04$ & 23,66 & ASTER \\
\hline T0 (valley) & MO-03-51(T) & 0 & 2100 & $1,212 \mathrm{E}+05$ & $2,053 \mathrm{E}+04$ & 23,66 & ASTER \\
\hline T0 (valley) & MO-03-55(B) & 0 & 2100 & $1,852 \mathrm{E}+05$ & $1,870 \mathrm{E}+04$ & 23,66 & ASTER \\
\hline
\end{tabular}
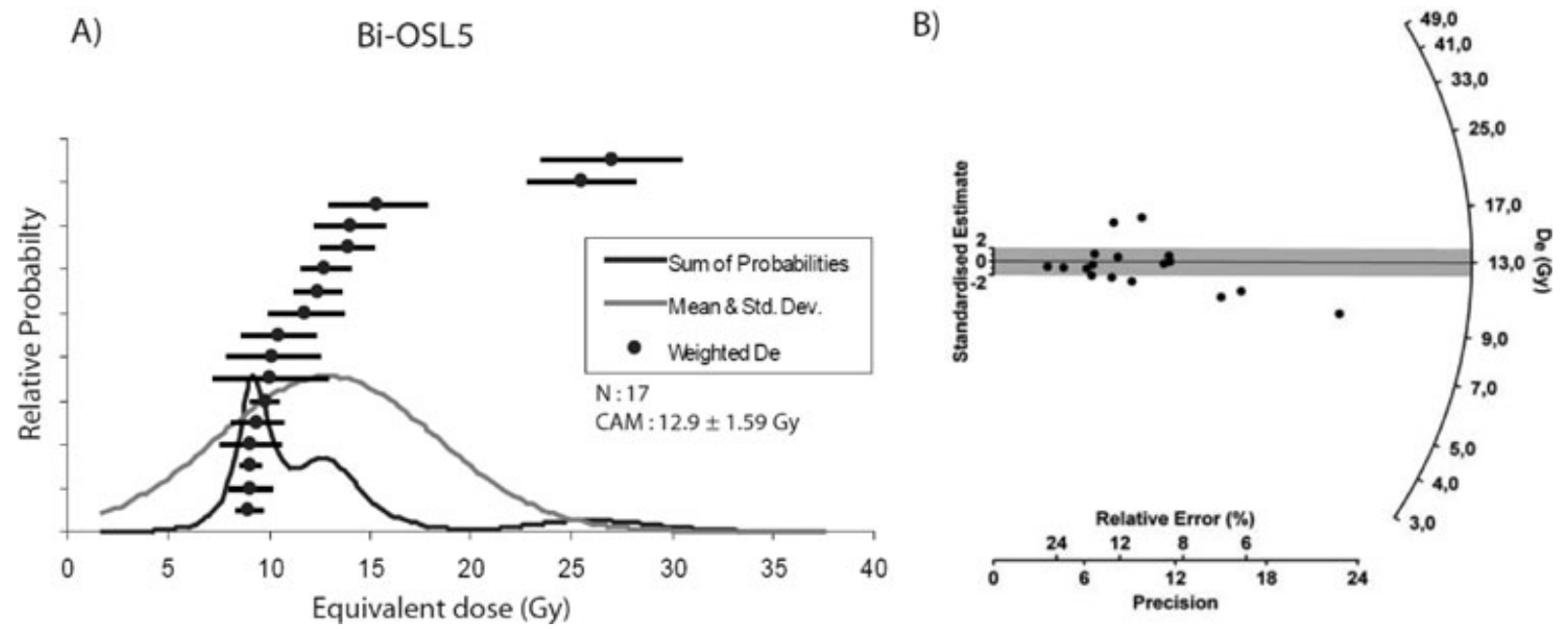

Figure B1. Results of OSL dating on the 250-180 $\mu \mathrm{m}$ quartz grains for Bi-OSL5 sample. (A) Relative probability of equivalent dose (De) distribution. The black filled dots are the individual De values for each aliquot, the grey line is the distribution of the Gaussian function, and the black line is the probability density function. $N$ represents the total number of aliquots number. (B) Radial plots of the measured doses using Galbraith et al. (1999).

are addressed in this Table B2. Fading tests were carried out following the instructions of Auclair et al. (2003). The fading rate can be quantified by the $g$-value, which corresponds to the percentage fading loss per decade of time. These values are a ratio of lumi- nescence emission after storage of $21 \mathrm{~d}$ divided by the immediate measurement (a ratio of 1.0 indicates stable luminescence), and we corrected to the " $g$ " factor (i.e. Huntley \& Lamothe 2001) using their formulae in a simple worksheet. 
Table B1. Luminescence parameters for OSL used in preparation and analyses of samples

\begin{tabular}{|c|c|}
\hline \multicolumn{2}{|l|}{$\begin{array}{r}\text { Measurement } \\
\text { parameters: }\end{array}$} \\
\hline Mineral; grain size: & quartz: $250-180 \mu \mathrm{m}$ \\
\hline Stimulation source: & four clusters LED, emission centred at $470 \mathrm{~nm}$ \\
\hline $\begin{array}{l}\text { Power delivered to } \\
\text { aliquot: }\end{array}$ & $22 \mathrm{~mW} \mathrm{~cm}{ }^{-2}$ \\
\hline $\begin{array}{l}\text { Duration of } \\
\text { stimulation: }\end{array}$ & $40 \mathrm{~s}$ \\
\hline Photomultiplier: & TL/OSL DA 15A/B Reader, Minisys 14 \\
\hline Aliquot temperature: & $125^{\circ} \mathrm{C}$ \\
\hline Detection filters: & 2 Hoya U-340 \\
\hline Normalization: & natural $(0.5 \mathrm{~s})$ \\
\hline Pre-heat: & $260{ }^{\circ} \mathrm{C}$ for $10 \mathrm{~s}$ with same cut heat \\
\hline $\begin{array}{l}\text { Equivalent dose } \\
\text { evaluation: }\end{array}$ & single aliquot regeneration (SAR) \\
\hline Dose-rate evaluation: & lab and portable $\chi$-spectrometer \\
\hline Dose-rate range: & $3.4 \mathrm{~Gy} \mathrm{ka}^{-1}$ \\
\hline Water content: & 27 per cent \\
\hline $\begin{array}{l}\text { Cosmic-ray } \\
\text { contribution: }\end{array}$ & 3 per cent of total dose rate \\
\hline
\end{tabular}

Table B2. Luminescence parameters for IRSL used in preparation and analyses of samples.

\begin{tabular}{ll}
\hline Measurement parameters: & \\
\hline Mineral; grain size: & polymineral: $4-11 \mu \mathrm{m}$ \\
Stimulation source: & $30 \mathrm{IR}$ diodes, emission centred on $880 \mathrm{~nm}$ \\
Power delivered to aliquot: & $17 \mathrm{~m} \mathrm{~W} \mathrm{~cm}{ }^{-2}$ \\
Duration of stimulation: & $100 \mathrm{~s}$ \\
Final signal level: & 10 per cent of initial \\
Photomultiplier: & Thorn-EMI 9635Q \\
Aliquot temperature: & $30^{\circ} \mathrm{C}$ IRSL \\
Detection filters: & $390-490$ (blue) \\
Normalization: & natural $(0.5 \mathrm{~s})$ \\
Pre-heat: & $124{ }^{\circ} \mathrm{C}$ for $64 \mathrm{hr}$ \\
Delay before measurement: & 24 hr or more \\
Equivalent dose evaluation: & additive method using integrated \\
& $\quad$ OSL/satisfactory plateau \\
Background evaluation: & after bleaching with natural sunlight and \\
& quartz window \\
Alpha effectiveness: & fine grains: a $=0.07-0.09$ \\
Dose-rate evaluation: & lab and portable $\chi$-spectrometer \\
Dose-rate range: & $5.18-10.30$ Gy ka ${ }^{-1}$ \\
Water content: & $17-29$ per cent \\
Cosmic-ray contribution: & $6-8$ per cent of total dose rate \\
\hline
\end{tabular}

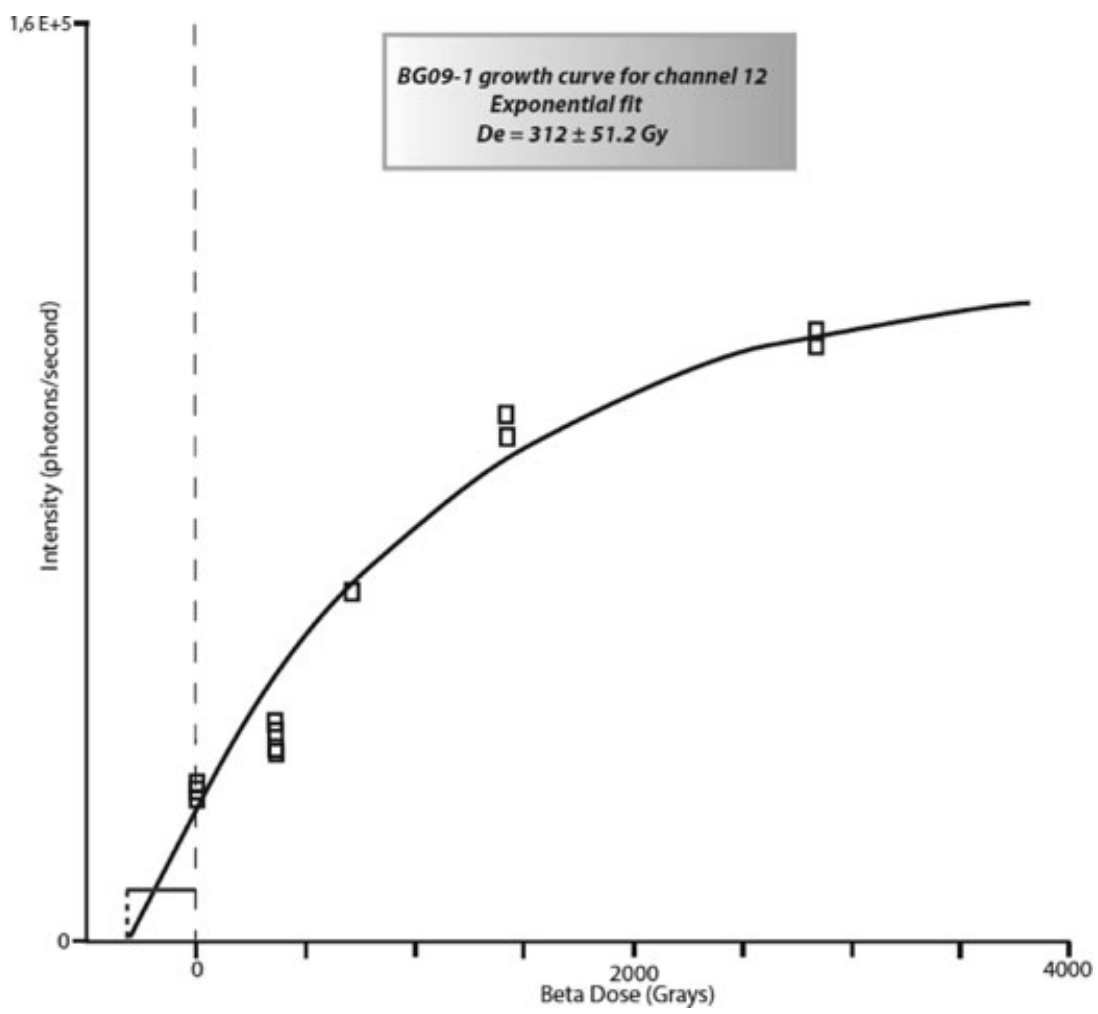

Figure B2. BG09-1 growth curve for IRSL, with the natural plotted on the intensity axis (photons/s). Multiple aliquot additive doses increase in response to increasing beta radiation and are fitted to an exponential. Dose is measured in Grays with $12 \mathrm{~s}$ of stimulation shown as $312 \pm 51.2$ Grays. To obtain the average doses all measurements from 1 to $30 \mathrm{~s}$ are used. 